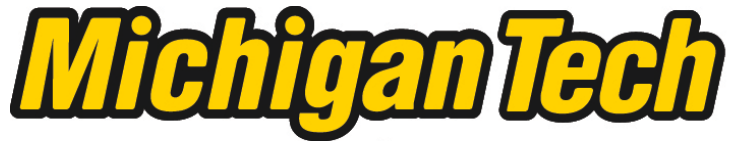 \\ Michigan Technological University Create the Future Digital Commons @ Michigan Tech
}

Dissertations, Master's Theses and Master's Reports - Open

Dissertations, Master's Theses and Master's

Reports

2009

Optimization of ethanol production by yeasts from lignocellulosic feedstocks

Stephanie Lee Groves

Michigan Technological University

Follow this and additional works at: https://digitalcommons.mtu.edu/etds

Part of the Biology Commons

Copyright 2009 Stephanie Lee Groves

\section{Recommended Citation}

Groves, Stephanie Lee, "Optimization of ethanol production by yeasts from lignocellulosic feedstocks", Master's Thesis, Michigan Technological University, 2009.

https://doi.org/10.37099/mtu.dc.etds/195

Follow this and additional works at: https://digitalcommons.mtu.edu/etds

Part of the Biology Commons 


\title{
OPTIMIZATION OF ETHANOL PRODUCTION BY YEASTS FROM \\ LIGNOCELLULOSIC FEEDSTOCKS
}

By

STEPHANIE LEE GROVES

\author{
A Thesis \\ Submitted in partial fulfillment of the requirements \\ for the degree of \\ MASTER OF SCIENCE \\ (Biological Sciences) \\ MICHIGAN TECHNOLOGICAL UNIVERSITY \\ 2009
}

Copyright $($ Stephanie L. Groves 2009 
This thesis, "Optimization of ethanol production by yeasts from lignocellulosic feedstocks," is hereby approved in partial fulfillment of the requirements for the degree of MASTER OF SCIENCE in BIOLOGICAL SCIENCES.

DEPARTMENT or PROGRAM:

Biological Sciences

Signatures:

Thesis Advisor

Dr. Susan T. Bagley

Department Chair

Dr. John Adler

Date 


\section{Acknowledgements}

I would like to take this opportunity to express my extreme gratitude and appreciation to the people who have generously contributed to my success as a graduate student. I will forever be indebted to Dr. Susan Bagley who graciously and patiently served as my advisor. Dr. Bagley provided me with excellent academic and professional opportunities as well as guidance and support throughout my time at MTU. She is directly responsible of me being able to achieve the things I have as a graduate student.

I greatly appreciate the advice and support of my Graduate Committee. Dr. David Shonnard and Dr. Rupali Datta brought an interdisciplinary approach to my education. Their broad range of knowledge and backgrounds of fields outside of microbiology only strengthen my education.

I would like to thank Dr. Tom Jeffries of the Institute for Microbial and Biochemical Technology, USDA, Forest Service, Forest Products Laboratory, Madison, Wisconsin for so generously providing MTU with Pichia stipitis CBS 6054. I would like to thank General Motors for so generously funding the project.

I would like to express special thanks to Jill Jensen, Chemical Engineering $\mathrm{PhD}$ student, and Jessica Beck, Senior Undergraduate Research Assistant, for their never ending help and support. I truly would not be where I am today without them. I would also like to thank Ratul Saha, Corey Hecksel, Lucas Wyzlic, Louis Paladino, and Juan Morinelly for their technical support and guidance. 
Finally, I would like to thank my family and friends that who were always there for me regardless of the situation or need. My deepest thanks go out to my parents, Rick and Cindy Gleason, and husband, Nathan Groves, for their never ending encouragement and guidance. I would also like to mention that I could not have done this without the help from my best friends: Jackie Haywood, Katie Cooper, Lana Nelson, and Amy Ruba. Thanks to all my MTU friends that made my time here one I will never forget. 


\section{Table of Contents}

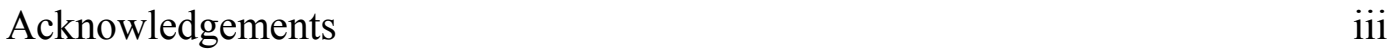

Table of Contents $\quad \mathrm{V}$

List of Figures vii

List of Tables $\quad$ xi

List of Abbreviations xiv

Abstract 1

Introduction 4

$\begin{array}{ll}\text { Thesis Objectives } & 6\end{array}$

Chapter 1. Literature Review

1.1 Lignocellulosic material and Ethanol Producing Organisms 9

$\begin{array}{ll}1.2 \text { Pretreatment and Toxicity } & 18\end{array}$

1.3 Optimization of Fermentation Conditions 22

Chapter 2. Methods

2.1 Organism Cultivation and maintenance 25

2.2 Growth Studies 26

$\begin{array}{ll}2.3 \text { Fermentation } & 28\end{array}$

$\begin{array}{ll}2.4 \text { Organism Characteristics } & 30\end{array}$

2.5 Lignocellulosic Hydrolysate Studies 31

2.6 Toxicity 32

2.7 Adaptation 34

2.8 Media Optimization 36 
Chapter 3. Results and Discussion

3.1 Single substrate Utilization by P. stipitis and S. cerevisiae (ER) 37

3.2 Mixed Utilization and Fermentations 41

3.3 Enzymatic Pretreatment 45

$\begin{array}{ll}3.4 \text { Toxicity } & 50\end{array}$

3.5 Adaptation 58

3.6 Fermentation Optimization 63

$\begin{array}{ll}\text { Conclusions } & 64\end{array}$

$\begin{array}{ll}\text { Recommendations } & 65\end{array}$

$\begin{array}{ll}\text { References } & 66\end{array}$

Appendix A. Ethanol production from glucose by S. cerevisiae 74

Appendix B. Mixed substrate fermentation by P. stipitis and S. cerevisiae $\quad 78$

Appendix C. Effect of inhibitory compounds on biomass production by 85

$$
\text { P. stipitis }
$$

Appendix D. Adaptation comparison data $\quad 88$

Appendix E. Growth of P. stipitis on different media 91 


\section{List of Figures}

\section{$\underline{\text { Thesis Objectives }}$}

Figure 1. Diagram of carbohydrate components of lignocellulose after dilute acid pretreatment and enzymatic hydrolysis

Figure 2. Diagram of the evaluations that were performed on thehemicellulose and cellulose feedstocks after hydrolysis

\section{Chapter 1. Literature Review}

Figure 3. The composition of lignocellulose and the breakdown of the sugars present in cellulose and hemicellulose. The letters represent a different sugar:Gglucose; Gal-galactose; M-mannose; X-xylose; and A-arabinose (Modified from

Zaldivar et al., 2000)

Figure 4. The catabolism if glucose by Saccharomyce cerevisiae using the Enbden- 12 Meyerhof glycolytic pathway (Modified from van Maris et al., 2006)

Figure 5.The native metabolic pathway of wild-type Pichia stipitis for ethanol production from xylose. The products utilize the pentose phosphate pathway (PPP) once xylose has been converted to xylitol and then to xylulose (Zalidivar et al., 2001) (Modified from van Maris et al., 2006).

Figure 6. The catabolism of glucose and it isomers by Saccharomyces cerevisiae (Modified from van Marin, 2006).

Figure 7. A summary of lignocellulosic feedstreams that can be used to produce ethanol. (Modified from Karakashev et al., 2007).

Figure 8. The composition of lignocellulose and the breakdown of the sugars present in cellulose and hemicellulose. The dilute acid pretreatment degradation products and their sources are shown. The letters represent a different sugar: Gglucose; Gal-galactose; M-mannose; X-xylose; and A-arabinose (Modified from Zaldivar et al., 2001).

\section{Chapter 2. Methods}

Figure 9. Sample flow chart diagramming the adaptation studyof Pichia stipitis CBS6054 for greater ethanol production from aspen hydrolysate. (DAP-Dilute Acid Pretreated,Syn.-synthetic aspen media, Hydro - hydrolysate). 


\section{Chapter 3. Results and Discussion}

Figure 10. The effect of glucose/xylose concentrations $(5 \mathrm{~g} / \mathrm{L})(\mathrm{w} / \mathrm{v})$ on $S$. cerevisiae (ER) growth. ER was grown in YP with the varying levels of glucose/xylose mixtures at $35^{\circ} \mathrm{C}$ for 24 hours, $\mathrm{pH} 5.5$.

Figure 11. Ethanol yield from enzymatic pretreated hydrolysate (Aspen-SCA, Balsam - SCB, and Switchgrass- SCS) fermented by S. cerevisiae (ER) over 120 hours $\left(30^{\circ} \mathrm{C}, \mathrm{pH} 5.5\right)$.

Figure 12. The effects of furfural concentrations on $S$. cerevisiae (ER) (biomass production in YPG media for 24 hours $)\left(30^{\circ} \mathrm{C}, \mathrm{pH} 5.5\right)$.

Figure 13. Comparison of 72 hour ethanol yields produced by an adapted Pichia stipitis CBS 6054(solid markers) and the parent strain (hollow markers) on varying percentages of dilute acid pretreated aspen hydrolysate supplemented with a sugar $\operatorname{mix}$.

\section{$\underline{\text { Appendix A. Ethanol production from glucose by } S \text {. cerevisiae }}$}

Figure A.1. Ethanol production and substrate utilization by $S$. cerevisiae on $100 \%$ glucose $(6.25 \mathrm{~g} / \mathrm{L})$ after 24 hours in YP media $\left(30^{\circ} \mathrm{C}, \mathrm{pH} 5.5\right)$.

Figure A.2. Ethanol production and substrate utilization by $S$. cerevisiae on $75 \%$ glucose: $25 \%$ xylose mixtures $(8.2 \mathrm{~g} / \mathrm{L})$ after 24 hours in YP media ( $\left.30^{\circ} \mathrm{C}, \mathrm{pH} 5.5\right)$.

Figure A.3. Ethanol production and substrate utilization by $S$. cerevisiae on 60\%:40\% glucose : xylose $(3.8 \mathrm{~g} / \mathrm{L})$ after 24 hours in YP media $\left(30^{\circ} \mathrm{C}, \mathrm{pH} 5.5\right)$.

Figure A.4. Ethanol production and substrate utilization by $S$. cerevisiae on 25\%:75\% glucose : xylose (4.1g/L) after 24 hours in YP media $\left(30^{\circ} \mathrm{C}, \mathrm{pH} 5.5\right)$.

Figure A.5. Ethanol production and susbstrate utilization by $S$. cerevisiae on 25\%:75\% glucose : xylose (3.5 g/L) after 24 hours in YP media $\left(30^{\circ} \mathrm{C}, \mathrm{pH} 5.5\right)$.

\section{$\underline{\text { Appendix B. Mixed substrate fermentation by } P \text {. stipitis and } S \text {. cerevisiae }}$}

Figure B.1. Growth of $P$. stipitis on YP media without a carbon source compared to YPX $(20 \mathrm{~g} / \mathrm{L})$ media after 24 hours $\left(30^{\circ} \mathrm{C}, \mathrm{pH} 5.5\right)$.

Figure B.2. Fermentation of a 50:50 mixture xylose $(50 \mathrm{~g} / \mathrm{L})$ and glucose $(50 \mathrm{~g} / \mathrm{L})$ in YP media by Pichia stipitis CBS 6054 after 72 hours $\left(30^{\circ} \mathrm{C}, \mathrm{pH} 5.5\right)$.

Figure B.3. Fermentation of a mixture of 1:2 mixture of arabinose and xylose in YP Media by Pichia stipitis CBS 6054 after 72 hours $\left(30^{\circ} \mathrm{C}\right.$, pH 5.5). 
Figure B.4. Fermentation of a mixture of 1:1:2 mixture of galactose, mannose, and glucose in YP Media by Pichia stipitis CBS 6054 after 72 hours $\left(30^{\circ} \mathrm{C}, \mathrm{pH} 5.5\right)$.

Figure B.5. Comparison of ethanol concentrations in a glucose: xylose, pentose, and hexose fermentation by Pichia stipitis CBS 6054 after 72 hours in YP media $\left(30^{\circ} \mathrm{C}\right.$, $\mathrm{pH}$ 5.5).

Figure B.6. Sugar concentration in synthetic dilute acid pretreated aspen hydrolysate at 0 and 72 hours during a fermentation b y $P$. stipits $\left(30^{\circ} \mathrm{C}, \mathrm{pH} 5.5\right)$.

Figure B.7. Sugar concentration in synthetic dilute acid pretreated balsam hydrolysate at 0 and 72 hours during a fermentation b y $P$. stipits $\left(30^{\circ} \mathrm{C}, \mathrm{pH} 5.5\right)$.

Figure B.8. Sugar concentration in synthetic dilute acid pretreated switchgrass hydrolysate at 0 and 72 hours during a fermentation b y $P$. stipits $\left(30^{\circ} \mathrm{C}, \mathrm{pH} 5.5\right)$.

Figure B.9. Fermentation results of ethanol production from enzymatic pretreated aspen by $S$. cerevisiae after 24 hours in Enzymatic hydrolysate supplemented withYP media $\left(30^{\circ} \mathrm{C}, \mathrm{pH} 5.5\right)$.

Figure B.10. Fermentation results of ethanol production from enzymatic pretreated balsam by S.cerevisia after 24 hours in Enzymatic hydrolysate supplemented withYP media $\left(30^{\circ} \mathrm{C}, \mathrm{pH} 5.5\right)$.

Figure B.11. Fermentation results of ethanol production from enzymatic pretreated switchgrass by S.cerevisiae after 24 hours in Enzymatic hydrolysate supplemented withYP media $\left(30^{\circ} \mathrm{C}, \mathrm{pH} 5.5\right)$.

\section{$\underline{\text { Appendix C. Effect of inhibitory compounds on } P \text {. stipitis }}$}

Figure C.1 Biomass production of Pichia stipitis in synthetic aspen hydrolysate supplemented with acetic acid [8 g/L (A8A) and $10 \mathrm{~g} / \mathrm{L}$ (A10A))

Figure C.2. Biomass production by $P$. stipitis in the presence of furfural after 24 hours in synthetic aspen media $\left(30^{\circ} \mathrm{C}\right.$

Figure C.3. Ethanol production by $P$. stipitis in the presence of furfural in after 72 hours synthetic aspen media $\left(30^{\circ} \mathrm{C}\right.$

\section{Appendix D. Adaptation comparison data}

Figure D.1. Comparison of total starting sugars used by an adapted Pichia stipitis CBS 6054 and the parent strain on varying percentages of dilute acid pretreated aspen hydrolysate supplemented with a sugar mix $(n=2)\left(30^{\circ} \mathrm{C}, \mathrm{pH} 5.5\right)$. 
Figure D.2. Comparison of 72 hour ethanol concentrations produced by an adapted Pichia stipitis CBS 6054 and the parent strain on varying percentages of dilute acid pretreated aspen hydrolysate supplemented with a sugar mix $(n=2)\left(30^{\circ} \mathrm{C}, \mathrm{pH} 5.5\right)$.

Figure D.3. Comparison of 72 hour percent theoretical yield produced by an adapted Pichia stipitis CBS 6054 and the parent strain on varying percentages of dilute acid pretreated aspen hydrolysate supplemented with a sugar mix $(n=2)\left(30^{\circ} \mathrm{C}\right.$, $\mathrm{pH}$ 5.5).

Figure D.4. Comparison of 72 hour ethanol yields produced by an adapted Pichia stipitis CBS 6054 and the parent strain on varying percentages of dilute acid pretreated aspen hydrolysate supplemented with a sugar mix $(\mathrm{n}=2)\left(30^{\circ} \mathrm{C}, \mathrm{pH} 5.5\right)$.

\section{Appendix E. Growth of $\boldsymbol{P}$. stipitis on different media}

Figure E. 1. Growth of $P$, stipits in YPX media $(50 \mathrm{~g} / \mathrm{L})$ during 24 hours $\left(30^{\circ} \mathrm{C}, \mathrm{pH}\right.$ $5.5)$.

Figure E. 2. Growth of $P$. stipitis in YNB media $(50 \mathrm{~g} / \mathrm{L})$ over 24 hours $\left(30^{\circ} \mathrm{C}, \mathrm{pH}\right.$ $5.5)$. 


\section{List of Tables}

\section{Chapter 1. Literature Review}

Table 1. Organisms that can use sugars in lignocellulosic material for the production of ethanol.

\section{Chapter 2. Methods}

Table 2. Media composition

Table 3. Sugar concentrations (g/L) for synthetic dilute acid pretreated hydrolysate fermentations by Pichia stipitis CBS 6054. Taken from data obtained by Michigan Tech

Table 4. Medium composition for synthetic hydrolysate.

\section{Chapter 3. Results and Discussion}

Table 5. Growth rate of $S$. cerevisiae (ER) at varying glucose concentrations in YP media $\left(30^{0} \mathrm{C}, \mathrm{pH} 5.5\right.$ for 24 hours $)$

Table 6. Summary of single substrate fermentation data for xylose and glucose fermentations by Pichia stipitis CBS 6054 for 72 hours $\left(30^{\circ} \mathrm{C}, \mathrm{pH} 5.5\right)$.

Table 7. The maximum biomass produced by S. cerevisiae (ER) (1) and Pichia stipitis (2) on glucose, xylose, galactose, mannose, and arabinose in YP media at $30^{0} \mathrm{C}, \mathrm{pH} 5.5$.

Table 8. The growth rate (k) of $S$. cerevisiae (ER) during mixed substrate fermentations. (ER was grown in YP with the varying levels of glucose/xylose mixtures at $35^{\circ} \mathrm{C}$ for 24 hours, $\mathrm{pH}$ 5.5.)

Table 9. Ethanol production by $P$. stipitis CBS 6054 from glucose:xylose, pentose (arabinose and xylose), and hexose (galactose, glucose, and mannose) sugar mixtures in a 48 hour period.

Table 10. Biomass of $P$. stipitis (PS) and $S$. cerevisiae (ER) produced in 16 hours in media, (YPX or YPG) containing $0.03 \mathrm{~g} / \mathrm{L}$ cycloheximide

Table 11. Glucose levels in enzymatic pretreated cellulose from aspen, balsam, and switchgrass and ethanol yield by S. cerevisiae (ER) for 24 hours $\left(30^{\circ} \mathrm{C}, \mathrm{pH} 5.5\right)$.

Table 12. Ethanol yield by Pichia stipitis on synthetic non-toxic hydrolysate after 72 hrs. of growth $\left(30^{\circ} \mathrm{C}, \mathrm{pH} 5.5\right)$. 
Table 13. Biomass production (g/L) by Pichia stipitis with different concentrations of furfural in YPX medium after 24 hours $\left(30^{\circ} \mathrm{C}, \mathrm{pH} 5.5\right)$.

Table 14. Biomass production (g/L) by Pichia stipitis with different concentrations of acetic acid in YPX medium after 24 hours $\left(30^{\circ} \mathrm{C}, \mathrm{pH} 5.5\right)$.

Table 15. Biomass production (g/L) by Pichia stipitis with different concentrations of furfural(ff), acetic acid(aa), and combinations of the two in synthetic aspen media.

Table 16. Biomass production by Pichia stipitis CBS 6054 in the presence of: acetic acid (aa; 4, 8, $12 \mathrm{~g} / \mathrm{L}$ ), 5B. furfural (ff; 1.5, 3, $4.5 \mathrm{~g} / \mathrm{L}$ ); and combinations of the two $(4: 1.5,8: 3,12: 4.5 \mathrm{~g} / \mathrm{L})$ in synthetic aspen hydrolysate in synthetic aspen media after 24 hours $\left(30^{\circ} \mathrm{C}, \mathrm{pH} 5.5\right)$.

Table 17. Maximum ethanol yields from concentrated sugar mixtures modeled after aspen hydrolysate by $P$. stipitis CBS 6054 over 120 hours in $\mathrm{YP}\left(30^{\circ} \mathrm{C}, \mathrm{pH} 5.5\right)$.

Table 18. Composition of two batches of dilute acid pretreated aspen hydrolysate.

Table 19. Ethanol yields from an adapted strain of Pichia stipitis CBS 6054 on real dilute acid pretreated aspen hydrolysate after 72 hours $\left(30^{\circ} \mathrm{C}, \mathrm{pH} 5.5\right)$.

Table 20. MTU adapted strain of Pichia stipitis CBS 6054 compared to other adapted strains of Pichia strains in the literature.

Table 21. Summary of fermentation results of three different media types: (Yeast Nitrogen Base (YNB), Yeast Peptone Broth (YPX), and Corn Steep Liquor Media (CSL) using Pichia stipitis on glucose and/or xylose $\left(30^{\circ} \mathrm{C}, \mathrm{pH} 5.5\right)^{\mathrm{a}}$.

\section{$\underline{\text { Appendix A. Ethanol production from glucose by } S \text {. cerevisiae }}$}

Table A.1. Production of ethanol from glucose by S. cerevisiaein 24 hours $\left(30^{\circ} \mathrm{C}\right.$, $\mathrm{pH}$ 5.5).

Table A.2. Example of the ethanol yield model using results of HPLC data for a $100 \%$ glucose $(5 \mathrm{~g} / \mathrm{L})$ fermentation using $S$. cerevisiae (ER) after 24 hours in YP media $\left(30^{\circ} \mathrm{C}\right.$. ph 5.5$)$. 


\section{$\underline{\text { Appendix C. Effect of inhibitory compounds on } P \text {. stipitis }}$}

Table C.1.The growth rate (k) of Pichia stipitis with different concentrations of furfural in YPX after 24 hours $\left(30^{\circ} \mathrm{C}, \mathrm{pH} 5.5\right)$.

Table C.2. The growth rate (k) and generation time (t) of Pichia stipitis with different concentrations of acetic acid in YPX after 24 hours $\left(30^{\circ} \mathrm{C}\right.$, pH 5.5).

Table C.3 Growth rate (k) of Pichia stipitis in synthetic aspen hydrolysate supplemented with acetic acid [8 g/L (A8A) and $10 \mathrm{~g} / \mathrm{L}$ (A10A)), furfural (2 g/L $(\mathrm{A} 2 \mathrm{~F})$ and $4 \mathrm{~g} / \mathrm{L}(\mathrm{A} 4 \mathrm{~F})]$, and combinations of the two toxins $[2 \mathrm{~g} / \mathrm{L}$ furfural with 8 $\mathrm{g} / \mathrm{L}]$

\section{Appendix D. Adaptation comparison data}

Table D.1. Summary of adapted Pichia stipitis CBS 6054 adapted to dilute acid pretreated hydrolysate $\left(30^{\circ} \mathrm{C}, \mathrm{pH} 5.5\right)$. 


\title{
List of Abbreviations
}

\author{
AP - Acid Pretreatment \\ CSL- Corn Steep Liquor \\ DAD - Diode Array Detector \\ DAP - Dilute Acid Pretreatment \\ ER - Ethanol Red (Saccharomyces cerevisiae) \\ HMF - 5-Hydroxymethylfurfural \\ HPLC - High Performance Liquid Chromatography \\ $\mathrm{k}$ - growth rate \\ RID- Refractive Index Detector \\ SD - Standard Deviation \\ SDB - Sabouraud Dextrose Broth \\ YNB - Yeast Nitrogen Base \\ YP - Yeast Peptone Broth \\ YPG - Yeast Extract-Peptone-Glucose \\ YPX- Yeast Extract-Peptone-Xylose \\ YP-Hexose - Yeast Extract-Peptone-Hexose \\ YP-Pentose - Yeast Extract-Peptone-Pentose
}




\begin{abstract}
Ethanol from lignocellulosic feedstocks is not currently competitive with corn-based ethanol in terms of yields and commercial feasibility. Through optimization of the pretreatment and fermentation steps this could change. The overall goal of this study was to evaluate, characterize, and optimize ethanol production from lignocellulosic feedstocks by the yeasts Saccharomyces cerevisiae (strain Ethanol Red, ER) and Pichia stipitis CBS 6054.
\end{abstract}

Through a series of fermentations and growth studies, P. stipitis CBS 6054 and S. cerevisiae (ER) were evaluated on their ability to produce ethanol from both single substrate (xylose and glucose) and mixed substrate (five sugars present in hemicellulose) fermentations. The yeasts were also evaluated on their ability to produce ethanol from dilute acid pretreated hydrolysate and enzymatic hydrolysate. Hardwood (aspen), softwood (balsam), and herbaceous (switchgrass) hydrolysates were also tested to determine the effect of the source of the feedstock. P. stipitis produced ethanol from 66$98 \%$ of the theoretical yield throughout the fermentation studies completed over the course of this work. S. cerevisiae (ER) was determined to not be ideal for dilute acid pretreated lignocellulose because it was not able to utilize all the sugars found in hemicellulose. S. cerevisiae (ER) was instead used to optimize enzymatic pretreated lignocellulose that contained only glucose monomers. It was able to produce ethanol from enzymatically pretreated hydrolysate but the sugar level was so low ( $>3 \mathrm{~g} / \mathrm{L}$ ) that it would not be commercially feasible. 
Two lignocellulosic degradation products, furfural and acetic acid, were evaluated for whether or not they had an inhibitory effect on biomass production, substrate utilization, and ethanol production by $P$. stipitis and S. cerevisiae (ER). It was determined that inhibition is directly related to the concentration of the inhibitor and the organism.

The final phase for this thesis focused on adapting P. stipitis CBS 6054 to toxic compounds present in dilute acid pretreated hydrolysate through directed evolution. Cultures were transferred to increasing concentrations of dilute acid pretreated hydrolysate in the fermentation media. The adapted strains' fermentation capabilities were tested against the unadapted parent strain at each hydrolysate concentration. The fermentation capabilities of the adapted strain were significantly improved over the unadapted parent strain. On media containing $60 \%$ hydrolysate the adapted strain yielded $0.30 \mathrm{~g} \_$ethanol $/ \mathrm{g} \_$sugar $\pm 0.033(\mathrm{~g} / \mathrm{g})$ and the unadapted parent strain yielded $0.11 \mathrm{~g} / \mathrm{g}$ \pm 0.028 . The culture has been successfully adapted to growth on media containing $65 \%$, $70 \%, 75 \%$, and $80 \%$ hydrolysate but with below optimal ethanol yields $(0.14-0.19 \mathrm{~g} / \mathrm{g})$. Cell recycle could be a viable option for improving ethanol yields in these cases.

A study was conducted to determine the optimal media for production of ethanol from xylose and mixed substrate fermentations by $P$. stipitis. Growth, substrate utilization, and ethanol production were the three factors used to evaluate the media. The three media tested were Yeast Peptone (YP), Yeast Nitrogen Base (YNB), and Corn Steep Liquor (CSL). The ethanol yields $(\mathrm{g} / \mathrm{g})$ for each medium are as follows: YP - 0.40-0.42, YNB 0.28-.030, and CSL - 0.44-.051. The results show that media containing CSL result in slightly higher ethanol yields then other fermentation media. 
P. stipitis was successfully adapted to dilute acid pretreated aspen hydrolysate in increasing concentrations in order to produce higher ethanol yields compared to the unadapted parent strain. S. cerevisiae (ER) produced ethanol from enzymatic pretreated cellulose containing low concentrations of glucose $(1-3 \mathrm{~g} / \mathrm{L})$. These results show that fermentations of lignocellulosic feedstocks can be optimized based on the substrate and organism for increased ethanol yields. 


\section{Introduction}

As the push for ethanol to reduce the reliance on petroleum-based fuels increases, so does research in the area of optimizing ethanol production through the bioconversion of lignocellulose. Lignocellulose is the most abundant renewable resource on the planet (Zaldivar et al., 2001). It is made up of three components: cellulose; hemicellulose; and lignin. Cellulose and hemicellulose can be converted to ethanol through a multistage process that typically begins with a chemical and/or mechanical pre-treatment. The pretreatment makes the material more available to hydrolysis by increasing the surface area (Karimi et al., 2006). The pretreatment is followed by a hydrolysis step, which liberates sugars locked in the complex structure. This either can be carried out chemically or by enzymes. The hydrolysate then provides the substrate for the bioconversion of monosaccharides to ethanol through microbiological fermentation (van Maris et al., 2006). Current research in the area of fermentation is focused on the optimization of the bioconversion of monosaccharides and disaccharides to ethanol. The majority of it is centered on finding an optimum organism for a given substrate. Coupled with finding the organism is developing the optimal fermentation conditions.

Pichia stipitis CBS 6054 is a strain of yeast that has been shown to produce ethanol from many of the sugars found in lignocellulosic material (Agbogbo et al., 2006). It is a native xylose-fermenting (the most abundant sugar in hemicelluloses) yeast that can yield up to 0.42-0.47 gram of ethanol per gram of substrate used (Agbogbo and Coward-Kelly, 2008). Numerous studies have shown its ability to be adapted to dilute acid pretreated hydrolysate for optimum ethanol yields (Nigam, 2001; Parekh et al., 1988; Sreenath and 
Jeffries, 2000). For this reason, P. stipitis CBS 6054 has the potential to be an excellent candidate for optimizing ethanol production in a lignocellulosic feedstock system. Saccharomyces cerevisiae (ER) has not been reported in the literature as being used in lignocellulosic fermentations. It has the ability to ferment three of the five sugars found in lignocellulosic feedstocks to high ethanol yields. The yeast is ideal for using in fermentation involving enzymatically pretreated cellulose, which consists solely of glucose monomers. 


\section{Thesis Objectives}

Lignocellulosic-based ethanol is a viable alternative to corn-based ethanol. However, the system is more complex than a simple starch to ethanol fermentation. Research was conducted in order to optimize each stage of biofuel production from lignocellulosic feedstocks (Figure 1). The optimization of the fermentation step was divided into two stages: organism evaluation and condition optimization (Figure 2). Two organisms, Pichia stipitis CBS 6054 and Saccharomyces cerevisiae (ER) that have shown to utilize one or more sugars present in lignocellulose were evaluated.

The specific objectives were:

1. Characterize the ability of S. cerevisiae (ER) and P. stipitis CBS 6054 to produce ethanol from the sugars present in lignocellulosic material from aspen, balsam, and switchgrass.

2. Characterize the toxic effect of dilute acid-pretreated hemicellulose and enzymatic hydrolysate for each yeast species in terms of growth, substrate utilization, and ethanol production.

3. Determine the effectiveness of adaptation of $P$. stipitis CBS6054 to the conditions present in dilute acid pretreated hemicellulose for improved ethanol production and substrate utilization.

4. Optimize the fermentation system for the maximum ethanol yields from aspen hydrolysate through fermentation media and cell recycle. 


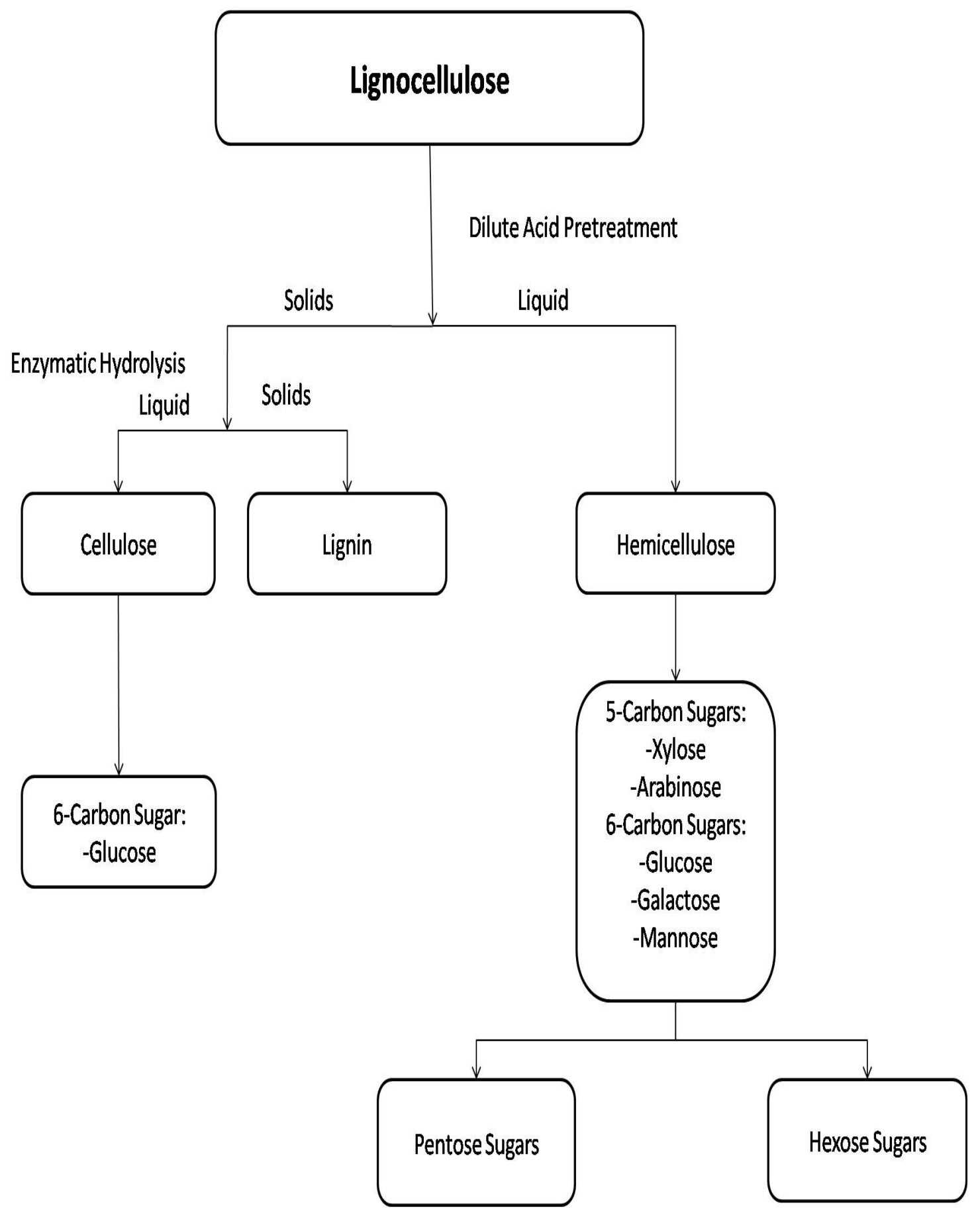

Figure 1. Diagram of carbohydrate components of lignocellulose after dilute acid pretreatment and enzymatic hydrolysis. 


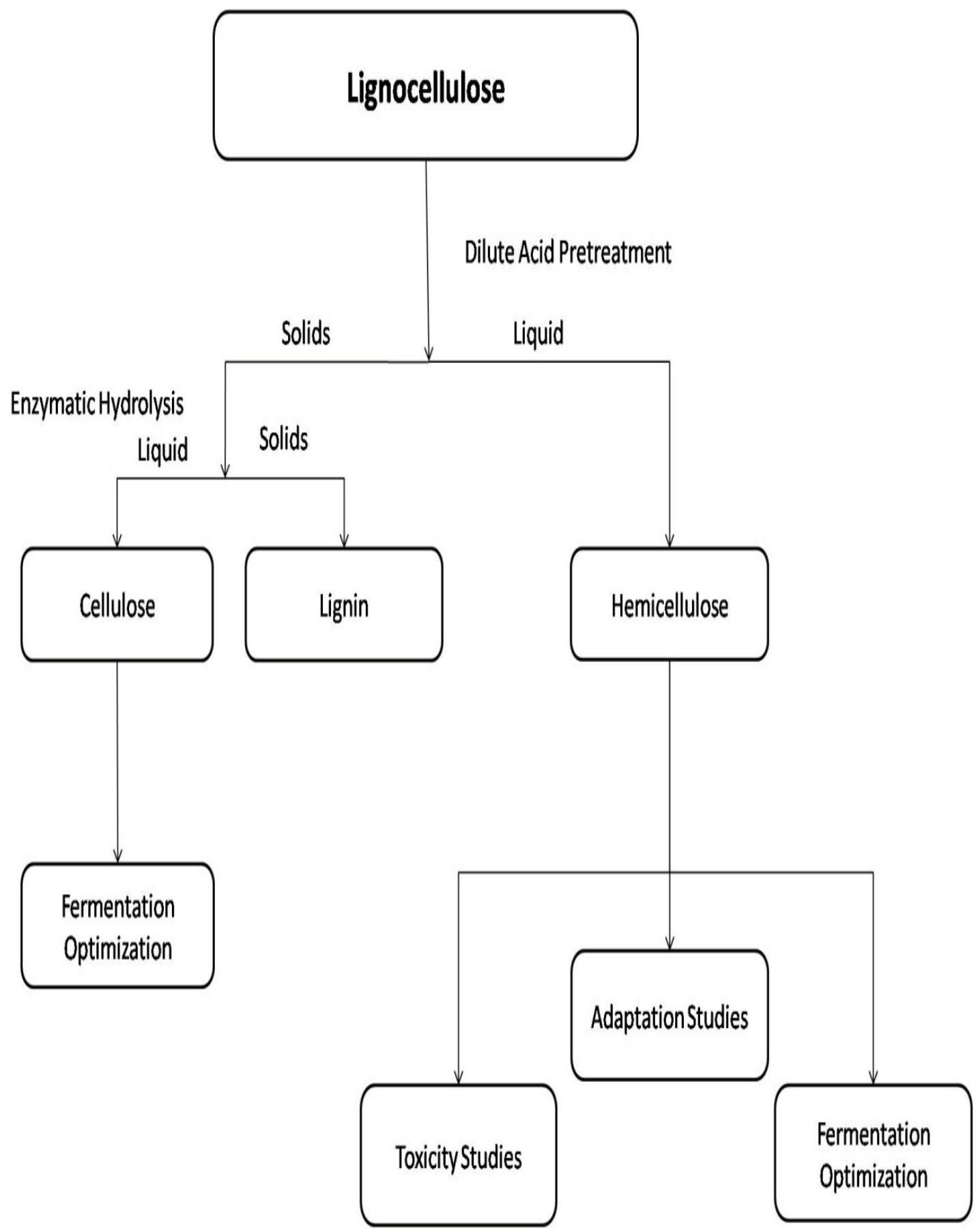

Figure 2. Diagram of the evaluations that were performed on the hemicellulose and cellulose feedstocks after hydrolysis. 


\section{Chapter 1. Literature Review}

\subsection{Lignocellulosic Material and Ethanol producing Microorganisms}

When using lignocellulosic feed stock there are three possible substrates that can be used in fermentations. They are cellulose, hemicellulose and a mixture of the two. Each type of substrate contains fermentable sugars (Figure 3). Cellulose is composed of the hexose (6-carbon sugar) glucose. Hemicellulose is composed primarily of the hexoses: glucose, galactose, and mannose and the pentoses (5-carbon sugar) xylose and arabinose (Zaldivar et al., 2000). The fermentation processes for each of the three substrates will be discussed in detail, as well as the ability of many different organisms to ferment the available substrates to ethanol (Table 1).

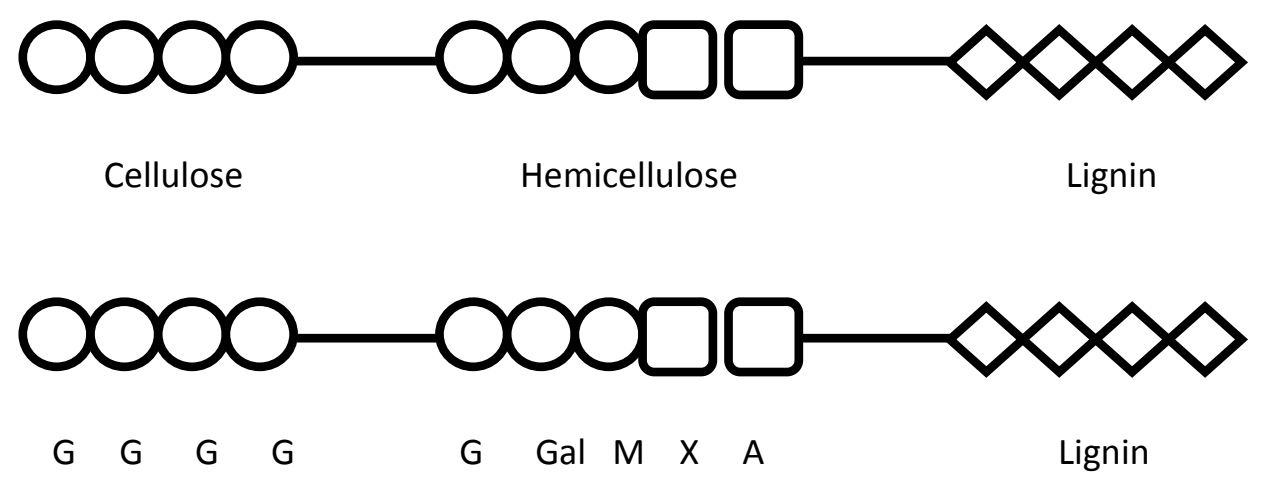

Figure 3. The composition of lignocellulose and the breakdown of the sugars present in cellulose and hemicellulose. The letters represent a different sugar: G-glucose; Galgalactose; M-mannose; X-xylose; and A-arabinose (Modified from Zaldivar et al., 2000) 
Table 1. Organisms that can use sugars in lignocellulosic material for the production of ethanol.

\begin{tabular}{|c|c|c|c|c|c|c|c|c|}
\hline \multirow[t]{2}{*}{ Organism } & \multirow{2}{*}{$\begin{array}{c}\mathrm{O}_{2}{ }^{\mathrm{a}} \\
\begin{array}{c}\text { Fermentation } \\
\text { conditions }\end{array} \\
\end{array}$} & \multicolumn{2}{|c|}{ Optimum } & \multicolumn{2}{|c|}{ Substrate $^{b}$} & \multirow[t]{2}{*}{ Pros for Use } & \multirow[t]{2}{*}{ Cons for Use } & \multirow[t]{2}{*}{ References } \\
\hline & & $\begin{array}{c}\text { Temp } \\
\left({ }^{\circ} \mathrm{C}\right)\end{array}$ & pH & Cellulose & Hemicellulose & & & \\
\hline \multicolumn{9}{|l|}{ Yeast } \\
\hline $\begin{array}{c}\text { Saccharomyces cerevisiae } \\
\text { (Wild-type) }\end{array}$ & $\begin{array}{l}\text { Anaerobic }^{\mathrm{d}} \\
\text { Aerobic }\end{array}$ & 30 & 5 & Yes & Yes - M, Gal & $\begin{array}{l}\text {-High Ethanol } \\
\text { Tolerance } \\
\text {-Native Metabolism } \\
\text { (glucose) }\end{array}$ & $\begin{array}{c}\text {-No cellulase } \\
\text { activity } \\
\text {-Complex Growth } \\
\text { Factors }\end{array}$ & $\begin{array}{l}\text { Van Maris } \\
\text { et al., } 2006\end{array}$ \\
\hline $\begin{array}{l}\text { S. cerevisiae (Ethanol Red - } \\
\text { high temp. and EtOH } \\
\text { tolerant strain) }\end{array}$ & $\begin{array}{l}\text { Anaerobic }^{\mathrm{d}} \\
\text { Aerobic }\end{array}$ & $30-40$ & 5 & Yes & Yes- $\mathrm{M}$ and $\mathrm{Gal}$ & $\begin{array}{c}\text {-High Ethanol } \\
\text { Tolerance } \\
\text {-Native Metabolism } \\
\text {-SSF }\end{array}$ & $\begin{array}{c}\text {-No cellulase } \\
\text { activity } \\
\text {-Complex Growth } \\
\text { Factors }\end{array}$ & $\begin{array}{l}\text { Karimi et } \\
\text { al., } 2006\end{array}$ \\
\hline Kluyveromyces marxianus & $\begin{array}{l}\text { Anaerobic }^{\mathrm{d}} \\
\text { Aerobic }\end{array}$ & 40 & 5 & Yes & No & $\begin{array}{l}\text {-Ideal Temp for SSF } \\
\text {-Native Metabolism }\end{array}$ & $\begin{array}{c}\text {-Low Ethanol } \\
\text { Yields } \\
\text {-Complex Growth } \\
\text { Factors } \\
\end{array}$ & $\begin{array}{l}\text { Ballesteros } \\
\text { et al., } 2004\end{array}$ \\
\hline Pichia stipitis CBS 6054 & $\begin{array}{l}\text { Microaerophilic }^{\mathrm{d}} \\
\text { Aerobic }\end{array}$ & $30-40$ & 5 & Yes & $\begin{array}{l}\text { Yes-X, G, Gal, } \\
\text { and } \mathrm{M}\end{array}$ & Native Metabolism & $\begin{array}{c}\text {-Low Ethanol } \\
\text { tolerance } \\
\text {-Uses only Xylose }\end{array}$ & $\begin{array}{l}\text { Jefferies } \\
\text { and Jin, } \\
2000\end{array}$ \\
\hline \multicolumn{9}{|l|}{ Mold } \\
\hline Fusarium oxysporum & Microaerophilic & 30 & 4.5 & Yes & Yes-all & $\begin{array}{l}\text {-Native Metabolism } \\
\text {-Cellulase Activity }\end{array}$ & $\begin{array}{l}\text {-Low Ethanol } \\
\text { yields }\end{array}$ & $\begin{array}{c}\text { Ruiz et al., } \\
2006\end{array}$ \\
\hline \multicolumn{9}{|l|}{ Bacteria } \\
\hline Zymomonas mobilis & Anaerobic & $30-40$ & 5 & Yes & Yes -all & $\begin{array}{l}\text {-Ideal Temp for SSF } \\
\text {-Native Metabolism }\end{array}$ & Not Hardy & $\begin{array}{l}\text { Lin and } \\
\text { Tanaka, } \\
2005\end{array}$ \\
\hline Escherichia coli KO11 & $\begin{array}{c}\text { Anaerobic } \\
\text { Microaerophilic }^{c}\end{array}$ & $30-35$ & $6-8$ & Yes & Yes - all & $\begin{array}{l}\text {-Easy to culture } \\
\text { - Minimal growth } \\
\text { requirements }\end{array}$ & $\begin{array}{c}\text {-Narrow pH Range } \\
\text {-Genetic } \\
\text { Modification }\end{array}$ & $\begin{array}{c}\text { Underwoo } \\
\text { d et } \\
\text { al.,2002 }\end{array}$ \\
\hline
\end{tabular}

a Oxygen conditions under which the organism produces ethanol
${ }^{b}$ Refers to whether the organism can ferment the sugars to ethanol. Cellulose contains: glucose. Hemicellulose contains: glucose; galactose (Gal); mannose (M); xylose (X); and arabinose (A)

${ }^{\mathrm{C}}$ Ee coli $\mathrm{KO} 11$ was shown to have higher xylose utilization ratios with microaeration (Okuda et al., 2006)

¿ Optimum ethanol yield 


\section{Cellulose}

Cellulose is a polymer of glucose connected by $\beta-(1,4)$-glycosidic bonds (Ohgen et al., 2006). Due to its close association with the other material in plant biomass and its conformation, it is highly resistant to hydrolysis (Zaldivar et al., 2000). The hydrolysis of cellulose is made possible by chemicals or enzymes. Enzymatic hydrolysis is the preferred means because it does not produce inhibitory compounds that chemical hydrolysis produces (van Maris et al., 2006). However, there are two antibiotics added during this hydrolysis, tetracycline and cycloheximide. These compounds are added to prevent microbial growth during the enzymatic pretreatment. Cycloheximide, which inhibits ribosomal function in eukaryotes, has the potential to negatively impact growth and subsequent ethanol production by the yeast cultures (de Kleot, 1966).

The benefit of using cellulose to produce ethanol is that glucose is easily and naturally metabolized by many organisms, such as wild-type strains of $S$. cerevisiae (Figure 4). Its high yields and high ethanol tolerance make it the ideal organism for glucose fermentations. S. cerevisiae does not have any natural cellulytic activity and the fact that cellulose is resistant to hydrolysis does pose some problems. By default, the added step of enzymatic hydrolysis makes cellulose more expensive to work with than hemicellulose. Simultaneous Saccharification and Fermentation (SSF), however, can be done using cellulase enzymes coupled with $S$. cerevisiae. The fermentations can be carried out aerobically (lower yields) and anaerobically, which is another added benefit to using

cellulose (Karimi et al., 2006). The efficiency of S. cerevisiae at glucose metabolism is 
unmatched especially under anaerobic conditions; it converts $1 \mathrm{~mol}$ of glucose to $2 \mathrm{~mol}$ of ethanol (Zaldivar et al., 2000).

There are a few reasons to use or even consider using other organisms to carry out this conversion. One is apparent when conducting SSF. The cellulase enzymes require a higher temperature for complete hydrolysis of the cellulose. The optimum temperature is around $40-45^{\circ} \mathrm{C}$ for cellulytic enzymes and the optimal growth temperature for most yeast is $30^{\circ} \mathrm{C}$ (Ballesteros et al., 2004).

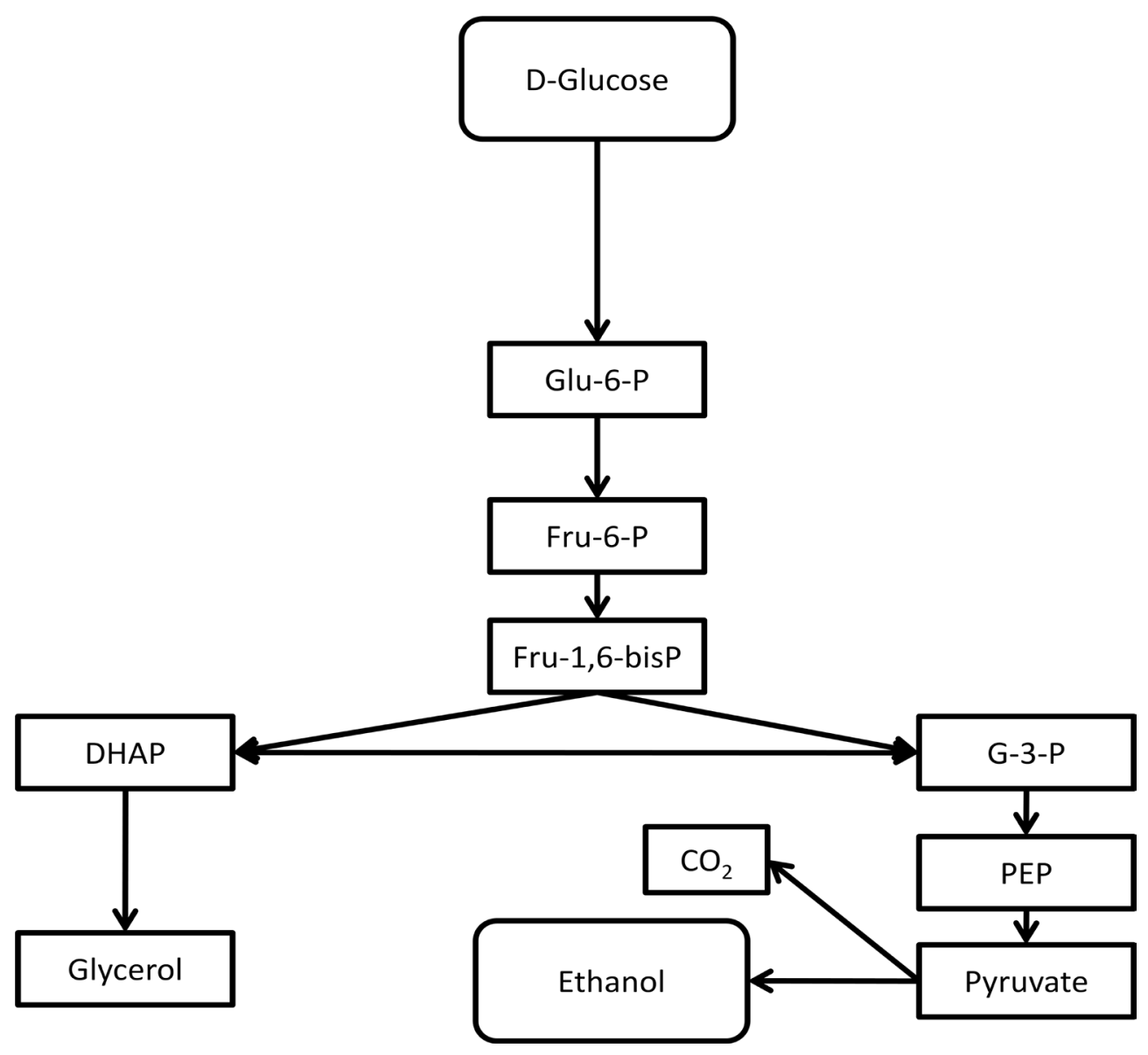

Figure 4. The catabolism of glucose by Saccharomyces cerevisiae using the EmbdenMeyerhof glycolytic pathway (Modified from van Marin, 2006). 
In addition to $S$. cerevisiae and its respective strains, there are some bacteria that will convert glucose to ethanol at levels that rival yeast. The bacterium Zymomonas mobilis produces ethanol at roughly the same theoretical yields as $S$. cerevisiae, $90-95 \%$ (Yomano et al., 1998). Thermophilic bacteria and other species of thermotolerant yeasts have also been used for SSF but they have shown reduced levels of ethanol production compared to Z. mobilis and S. cerevisiae (Ballesteros et al., 2004) (Karimi et al., 2006). S. cerevisiae is typically chosen over ethanologenic bacteria, like Z. mobilis, because it is a hardy culture that is easy to maintain (Lin and Tanaka, 2005).

\section{Hemicellulose}

Unlike cellulose that is a polymer of one sugar, hemicellulose is a polymer of several sugars. Hemicellulose may be converted directly to monomeric sugars from the pretreatment of the material with dilute acid hydrolysis (Jefferies and Jin, 2000). This direct hydrolysis may result in the presence of compounds that will inhibit bioconversion of the sugars. The most abundant of the sugars in hemicellulose is xylose. Xylose is a pentose that is not naturally fermented by many organisms. For the most part, genetically modified organisms need to be utilized for xylose fermentations on an industrial scale. A small number of yeast will ferment the sugar but they are not industrially feasible because they have low yields and low ethanol tolerance (Jeppenson et al., 1996). However, one promising yeast is Pichia stipitis, which naturally ferments xylose to ethanol at high yields (Jeffries et al., 2007) (Table 1). P. stipitis converts xylose to xylulose using the pentose-phosphate pathway and two enzymes, xylose reductase and xylitol 
dehydrogenase (Almeida et al., 2008). Xylose must be converted to xylulose in order to be utilized by Pichia's fermentation pathway without genetic modification (Figure 5).

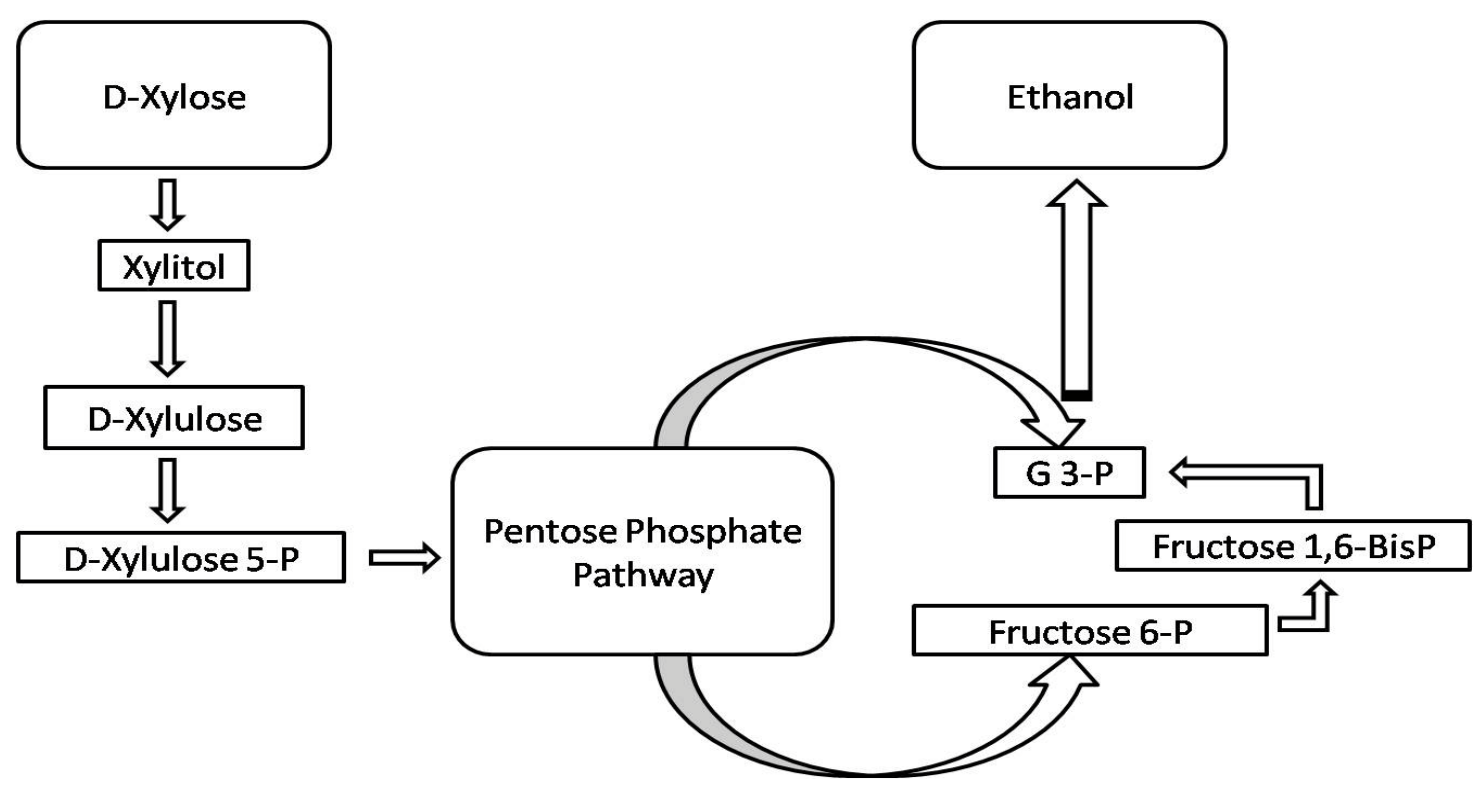

Figure 5. The native metabolic pathway of wild-type Pichia stipitis for ethanol production from xylose. The products utilize the pentose phosphate pathway (PPP) once xylose has been converted to xylitol and then to xylulose (Zalidivar et al., 2001) (Modified from van Maris et al., 2006).

S. cerevisiae has shown an ability to ferment xylulose at slow rates but it lacks the pathway to convert xylose to xylulose and therefore cannot produce ethanol from it (Kuyper et al., 2005). The two genes encoding for xylose reductase and xylitol dehydrogenase from $P$. stipitis have been integrated into S. cerevisiae's genetic material to make the conversion occur. The over-production of xylitol, a by-product, must be overcome and the bacterial enzyme xylose isomerase must be expressed in order for there to be an optimization of xylose metabolism (Kuyper et al., 2005). Though S. cerevisiae is not able to utilize xylose without genetic modification, it can use other hemicellulose 
sugars. It readily ferments the glucose isomers mannose and fructose. Using the Leloir pathway, it will also convert galactose and mannose to ethanol (Figure 6). This pathway however is regulated by the presence of glucose (van Maris et al., 2006).

Bacteria that naturally produce ethanol from xylose seem to suffer the same problems as the yeasts that utilize xylose: they are not suitable for commercial production of ethanol. The most promising xylose-fermenting bacteria are strains of genetically modified Escherichia coli. One strain, KO11, using the native glycolytic pathway, has the ability to produce ethanol at high yields from xylose and other hemicellulose sugars (Underwood et al., 2002). KO11 contains genes from Z. mobilis. These genes encode for pyruvate decarboxylase and alcohol dehydrogenase $(p d c$ and $a d h B)$ and are integrated in to its chromosome (Underwood et al., 2002). In addition to utilizing xylose, KO11 will simultaneously use glucose, galactose, arabinose, and mannose (Moniruzzaman and Ingram, 1998). This makes it an excellent candidate for mixed substrate fermentations. Unfortunately, KO11 can only operate in a narrow $\mathrm{pH}$ range and is less hardy then yeast (Lin and Tanaka, 2005). Another Escherichia coli, a mutant of strain K12, has been developed to convert glucose or xylose to ethanol at $82 \%$ yields using its native metabolism (Kim et al., 2007). 


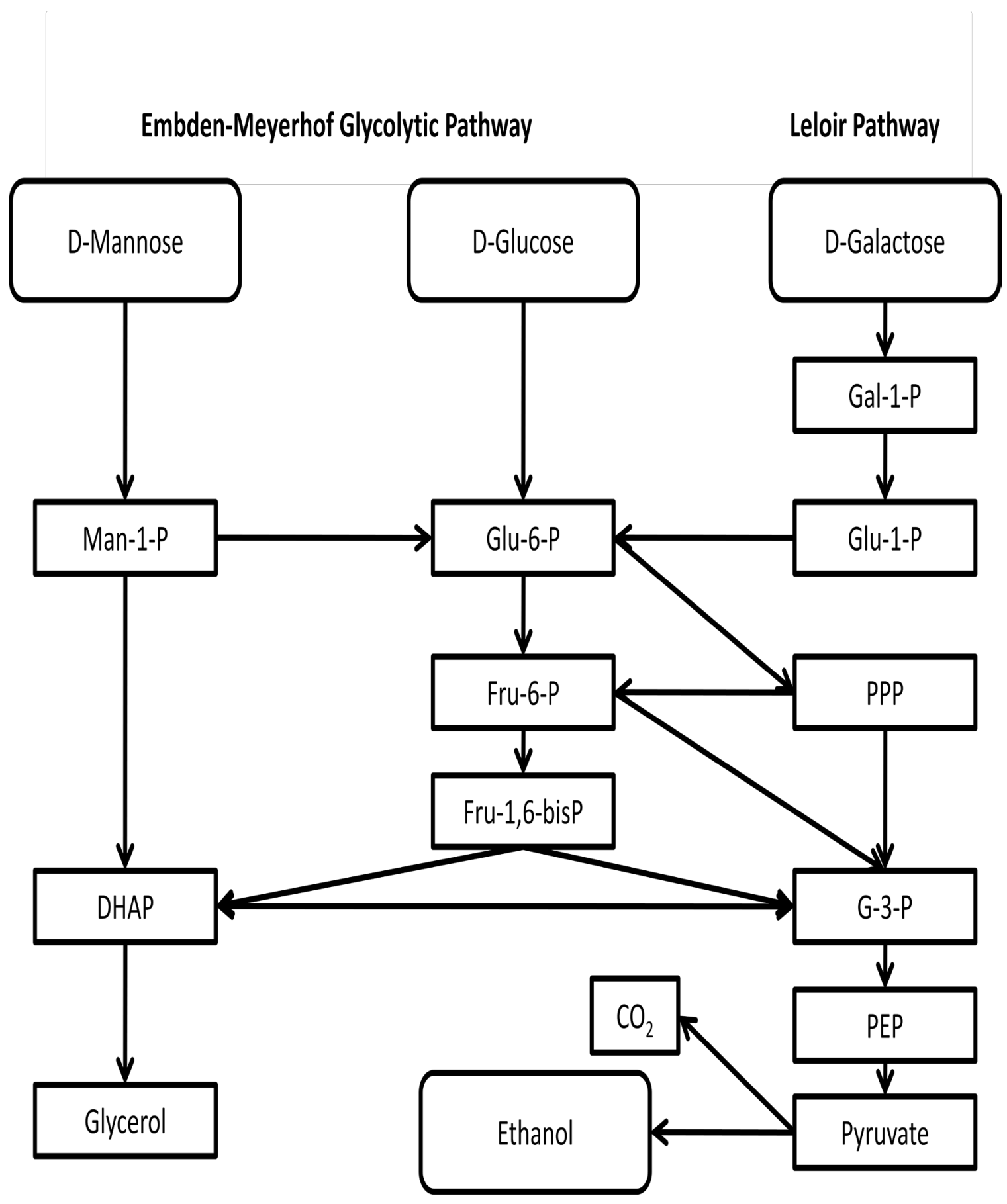

Figure 6. The catabolism of glucose and it isomers by Saccharomyces cerevisiae (Modified from van Marin, 2006). 


\section{Mixed Substrate}

Mixed substrate fermentations for lignocellulose would require a bacterium or yeast that could utilize a mixture of hexoses and pentoses (Table 1). P. stipitis CBS 6054 (CBS refers to the Netherlands' Culture Collection and 6054 is a strain designation) is a strain of yeast that has been shown to produce ethanol from both xylose and glucose (Agbogbo et al., 2006). P. stipitis CBS 6054 was first isolated from insect larvae and is considered to have the best native xylose to ethanol fermentation capacity of any known organism (Jeffries et al., 2007). Fusarium oxysporum is a direct cellulose to ethanol converter. It produces cellulases, xylanases, and $\beta$-glucosidases and is able to metabolize both hexoses and pentoses into ethanol (Ohgen et al., 2006). A study performed by Ruiz et al., found that $F$. oxysporum will produce ethanol from xylose/glucose mixes (Ohgren et al., 2006). A genetically modified $S$. cerevisiae has also been shown to carry out mixed substrate (glucose/xylose) fermentations (Jeppenson et al., 1996; Ohgren et al., 2006).

Mixed substrate fermentations have one downside. In the presence of glucose the utilization of the other main sugars (xylose and arabinose) is often delayed due to catabolite repression (Nichols et al., 2001). A mutation of the glucose phosphotransferase gene, ptsG, in $E$. coli was shown to eliminate the catabolite repression, resulting in simultaneous utilization of all sugars (Nichols et al., 2001). Another method for eliminating the effect of catabolite repression is controlling the ratio of glucose to xylose. Lawford and Rousseau (1994) stated that xylose uptake is inhibited when glucose exceeds $40 \%$ of the total sugar present in the fermentation media. Controlling the ratio of sugars is an easy way to get around genetic modification. Catabolite repression is a 
problem that can arise with all mixed substrate fermentations regardless of the organism used. Yeast will use other sugars in the presence of glucose only after all the glucose as been removed (Roca et al., 2003). Genetic modification has to occur to avoid this. Epimerase enzymatic hydrolysis could open the door for a broad range of sugar utilization by $S$. cerevisiae. A mixed culture, multiple organisms in one fermentation, is also a possibility.

\subsection{Pretreatment and Toxicity}

Before fermentation can occur the sugars must be liberated from cellulose and hemicellulose. In the case of hemicellulose the pretreatment will result in near complete chemical hydrolysis (van Maris et al., 2006). This means the monmer sugars are ready for fermentation without further hydrolysis, unlike with cellulose. Cellulose must undergo chemical or enzymatic hydrolysis. This can occur in one of two ways. The hydrolysis can be either carried out before the fermentation (separate hydrolysis and fermentation, SHF) or during the fermentation (SSF) (Karimi et al., 2006). SSF is the preferred method because it can be carried out in the same fermentor, thus reducing equipment costs. It is also beneficial in the case of enzyme hydrolysis. The enzyme is not inhibited by the build-up of sugars because they are removed by the microorganism as the fermentation proceeds (Ballesteros et al., 2004). The problem with SSF is that the optimal temperature of enzymatic hydrolysis is not the optimal temperature for common ethanologenic organism growth. For example, the typical optimum temperature for enzyme hydrolysis is $10-20^{\circ} \mathrm{C}$ higher than the optimal temperature for Saccharomyces cerevisiae, the main ethanol producing yeast (Karimi et al., 2006). The use of thermotolerant organisms, 
mixed cultures, and the addition of a pre-hydrolysis step in which the organism is added after a period of high temperature, are all ways around this problem (Karimi et al., 2006).

Through dilute acid pretreatment the hemicellulose portion of lignocellulose feedstock can be broken down into fermentable sugars for ethanol production (Figure 7). The Michigan Tech Dept. of Chemical Engineering is currently optimizing a dilute sulfuric acid pretreatment of aspen, balsam, and switchgrass hydrolysate for the highest monomeric sugar yields and subsequent enzymatic hydrolysis. In addition to the sugars (xylose, glucose, galactose, mannose, and arabinose), several degradation products are produced (Taherzadeh and Karmimi, 2007) (Figure 8). These compounds can potentially negatively affect growth, substrate utilization, and ethanol production (Liu et al., 2004). The key compounds of concern in the pretreated hydrolysate are acetic acid, furfural and 5-hydroxymethlyfurfural (HMF) (Almeida et al., 2008). Acetic acid is produced as the structure of hemicelluloses degrades. Furfural and HMF are sugar degradation products. Furfural results from the degradation of pentose sugars and HMF as a result hexose degradation (Almeida et al., 2008). Each compound has its own mechanism of action, for fermentation inhibiton. Acetic acid, in its dissociated form, acts to decrease the cells internal $\mathrm{pH}$, thus inhibiting growth (Taherzadeh and Karmimi 2007). Furfural initially increases the lag time but has little effect on final ethanol yield (Liu et al., 2004). HMF has a very limited inhibitory effect on growth and subsequent ethanol production (Liu et al., 2004). Though the individual effects are apparent, the synergistic effects of these compounds must be examined when dealing with the hydrolysate. This effect must be dealt with in order to optimize ethanol production. 


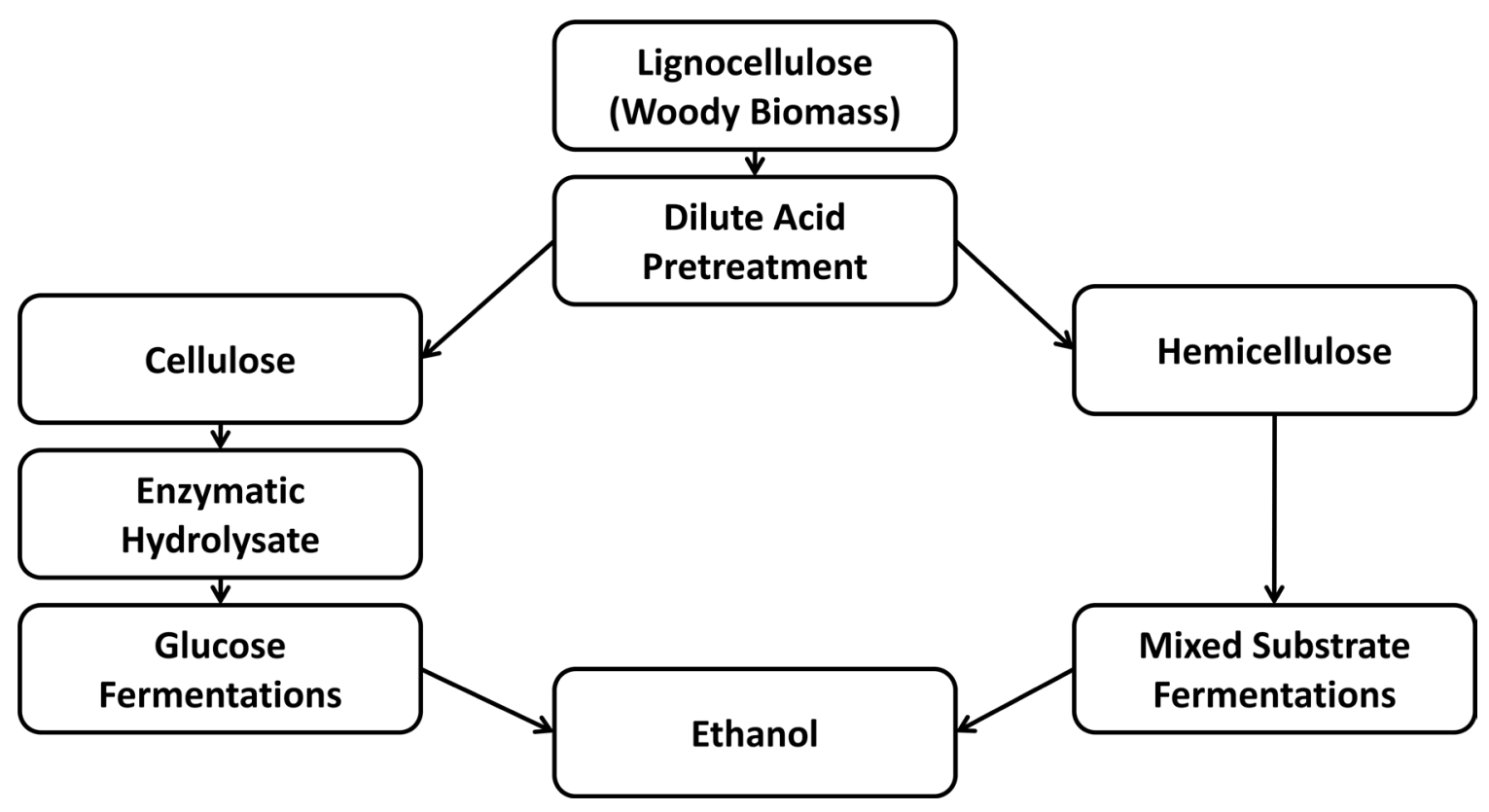

Figure 7. A summary of lignocellulosic feedstreams that can be used to produce ethanol (Modified from Karakashev et al., 2007).

Several means of detoxifying the hydrolysate have been developed: treating with activated charcoal, extraction with organic solvents, ion exchange, ion exclusion, molecular sieves, over liming, and steam stripping (Olsson and Hahn-Hagerdal, 1996). Though extremely effective, detoxification of the hydrolysate can be costly. Another time-saving and cost-effective method is to adapt a natural ethanol-producing organism to the growth conditions present in the hydrolysate. P. stipitis CBS 6054 has the potential of overcoming the toxic effect of the hydrolysate over the ethanol-producing powerhouse S. cerevisiae. P. stipitis has a xylose reductase/xylitol dehydrogenase pathway which has been shown to reduce HMF and furfural (Almeida et al., 2008). This pathway reduces the toxic effect of the two furfuraldehydes. In the past, this Pichia strain has shown adaptability to dilute acid hydrolysate resulting in increased ethanol production (Nigam, 
2001a; Amartey and Jefferies, 1996). Adaptation has shown to increase ethanol yields in several studies using dilute acid pretreated hydrolysate substrates. Nigam (2001a) saw a 1.6 fold increase in ethanol yield after adaptation to dilute acid pretreated red oak. Ethanol yields increased almost 13\% on aspen hydrolysate after adaptation (Parekh et al., 1986). S. cerevisiae has limited ability to produce ethanol from pentoses and does not possess the xylose reductase pathway (Almeida et al., 2008) making it a less desirable choice for adaptation.
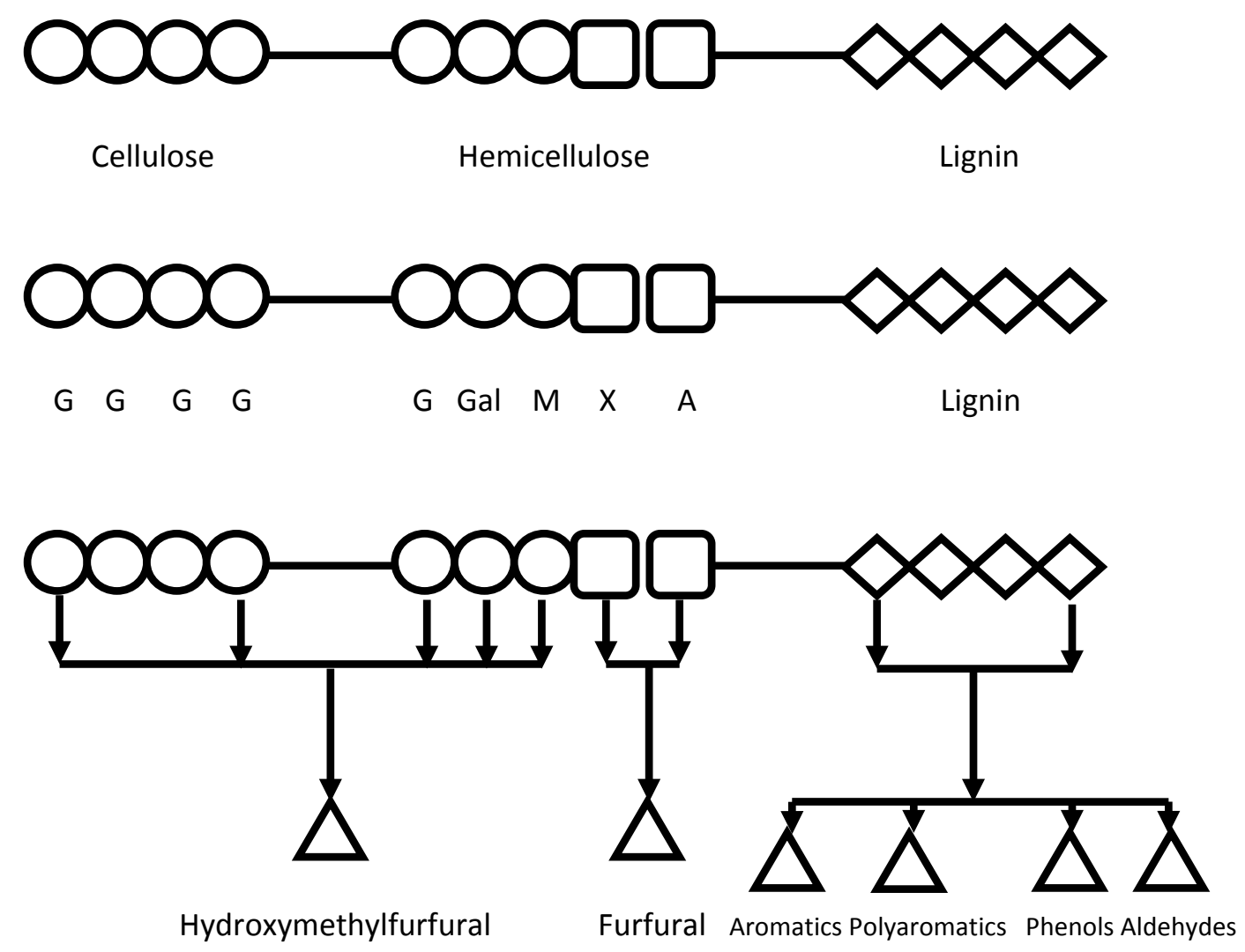

Figure 8. The composition of lignocellulose and the breakdown of the sugars present in cellulose and hemicellulose. The dilute acid pretreatment degradation products and their sources are shown. The letters represent a different sugar: G-glucose; Gal-galactose; Mmannose; X-xylose; and A-arabinose (Modified from Zaldivar et al., 2001). 


\subsection{Optimization of Fermentation Conditions}

The optimization of fermentation conditions involves a series of organism-specific factors. The hydrolysate characteristics also affect these factors. These factors include: cultivation method, cultivation/inoculation media, and cultivation conditions. Each factor can be optimized separately or as a unit depending on the desired result.

Cultivation methods fall into two categories: continuous and batch fermentations. Continuous fermentations are where media and nutrients are fed through the system at a continuous rate and effluent (spent media) and products are removed at the same rate. There is typically a cell recycle system set up in these types of fermentations. Batch culture fermentations are closed-system fermentations. Media and conditions are set at the beginning of the fermentation and once inoculated, the fermentation proceeds until a set stop point. There are considered to be three phases in industrial batch fermentations: lag, growth, and harvesting (Shuler and Kargi, 2002). A type of batch fermentation where substrate and other nutrients are fed throughout the fermentation but nothing is removed is referred to as a fed-batch fermentation. They are done in an effort to overcome limitations such as substrate inhibition and toxicity (Shuler and Kargi, 2002; Taherzadeh et al., 1998). Both continuous and fed-batch have shown to reduce the toxic effect of the dilute acid hydrolysate for furfural and HMF in $S$. cerevisiae fermentations (Bandberg et al., 2005; Taherzadeh et al., 1998).

Cultivation media are directly dependent on the substrate type and are organism-specific (Hahn-Hagerdal et al., 2005). Cultivation conditions refer to $\mathrm{pH}$, temperature, and 
agitation. They are fairly well defined for P. stipitis (Bandberg et al., 2005; Nigam, 2001). P. stipitis' optimum temperature is $30^{\circ} \mathrm{C}$ and the optimum $\mathrm{pH}$ range is $4.0-5.0$ (du Preez et al., 1985). Media play important roles in the ethanol production by Pichia stipitis CBS 6054. Several nutrients have shown to play a role in increasing both biomass and ethanol yield (Agbogbo and Coward-Kelly, 2008). Three common media used in the literature are Yeast-Peptone medium (YP), Yeast Nitrogen Base medium (YNB), and Corn Steep Liquor medium (CSL) (Table 2) (Agbogbo et al., 2006; Amartey and Jefferies, 1994). YNB has been shown to increase ethanol concentrations but causes a decrease in biomass production, whereas CSL has been shown to increase both biomass and ethanol concentration (Amartey and Jefferies, 1994). YP media are typically used as a cultivation and storage media for $P$. stipitis. It does, however, function as a supplement for fermentation media (Rodrigues et al., 2008). A number of other media can be used to produce ethanol using P. stipitis; it is a matter of choosing what is optimal for the application. S. cerevisiae (ER) can also be grown on all three media types. The effect of each on ethanol production has yet to be reported. Wild-type S. cerevisiae is capable of growing on YP and YP is used as the fermentation medium (Wahlbom et al., 2003)

Changing the cultivation method, media, and conditions are key to determining the optimum conditions for ethanol production by P. stipitis CBS 6054 and S. cerevisiae (ER). Choosing whether to separate the enzymatic and dilute acid pretreated portions of the feed-streams into a two fermentations or combined them for a single fermentation also needs to be considered. 
Table 2. Media composition . ${ }^{\mathrm{a}, \mathrm{b}}$

\begin{tabular}{|l|l|l|l|}
\hline Components (g/L) & YP & YNB & CSL \\
\hline Yeast Extract & 10 & - & - \\
\hline Peptone & 20 & 6.56 & - \\
\hline Urea & - & 2.26 & - \\
\hline Yeast Nitrogen Base & - & 1.17 & - \\
\hline Corn Steep Liquor & - & - & 30 \\
\hline
\end{tabular}

${ }^{\mathrm{a}}$ YP- Yeast Peptone, YNB- Yeast Nitrogen Base, and CSL- Corn Steep Liquor

${ }^{\mathrm{b}} \mathrm{pH}$ of all media is $5.5 \pm 0.1$. 


\section{Chapter 2. Methods}

\subsection{Organism Cultivation}

\section{Organism Source}

The focus of this research was on Pichia stipitis CBS 6054 (provided courtesy of Dr. Thomas Jeffries, Institute for Microbial and Biochemical Technology, USDA, Forest Service, Forest Products Laboratory, Madison, Wisconsin) and Saccharomyces cerevisiae (Ethanol Red) provided by Fermentis (Marcq-en-Baroeul, France). These two yeast species were chosen as a result of their adaptability and ethanol producing capabilities (Table 1). They were used in a series of studies in order to determine if they were suitable for ethanol production from lignocellulosic material. Their capabilities will be described in respect to the different types of substrates present in the lignocellulosic material.

\section{Culture Maintenance}

P. stipitis was maintained on Yeast-Peptone-Xylose (YPX) plates (xylose $20 \mathrm{~g} / \mathrm{L}$, and agar $15 \mathrm{~g} / \mathrm{L}$ ), with incubation at $30^{\circ} \mathrm{C}$ for 24 hours. All $P$. stipitis inocula are grown in YPX broth at $30^{\circ} \mathrm{C}$ for 24 hours. S. cerevisiae (ER) was maintained and grown on YPG (glucose $20 \mathrm{~g} / \mathrm{L}$, and agar $15 \mathrm{~g} / \mathrm{L}$ ). All studies are carried out in YP supplemented with sugar solutions. Early S. cerevisiae (ER) experiments were performed in Sabouraud Dextrose Broth (SDB). The inoculum was prepared by initially growing the yeast in YPX or YPG medium at $30^{\circ} \mathrm{C}$ for 24 hours on a gyratory shaker in $125 \mathrm{~mL}$ Erlenmeyer flasks with $25 \mathrm{~mL}$ of media. The well-mixed culture was divided into $1 \mathrm{~mL}$ aliquots and 
centrifuged (3000 rpm for 5 minutes); the supernatant was discarded. The pellet was resuspended in sterile distilled water (Agbogbo et al., 2006).

Specific media requirements or modifications are listed in Table 2 for the composition of all media used over the course of this investigation. The sugar requirements for each individual study are described as well as any other media additives with the methods for that study. All media and supplements were filter-sterilized using vacuum filtration and $0.2 \mu \mathrm{m}$ filters ( $47 \mathrm{~mm}$ diameter), except for CSL that was autoclaved for 20 minutes at $121^{\circ} \mathrm{C}$.

The properties of each yeast have been described extensively in the literature. An initial series of growth, sugar utilization, and ethanol production screening experiments were designed to verify these properties. Due to time constraints and the extensive background work already done with these organisms replicates were not performed on some studies.

\subsection{Growth Studies}

All of the growth studies were carried out in $250 \mathrm{~mL}$ baffled-bottom sidearm flasks with a working volume of $25 \mathrm{~mL}$. A $5 \%$ inoculum of actively growing culture (grown in the same medium as the fermentation) was used. The media composition of the growth studies varied with what was actually being tested but all treatments were supplemented with YP. The growth rate and generation time were determined over a 24 hour period using absorbance as an estimate of dry weight [equations 1, P. stipitis, and 2, S. cerevisiae (ER), (Govindaswamv and Vane, 2006)]. All absorbance measurements were

taken using UV/VIS spectroscopy at 600nm (P. stipitis) and 660nm (S. cerevisiae) using 
a Thermo Genesys 20 spectrometer (Model 4001/4). Total biomass yield was determined by filtering a sample onto a pre-weighed $0.2 \mu \mathrm{m}$ filter ( $47 \mathrm{~mm}$ diameter), then drying the filter for 24 hours at $80^{\circ} \mathrm{C}$ in a drying oven. The filter was then reweighed and the total biomass $(\mathrm{g} / \mathrm{L})$ was determined.

Equation 1. Estimated dry weight (W, g/L) of Pichia stipitis CBS 6054

$\mathrm{W}=2.04+1.80 \mathrm{~A}_{600}$

Equation 2. Estimated dry weight (W, g/L) of Saccharomyces cerevisiae (Ethanol Red)

$\mathrm{W}=1.06+4.76 \mathrm{~A}_{660}$

\subsection{Fermentations}

All fermentations were carried out in $125 \mathrm{ml}$ Erlenmeyer flasks with a $50 \mathrm{ml}$ working volume. The media varied for each treatment depending on what was being tested. Each substrate that was to be fermented was supplemented with YP. An inoculum was grown for 18-24 hours in the same media as the fermentation media. Fermentations were carried out for 24 hours for S. cerevisiae (ER) and 72 hours for P. stipitis. These flasks were covered with aluminum foil and sealed with parafilm incubated on a gyratory shaker at $30^{\circ} \mathrm{C}$. Samples were taken aseptically by using a sterile pipette and removing $0.5 \mathrm{~mL}$ from the flask. 


\subsection{Organism Characterization for Lignocellulosic Substrate Utilization}

\section{Single Substrate Utilization}

The growth characteristics of $S$. cerevisiae (ER) were determined using concentrations of 20, 50, and $100 \mathrm{~g} / \mathrm{l}$ glucose in SDB. The sugar solutions were filter-sterilized and added to $30 \mathrm{ml}$ of SDB without a carbon/energy source (Brandberg et al., 2005). The broth was inoculated with $100 \mu$ l of yeast inoculum.

P. stipitis was tested for growth characteristics using YPX $(20 \mathrm{~g} / \mathrm{L})$ under the same conditions. In a study of xylose utilization and ethanol production by Pichia stipitis the yeast was grown in YPX for 72 hours. That culture was then used to inoculate two flasks containing $30 \mathrm{ml}$ of YPX. These flasks were incubated for $24 \mathrm{hrs}$.

Both strains were tested for their ability to produce biomass from each of the five sugars known to be present in aspen hydrolysate. These five sugars are xylose, glucose, galactose, mannose, and arabinose. $100 \mathrm{ml} \mathrm{YP}$ was supplemented with either20 g/l xylose, glucose, arabinose, galactose, or mannose in $250 \mathrm{ml}$ Erlenmeyer flasks. The flasks were inoculated with $1 \mathrm{ml}$ of either P. stipitis or S. cerevisiae (ER). They were sealed and incubated for 24 hours. The absorbance was taken at 24 hours to determine the maximum biomass production in that time period for the specific substrate. Growth was monitored over time. A study was performed to test whether or not this setup would result in ethanol production by $S$. cerevisiae (ER). Four flasks were filled with YPG. Three of the flasks were inoculated with culture and the fourth was used as the control. All were tightly sealed in an incubator for 24 hours. The samples were then analyzed 
using high performance liquid chromatography (HPLC) to determine the presence of ethanol and the disappearance of glucose. Replicates were not performed.

\section{Mixed Substrate Utilization}

S. cerevisiae (ER) was tested for its ability to produce ethanol from glucose: xylose mixtures. $30 \mathrm{ml}$ of YP was inoculated with $0.13 \mathrm{~g}$ of dried S. cerevisiae (ER). (0.13 g was the average dry weight of a $1 \mathrm{ml}$ aliquot from the inoculation media.) Each flask contained a different sugar mix concentration for a total of five treatments and one control: (\% glucose $/ \%$ xylose) and (YP - Sugar Free). Each treatment had a total sugar concentration of $4 \mathrm{~g} / \mathrm{L}$. The five treatments were: $100 \%$ glucose, $75 \%: 25 \%$ glucose: xylose, 50\%:50\% glucose: xylose, 25\%:75\% glucose: xylose, and 100\% xylose. Samples were taken at 6 hour intervals and analyzed using HPLC (in a later section) to test for ethanol production and sugar disappearance. Growth was monitored every two hours for a 48 hour period using the absorbance values at $660 \mathrm{~nm}$. The treatments and sampling methods were designed based on those of Agbogbo et al. (2006).

P. stipitis was grown in YPX and YPG (glucose $50 \mathrm{~g} / \mathrm{L}$ ) and grown overnight. These cultures were then used to inoculate YPX, YPG (glucose $50 \mathrm{~g} / \mathrm{L}$ ), YP-Hexose mix (glucose $25 \mathrm{~g} / \mathrm{L}$, galactose $12.5 \mathrm{~g} / \mathrm{L}$, and mannose $12.5 \mathrm{~g} / \mathrm{L}$ ), and YP-Pentose mix (xylose $25 \mathrm{~g} / \mathrm{L}$ and arabinose $25 \mathrm{~g} / \mathrm{L}$ ) for 24 hours. Cultures grown in YPX were used to inoculate YPX and the YP-Pentose mix and cultures grown in YPG were used to inoculate YPG and the YP-Hexose mix. These flasks were sealed with aluminum foil and parafilm and incubated for $72 \mathrm{hrs}$. All fermentations were carried out in either $125 \mathrm{ml}$ or $250 \mathrm{ml}$ Erlenmeyer Flasks with a $50 \mathrm{ml}$ and $100 \mathrm{ml}$ working volume, respectively. Each sugar 
solution was supplemented with YP broth. The flasks were then inoculated with $1 \mathrm{ml}$ of yeast suspended in YP broth. All media and supplements were filter-sterilized. Samples were taken every 24 hours until there was complete sugar disappearance or the ethanol concentration dropped. The samples were analyzed using HPLC and sugar and ethanol concentrations were determined. Replicates were not performed

\subsection{Lignocellulose Hydrolysate Studies}

Enzymatic Hydrolysate

The enzymatic hydrolysate was made according to previous literature (Jensen et al., 2009.)

Enzymatic Hydrolysate-Toxicity

The toxic effect of cycloheximide was tested at the concentration seen in the enzymatic hydrolysate (0.03g/L) (NREL LAP009). Flasks containing $50 \mathrm{ml}$ YPG [for S. cerevisiae (ER)] and YPX (for P. stipitis) were supplemented with $1.5 \mathrm{mg}$ of cycloheximide. The flasks were inoculated with $1 \mathrm{ml}$ of its respective yeast suspended in YP. Another set of flasks with YPG and YPX without cycloheximide were also inoculated and served as the control. All four flasks were sealed and incubated for a 16 hour period. The dry weight was estimated through absorbance values.

\section{Enzymatic Hydrolysate-Fermentation}

Both $P$. stipitis and S. cerevisiae (ER) were used to determine ethanol production from three types of enzymatic hydrolysate: aspen, balsam, and switchgrass. $250 \mathrm{~mL}$ Erlenmeyer flasks were filled with $25 \mathrm{~mL}$ of enzymatic hydrolysate and $75 \mathrm{~mL}$ of YP 
broth. The flasks were then inoculated with $1 \mathrm{~mL}$ of yeast suspended in YP broth. The flasks were sealed an incubated. Samples were taken every 24 hours for a period of 120 hours. The samples were analyzed using HPLC and ethanol and glucose concentrations were determined.

Synthetic Acid Hydrolysate

P. stipitis CBS 6054 ability to produce ethanol was evaluated on synthetic media containing five sugars (xylose, glucose, mannose, galactose, and arabinose) in a ratio reflective of that seen in dilute acid pretreated aspen, balsam, and switchgrass hydrolysate (Table 3). These data are the mean concentrations and were obtained from HPLC analysis of dilute acid-pretreated lignocellulosic material by Michigan Tech's Dept. of Chemical Engineering. The concentrations reflect the mean of nine pretreatements for each type of hydrolysate. The time at which the maximum xylose concentration was achieved was used to obtain the concentrations for the other sugars. This is representative of the ratio of sugars that would be observed if the pretreatment was optimized for obtaining maximum xylose monomers. The yeast was grown in YP broth supplemented with the sugars for 72 hours. Replicates were not performed

Table 3. Sugar concentrations $(\mathrm{g} / \mathrm{L})$ for synthetic dilute acid pretreated hydrolysate fermentations by Pichia stipitis CBS 6054. Taken from data obtained by Michigan Tech

\begin{tabular}{|c|c|c|c|c|c|}
\hline $\begin{array}{l}\text { Treatment } \\
\text { ID }\end{array}$ & Xylose & Glucose & Galactose & Mannose & Arabinose \\
\hline Aspen $^{a}$ & $18.5 \pm 1.0$ & $4 \pm 0.9$ & $1 \pm 0.1$ & $2.5 \pm 0.9$ & $1 \pm 0.8$ \\
\hline Balsam $^{a}$ & $6.5 \pm 0.4$ & $4.5 \pm 0.3$ & $3 \pm 0.2$ & $10 \pm 0.7$ & $3.5 \pm 0.6$ \\
\hline Switchgrass $^{a}$ & $22 \pm 0.9$ & $5 \pm 0.08$ & $3 \pm 0.06$ & $1 \pm 0.2$ & $3 \pm 0.1$ \\
\hline
\end{tabular}




\subsection{Toxicity Studies}

\section{Furfural Toxicity Assays for Saccharomyces cerevisiae (Ethanol Red)}

S. cerevisiae (ER) was grown aerobically in $\mathrm{SDB}$ at $30^{\circ} \mathrm{C}$ on a gyratory shaker for 24 hours. This culture served as the inoculum for the experiment. Each experiment was carried out in $250 \mathrm{ml}$ Nephelo flasks containing $30 \mathrm{ml}$ of SDB. Different concentrations of furfural were then added to each flask to achieve specific experimental conditions or treatments, as follows:

1. $0 \mathrm{~g} / \mathrm{L}$ furfural Control

2. $1 \mathrm{~g} / \mathrm{L}$ furfural

3. $2 \mathrm{~g} / \mathrm{L}$ furfural

4. $4 \mathrm{~g} / \mathrm{L}$ Furfural

The levels of furfural were chosen as a result of HPLC analysis performed by Michigan Tech's Dept. of Chemical Engineering. Replicates were not performed.

Furfural and Acetic Acid Toxicity Assays for Pichia stipitis CBS 6054

Initial toxicity studies were carried out in YPX media supplemented with a given concentration of either acetic acid or furfural. Acetic acid was tested at 2, 4, 6, 8, and 10 $\mathrm{g} / \mathrm{L}$ and furfural was tested at 1,2 , and $4 \mathrm{~g} / \mathrm{L}$. Toxicity assays were also performed in synthetic aspen hydrolysate media (Table 4) supplemented with furfural, acetic acid, or combinations of the two. The synthetic hydrolysate was made by combining $1 \mathrm{~L}$ of YP with the five sugars. The mixture was then filter-sterilized. The toxic effect of furfural and acetic acid were tested on the growth of $P$. stipitis. The toxicity studies were carried out in $125 \mathrm{~mL}$ Erlenmeyer flasks containing $50 \mathrm{~mL}$ of media. Dry weight was determined 
using absorbance. Furfural was tested at 2 and $4 \mathrm{~g} / \mathrm{l}$ and acetic acid at 8 and $10 \mathrm{~g} / \mathrm{L}$. Two combinations of the two compounds were also tested. There was a $2 \mathrm{~g} / \mathrm{L}$ furfural with 8 $\mathrm{g} / \mathrm{L}$ acetic acid in synthetic aspen hydrolysate treatment and a $4 \mathrm{~g} / \mathrm{L}$ furfural and $10 \mathrm{~g} / \mathrm{L}$ acetic acid treatment. To determine furfural's and acetic acid's effect on ethanol production and substrate utilization increased levels of inhibitory compounds were used: 1.5, 3, and $4.5 \mathrm{~g} / \mathrm{L}$ furfural and 4,8 , and $12 \mathrm{~g} / \mathrm{L}$ acetic acid. Combinations of the two were tested using 1.5:4, 3:8, and 4.5:12 $\mathrm{g} / \mathrm{L}$ of furfural and acetic acid respectively. These concentrations mimic what would be seen in a $1 \mathrm{X}, 2 \mathrm{X}$, and $3 \mathrm{X}$ aspen hydrolysate. Replicates were not performed

Table 4. Medium composition for synthetic hydrolysate.

\begin{tabular}{|l|l|}
\hline Compound & Concentration $(\mathbf{g} / \mathbf{L})$ \\
\hline Xylose & 18.5 \\
\hline Glucose & 4 \\
\hline Galactose & 1 \\
\hline Mannose & 2.5 \\
\hline Arabinose & 1 \\
\hline Yeast Extract & 10 \\
\hline Peptone & 20 \\
\hline
\end{tabular}

\section{Sugar Level Toxicity}

Synthetic concentrated dilute acid pretreated aspen media was made by taking the sugar ratio seen in the hydrolysate and making $1 \mathrm{X}, 2 \mathrm{X}$, and $3 \mathrm{X}$ sugar media. This was supplemented with YP. The cultures were incubated for 120 hours. Samples were taken 
every 24 hours to determine growth, substrate utilization, and ethanol production. Replicates were not performed

\subsection{Adaptation}

\section{Dilute Acid Pretreatment}

The conditions used for the dilute acid pretreated aspen used to produce the hydrolysate were reported by Jensen et al. (2008). The dilute acid pretreated aspen ( $5 \%$ solids) was neutralized with $\mathrm{KOH}(\mathrm{pH} 5.5 \pm 0.1)$ and filter-sterilized to remove the precipitate and particulates.

\section{Developing an Adapted Strain of Pichia stipitis CBS 6054}

The average dilute acid pretreated aspen hydrolysate composition was determined using HPLC. A synthetic aspen hydrolysate was supplemented with 10, 20, 30, 40, 50, 60, 65, $70,75 \%$, or $80 \%(\mathrm{v} / \mathrm{v})$ dilute acid pretreated aspen hydrolysate (Figure 9). The adaptation was carried out over a period of three weeks or until the cells could tolerate up to $80 \%$ of the hydrolysate (Amartey and Jefferies, 1994).

The original stock culture was grown in synthetic aspen media for 24 hours. The cells were then harvested and used to inoculate $2125 \mathrm{~mL}$ Erlenmeyer flasks. Each flask had $50 \mathrm{ml}$ of $10 \%$ adaptation medium (X\% of hydrolysate, YP, and synthetic aspen media). The cultures were incubated for 24 hours. Then, the contents of one of the flasks were transferred to two new flasks containing the next higher level of hydrolysate $(20 \%)$ and the process was repeated until an evolved population that could withstand growth at $80 \%$ 
hydrolysate was reached. The second flask went to storage after a sample for HPLC analysis had been removed.

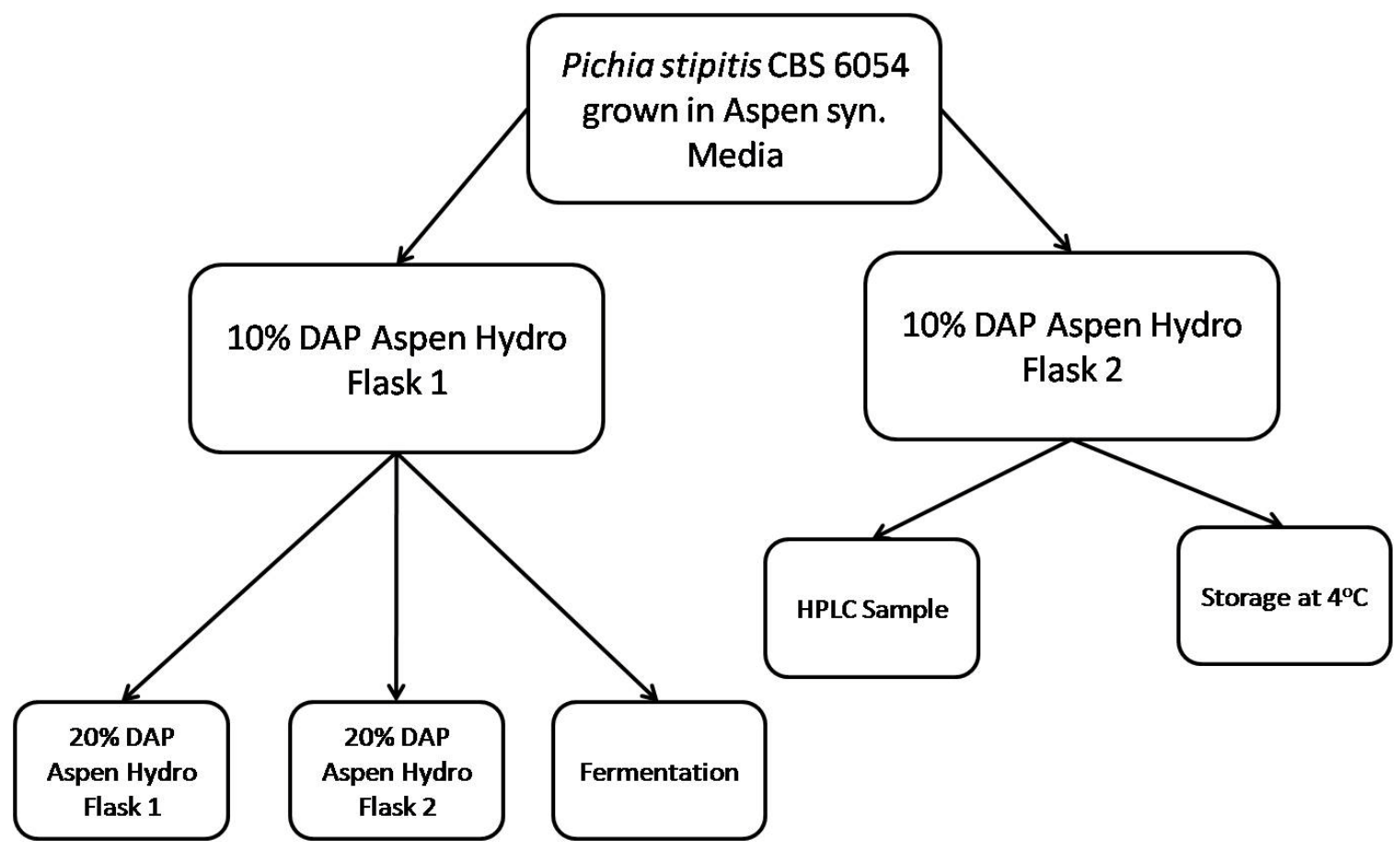

Figure 9. Sample flow chart diagramming the adaptation study of Pichia stipitis CBS6054 for greater ethanol production from aspen hydrolysate (DAP-Dilute Acid Pretreated, Syn.-synthetic aspen media, Hydro - hydrolysate).

\section{Fermentation Studies on Adapted Strain of Pichia stipitis CBS6054}

Fermentation studies were carried out using dilute acid pretreated aspen hydrolysate. The hydrolysate was supplemented with YP. Depending on the concentration of hydrolysate used it was also supplemented with xylose, glucose, galactose, arabinose, and mannose at the concentration in synthetic aspen media (Table 4). The unadapted strain was used in a series of fermentations (30 - 80\% hydrolysate media) to determine the baseline data for each adaptation level. The adapted cells were also evaluated at each level. In the case of the adapted strain the flasks were inoculated directly from one of the adaptation flasks. 
The inoculum for the unadapted strains came from culture grown overnight in their respective percentage of hydrolysate. The fermentations were allowed to run for 72 hours. Samples were taken at 0 and 72 hours and analyze on the HPLC. Each mutant was graded in the areas of growth, substrate utilization, and ethanol production/yield. The final adapted strain is maintained on yeast peptone xylose plates and in $80 \%$ aspen hydrolysate media.

\subsection{Media Optimization}

Three media were evaluated: YP, YNB, and CSL (Table 2) (Agbogbo and Coward-Kelly 2008). The media were supplemented with either $50 \mathrm{~g} / \mathrm{L}$ xylose as well as aspen synthetic media. For the treatments using aspen synthetic media the YP component was replaced with YNB or CSL. The fermentation was allowed to proceed for 72 hours.

\subsection{Analytical Methods}

High-performance liquid chromatography was used to determine ethanol, carbohydrate, and toxin levels in all samples following the methods described by Jensen et al. (2008). An Agilent 1200 Series HPLC with a Bio-Rad aminex HPX-87P column was used. Carbohydrates and ethanol was measured on a refractive-index detector (RID). The furfuraldehydes were measured on a diode array detector (DAD). 


\section{Chapter 3. Results and Discussion}

\subsection{Single Substrate Utilization by $P$. stipitis and $S$. cerevisiae (ER)}

\section{Glucose utilization by S. cerevisiae}

$S$. cerevisiae (ER) was tested at varying concentrations of glucose. The results of these aerobic $250 \mathrm{ml}$ Nephelo flask cultures show that glucose at these levels produces similar growth rates (Table 5), i.e., no apparent osmotic stress impacts. The typical growth rate for $S$. cerevisiae in glucose fermentations can range anywhere from $0.3-0.65 \mathrm{~h}^{-1}$ (Papagianni et al., 2007). Similar growth rates were found for $S$. cerevisiae at the $20 \mathrm{~g} / \mathrm{L}$ $\left(0.41 \mathrm{~h}^{-1}\right)$; the growth rates reported in this work for 50 and $100 \mathrm{~g} / \mathrm{L}$ are slightly higher than those reported in the literature (Papagianni et al., 2007). The lack in difference in growth rates reported in this work for the three concentrations shows that glucose does not have an inhibitory effect at these concentrations. This is expected because a typical glucose fermentation has a concentration above $100 \mathrm{~g} / \mathrm{L}$ (Lee et al., 1999).

Table 5. Growth rate of $S$. cerevisiae (ER) at varying glucose concentrations in YP media $\left(30^{0} \mathrm{C}, \mathrm{pH} 5.5\right.$ for 24 hours $)$

\begin{tabular}{|l|l|}
\hline Treatment (g/L) & k (hr-1) \\
\hline $\mathbf{2 0}$ & 0.41 \\
\hline $\mathbf{5 0}$ & 0.45 \\
\hline $\mathbf{1 0 0}$ & 0.42 \\
\hline
\end{tabular}

\section{Pichia stipitis Single Substrate Utilization}

A series of fermentations was setup to test substrate utilization patterns and subsequent ethanol production. Pichia stipitis CBS 6054 was evaluated for its ability to ferment 
xylose, glucose, glucose and xylose mixtures, hexose mixtures (glucose, galactose, and mannose), and pentose mixtures (arabinose and xylose). In single substrate xylose fermentations $(50 \mathrm{~g} / \mathrm{L}), 45.9 \%$ of sugar was utilized after 72 hours. Ethanol yields for xylose were $80 \%$ of theoretical and $84 \%$ of theoretical yields for glucose (Table 6). Biomass production was similar for both glucose and xylose. This is in agreement with studies showing higher ethanol yields from media containing glucose compared to ones containing xylose as the sole substrate (Agbogbo et al., 2006; du Preez et al., 1985).

A parallel study was conducted in baffled flasks to see if the added aeration had an effect on ethanol production. In the baffled flasks ethanol yields dropped to $0.32 \mathrm{~g} / \mathrm{g}$ and 0.27 $\mathrm{g} / \mathrm{g}$ in xylose and glucose, respectively. An increase in sugar consumption was observed in flasks containing xylose. There was no change in sugar consumption in the flask containing glucose. This observation is consistent with the literature. In the case of $P$. stipitis, oxygenation results in an increase in xylose uptake (Skoog and Hahn-Hagerdal, 1990). The sugar utilization in the xylose went to $99.7 \%$ with no change in utilization of glucose. Biomass increased in the baffled flasks for both glucose and xylose $(34 \mathrm{~g} / \mathrm{L}$ and $25 \mathrm{~g} / \mathrm{L}$, respectively). The baffled flasks thus have a negative effect on ethanol production for both substrate types and were not used for further fermentations. The flasks drastically decreased the ethanol yields. The decrease in ethanol production can be attributed to an increase in aeration (Agbogbo and Coward-Kelly, 2008). 
Table 6. Summary of single substrate fermentation data for xylose and glucose fermentations by Pichia stipitis CBS 6054 for 72 hours $\left(30^{\circ} \mathrm{C}, \mathrm{pH} 5.5\right) .^{\mathrm{a}}$

\begin{tabular}{|c|c|c|c|c|c|}
\hline Sugar & $\begin{array}{c}\text { Total } \\
\text { Sugars } \\
\text { (g/L) }\end{array}$ & $\begin{array}{c}\text { \% Sugar } \\
\text { Utilized }\end{array}$ & $\begin{array}{c}\text { Ethanol Conc. } \\
\text { (g/L) }\end{array}$ & $\begin{array}{c}\text { Ethanol Yield } \\
\text { g_EtOH/g_sugar }\end{array}$ & $\begin{array}{c}\text { Dry } \\
\text { Weight } \\
\text { (g/L) }\end{array}$ \\
\hline Xylose & $49.0 \pm 0.12$ & 45.7 & $9.25 \pm 1.5$ & $0.41 \pm 0.01$ & $13.5 \pm 0.01$ \\
\hline Glucose & $53.8 \pm 0.01$ & 100 & $22.9 \pm 0.5$ & $0.43 \pm 0.01$ & $12.2 \pm 0.01$ \\
\hline
\end{tabular}

${ }^{\mathrm{a}}$ Mean values $(\mathrm{n}=2, \pm 2 \mathrm{SD})$

Biomass Concentration from Five Sugars for P. stipitis and S. cerevisiae (ER)

S. cerevisiae (ER) and P. stipitis were used to determine the maximum biomass that each strain could produce on the five sugars found in hemicellulose (xylose, glucose, arabinose, galactose, and mannose). S. cerevisiae (ER) yielded the highest biomass on the hexose sugars (Table 7). There was no net growth on either pentose sugar; $S$. cerevisiae is not able to utilize pentose sugars (Jeppsson et al., 1996). The growth that is observed in those treatments can be attributed to the fact that YP supports very low-level growth of S. cerevisiae in the absence of an additional carbon source (Hahn-Hagerdal et al., 2005). In a separate study, $S$. cerevisiae was grown just in xylose and then just in YP without a carbon source (Figure 10). There is similar biomass production for the two treatments, i.e., $3.09 \mathrm{~g} / \mathrm{L}$ and $3.01 \mathrm{~g} / \mathrm{L}$, respectively. The higher biomass yields between the two studies are due to a difference between a $2 \%$ inoculum and $10 \%$ inoculum. It is important to note that YP and xylose produce similar biomass concentrations. Pichia produced the most biomass on glucose and mannose and the other three sugars yield similar results 
(Table 7). This is in agreement with other studies that show glucose yields a greater biomass then other substrates (Agbogbo et al., 2006). Background growth on YP media was performed for P. stipitis. When tested just on YP without a carbon source P. stipitis produced no net increase in biomass over a 24 hour period (Appendix B).

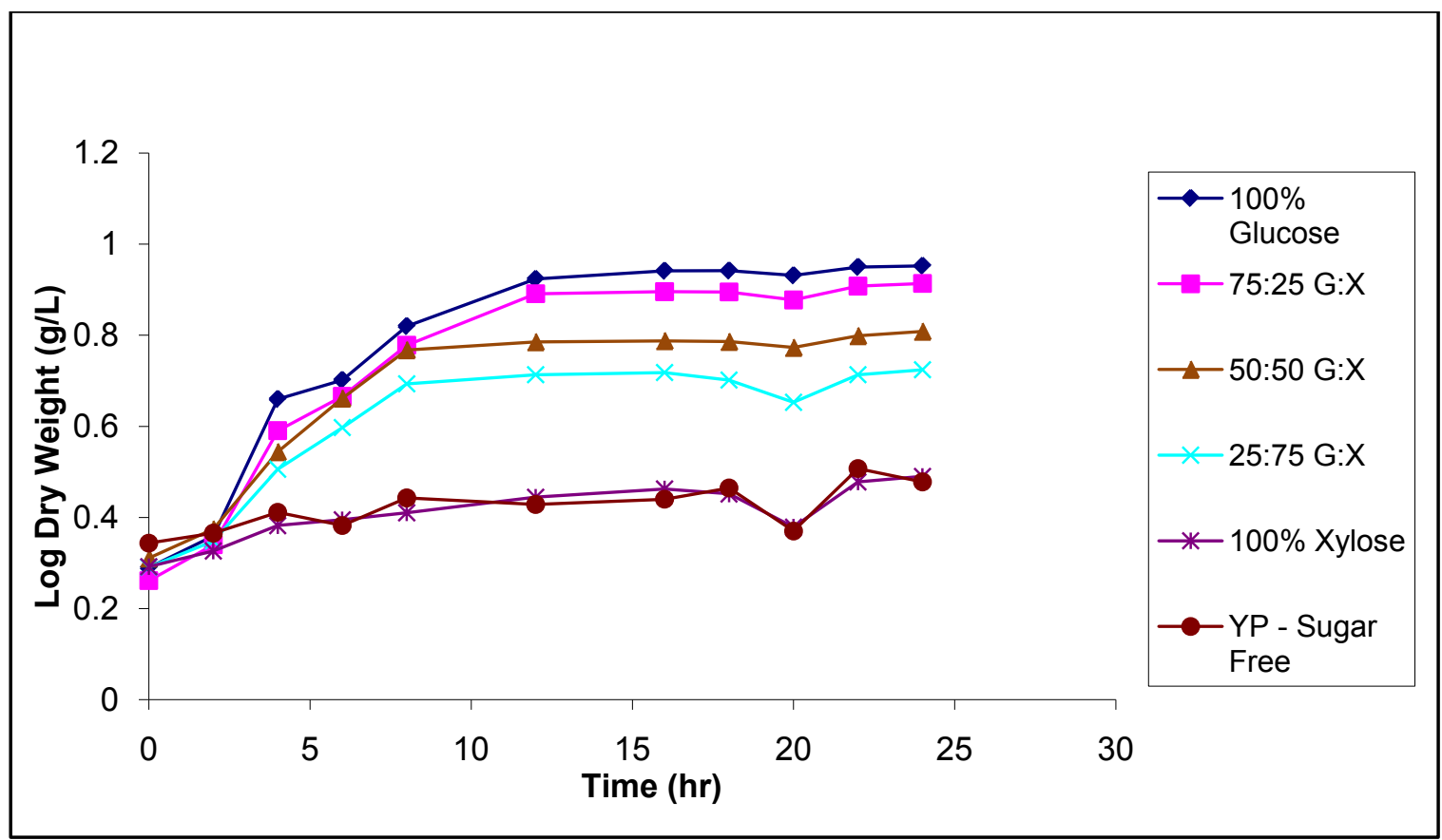

Figure 10. The effect of glucose/xylose concentrations $(5 \mathrm{~g} / \mathrm{L})(\mathrm{w} / \mathrm{v})$ on $S$. cerevisiae (ER) growth. ER was grown in YP with the varying levels of glucose/xylose mixtures $\left(35^{\circ} \mathrm{C}\right.$ for 24 hours, $\left.\mathrm{pH} 5.5\right)$. 
Table 7. The maximum biomass produced by $S$. cerevisiae (ER) (1) and Pichia stipitis (2) on glucose, xylose, galactose, mannose, and arabinose in YP media at $30^{\circ} \mathrm{C}, \mathrm{pH} 5.5$.

\begin{tabular}{|c|c|c|c|}
\hline Sample ID & $\begin{array}{c}\text { Biomass at T=0 } \\
(\mathbf{g} / \mathbf{L})\end{array}$ & $\begin{array}{c}\text { Biomass at T=24 } \\
(\mathbf{g} / \mathbf{L})\end{array}$ & \% Increase \\
\hline Glucose 1 & 2.08 & 8.85 & 325 \\
\hline Xylose 1 & 2.90 & 4.18 & 64.1 \\
\hline Arabinose 1 & 2.78 & 4.46 & 185 \\
\hline Galactose 1 & 3.24 & 9.24 & 178 \\
\hline Mannose 1 & 3.24 & 9.01 & 279 \\
\hline Glucose 2 & 1.96 & 9.43 & 167 \\
\hline Xylose 2 & 2.15 & 8.13 & 187 \\
\hline Arabinose 2 & 3.39 & 9.04 & 287 \\
\hline Galactose 2 & 2.67 & 7.66 & \\
\hline Mannose 2 & 2.29 & 8.86 & \\
\hline
\end{tabular}

\subsection{Mixed Substrate Utilization and Fermentations}

Saccharomyces cerevisiae (ER) fermentation and biomass production on glucose and xylose mixtures

S. cerevisiae (ER) was used to determine the effect of pentose/hexose mixed substrate fermentations on ethanol production and growth. The fermentation setup was first tested to see if ethanol could be produced. Results of that investigation can be seen in Appendix A, section 1 . The treatments were set up to be $100 \%$ glucose, $75: 25 \%$ glucose to xylose, $50: 50 \%$ glucose to xylose, $25: 75 \%$ glucose to xylose, and $100 \%$ xylose. The HPLC data showed that the mixtures were $100 \%, 85 \%, 38 \%, 27 \%$, and $0 \%$ glucose with xylose 
making up the other faction. This is either due to a sampling error or an error in the HPLC standards. The presence of xylose resulted in a reduction in biomass production (Figure 10) and reduced growth rates (Table 8). As noted earlier, this is not actually due to xylose utilization but rather background growth on YP or growth on residual materials and utilization of the glucose in the mixtures (Hahn-Hagerdal et al., 2005). The different growth rates observed can only be attributed to the presence of glucose in the media. $S$. cerevisiae biomass production was directly proportional to the amount of glucose in the media (Figure 10). The results of the HPLC analysis showed ethanol production only in treatments containing glucose. The results of the HPLC analysis also yielded glucose concentrations lower then what should have been in the treatments. This could be due to an HPLC sample preparation error. A shift in the retention time of glucose was also observed. The xylose levels remained, for the most part, constant throughout the experiment. This was the expected result because $S$. cerevisiae cannot metabolize xylose. The results, in terms of biomass of the $100 \%$ xylose and the YP-sugar free treatment, are relatively similar. It has been established that $S$. cerevisiae does not utilize xylose and it can grow on YP without a carbon source (Jeppsson et al., 1996; Hahn-Hagerdal et al., 2005). From this it can be inferred whatever growth is observed is due to background growth on YP. The mean biomass produced in 24 hours from YP media was determined to be $0.97 \mathrm{~g} / \mathrm{L} \pm 0.24$. Results of this fermentation can be found in Appendix A.

\section{Mixed Substrate Fermentations by Pichia stipitis}

In a glucose: xylose mixed substrate fermentation by $P$. stipitis, glucose was completely used in the first 24 hours while $53.2 \%$ of the xylose was consumed within this same time 
period. The xylose was completely gone within 48 hours. The total ethanol yield was $0.17 \mathrm{~g} / \mathrm{g} \_$sugar (Table 8 ). The yield was $34 \%$ of theoretical yield. This is an extremely low level according to the literature. Agbogbo et al., (2006) reports an ethanol yield of $0.44 \mathrm{~g} / \mathrm{g}$ on a $50: 50 \mathrm{mix}$ of glucose on xylose at 72 hours. In this work the fermentation was stopped at 48 hours. If it was allowed to precede to 72 hours higher ethanol levels might be observed. In the case of $P$. stipitis, xylose is consumed only after glucose is completely utilized (Agbogbo et al., 2008). Xylose consumption was reduced in the presence of glucose, which is due to the fact that glucose inhibits xylose uptake (Kilian and Uden 1988).

Table 8. The growth rate (k) of S. cerevisiae (ER) during mixed substrate fermentations. (ER was grown in YP with the varying levels of glucose/xylose mixtures at $35^{\circ} \mathrm{C}$ for 24 hours, $\mathrm{pH}$ 5.5.)

\begin{tabular}{|l|l|}
\hline Treatment & $\mathbf{k}\left(\mathbf{h r}^{-1}\right)$ \\
\hline $\mathbf{1 0 0} \%$ Glucose & 0.24 \\
\hline $\mathbf{7 5 : 2 5}$ G:X & 0.23 \\
\hline $\mathbf{5 0 : 5 0 ~ G : X}$ & 0.22 \\
\hline $\mathbf{2 5 : 7 5}$ G:X & 0.19 \\
\hline $\mathbf{1 0 0} \%$ Xylose & 0.04 \\
\hline YP - Sugar Free & 0.03 \\
\hline
\end{tabular}


It is well established in the literature that glucose consumption proceeds xylose consumption so the experiment was not designed to observe the order of sugar utilization (Agbogbo et al., 2008). If the study where to be repeated the order of sugar utilization would be taken in account. If glucose composes more then $40 \%$ of the media it has an inhibitory effect on other substrate utilizations (Lawford and Rousseau, 1994). Based on this information it can be assumed that mannose and galactose were not utilized until after the glucose was. If the rate of glucose consumption can be increased, the length of the fermentation will decrease.

Agbogbo et al. (2006) reported that, in 50:50 mixtures of glucose and xylose, the sugar consumption rate is $0.54 \mathrm{~g} / \mathrm{L} \mathrm{h}$ and $0.37 \mathrm{~g} / \mathrm{L} \mathrm{h}$, respectively. Applying those rates to this work's initial sugar concentration in the same mixture implies that the sugars should not be completely consumed at the 24-hour mark. From this it can be inferred that, if calculated, the rate of glucose and xylose consumption would be faster than those reported in the literature.

The pentose mixture had the lowest of ethanol yield $(0.14 \mathrm{~g} / \mathrm{g})$ of all the mixed substrate fermentations (Table 8). This can be attributed to the fact that Pichia does not ferment arabinose to ethanol (Agobogbo and Coward-Kelly, 2008). The hexose mixture had the highest ethanol yield $(0.21 \mathrm{~g} / \mathrm{g})$ (Table 9). Galactose and mannose are isomers of glucose and are fermented by the Leloir and the EM glycolytic pathways, respectively (Figure 6) (VanMaris et al., 2006). The ethanol concentration showed that same pattern that the $\mathrm{g} / \mathrm{g}$ yield did (Table 9). In terms of biomass production the hexose mix produced the most, $26.5 \mathrm{~g} / \mathrm{L}$, followed by glucose xylose mix, $20 \mathrm{~g} / \mathrm{L}$, and then the pentose mix $17.8 \mathrm{~g} / \mathrm{L}$. Graphical results for each mixture can be found in Appendix B Section 1. 
Table 9. Ethanol production by $P$. stipitis CBS 6054 from glucose:xylose, pentose (arabinose and xylose), and hexose (galactose, glucose, and mannose) sugar mixtures in a 48 hour period.

\begin{tabular}{|c|c|c|c|}
\hline Sugar Mixture & Total Sugars & $\begin{array}{c}\text { Ethanol Conc. } \\
(\mathrm{g} / \mathrm{L})\end{array}$ & $\begin{array}{c}\text { Ethanol Yield } \\
\text { (g/g_sugar) }\end{array}$ \\
\hline Glucose:Xylose $\mathrm{e}^{\mathrm{a}}$ & 102.6 & 17.5 & 0.17 \\
\hline Pentose $^{b}$ & 55.76 & 7.86 & 0.14 \\
\hline Hexose $^{c}$ & 54.64 & 11.6 & 0.21 \\
\hline
\end{tabular}

${ }^{\mathrm{a}} 50: 50$ mixture

${ }^{\mathrm{b}} 75: 25$ arabinose to xylose

' 50:25:25 glucose to galactose to mannose

\subsection{Enzymatic Hydrolysate Fermentations}

Enzymatic Hydrolysate- Cycloheximide Toxicity for P. stipitis and S. cerevisiae (ER)

The main component of the liquor is glucose. As a result, S. cerevisiae (ER) and P. stipitis were used in these investigations. There are two antibiotics added during the hydrolysis, tetracycline and cycloheximide. Cycloheximide, which inhibits ribosomal function in eukaryotes, has the potential to negatively impact growth and subsequent ethanol production by the yeast cultures (de Kleot, 1966). The toxic effect of cycloheximide was first tested at the concentration seen in the enzymatic hydrolysate (0.03g/L) (NREL LAP009, 2008). P. stipitis and S. cerevisiae (ER) were tested to 
determine if cycloheximide had an inhibitory effect on growth in either organism. The results show that the compound, at this level, did not have a effect on growth (Table 10). After 48 hours, an unidentified pink yeast was found to have contaminated the enzymatic hydrolysate. This yeast was able to utilize both xylose and glucose but did not produce ethanol in subsequent tests. Some pink yeasts are known for their ethanol utilization (Belloch et al., 2007) properties. The decrease in ethanol concentration after 48 hours could possibly be a result of this contamination. As a result the enzymatic pretreatment was filter-sterilized right after hydrolysis.

Table 10. Biomass of $P$. stipitis (PS) and S. cerevisiae (ER) produced in 16 hours in media, (YPX or YPG) containing $0.03 \mathrm{~g} / \mathrm{L}$ cycloheximide

\begin{tabular}{|c|c|c|c|}
\hline Treatment & $\begin{array}{c}\text { Biomass (g/L) at } \\
\mathbf{T}=\mathbf{0}\end{array}$ & $\begin{array}{c}\text { Biomass }(\mathbf{g} / \mathbf{L}) \text { at } \\
\mathbf{T}=\mathbf{1 6}\end{array}$ & $\begin{array}{c}\text { \% Biomass } \\
\text { increase }\end{array}$ \\
\hline PS YPX & 3.2 & 8.9 & $183 \%$ \\
\hline PS YPX -Cycloheximide & 3.5 & 8.6 & $146 \%$ \\
\hline SC YPG & 2.7 & 6.6 & $145 \%$ \\
\hline SC YPG-Cycloheximide & 2.7 & 7.4 & $171 \%$ \\
\hline
\end{tabular}

Enzymatic Hydrolysate-Fermentation

A mixture of $25 \%$ YP to $75 \%$ hydrolysate was chosen as the medium, because it provided the highest glucose concentration with the optimal supplement level. Both organisms, P. stipitis and S. cerevisiae, were tested for their ability to produce ethanol on this mixture. P. stipitis did not produce any ethanol over a 120 hour period. This could be 
due to the minimal sugar levels available. $P$. stipitis produces ethanol optimally at sugar levels above $50 \mathrm{~g} / \mathrm{L}$ (Agbogbo and Coward-Kelly, 2008). The enzymatic hydrolysate had between $0.25-2.14 \mathrm{~g} / \mathrm{L}$ of glucose, depending on the source (Table 11). This is low compared to reported values (Jensen et al., 2009). The low level is most likely due to a contaminant, a pink-pigmented yeast, that was found in the enzymatic hydrolysate. $S$. cerevisiae (ER) produced ethanol in the greatest quantity between 24-48 hours (Figure 11). It also produced the most ethanol from switchgrass enzymatic hydrolysate and the least from balsam. All treatments show the presence of ethanol at $\mathrm{T}=0$. It is unknown why this may have occurred. As a result, the data were corrected to determine the ethanol yield (Table 11). The yields were higher than theoretical yields for glucose fermentations $(0.51 \mathrm{~g} / \mathrm{g})(>100 \%)$. This could be to an analytical error or a sampling error. Another possibility is that the glucose levels were in fact higher then what was calculated from the HPLC data. When the samples were initially run on the HPLC, right after the hydrolysis was complete, the concentration of glucose was $3.97 \mathrm{~g} / \mathrm{L}$ (aspen), $0.40 \mathrm{~g} / \mathrm{L}$ (balsam), and $2.39 \mathrm{~g} / \mathrm{L}$ (switchgrass). Using those values as the initial sugar concentration rather than the calculated values the ethanol yields were $57 \%$ and $73 \%$ of the theoretical yield for aspen and switchgrass respectively. Despite the low sugar levels and contamination, this study demonstrates that enzymatic hydrolysate can be converted to ethanol by $S$. cerevisiae. Further steps to optimize this process were not performed due to the low sugar levels seen in the hydrolysate. Results for substrate utilization and ethanol production can be found in Appendix B section 2.

Table 11. Glucose levels in enzymatic pretreated cellulose from aspen, balsam, and switchgrass and ethanol yield by $S$. cerevisiae (ER) for 24 hours $\left(30^{\circ} \mathrm{C}, \mathrm{pH} 5.5\right)$. 


\begin{tabular}{|l|l|l|}
\hline Cellulose Source & Glucose (g/L) & Ethanol Yields (g/g) \\
\hline Aspen & 2.14 & 0.64 \\
\hline Balsam & .25 & 0 \\
\hline Switchgrass & 1.87 & $0.97^{*}$ \\
\hline
\end{tabular}

*48 hour value

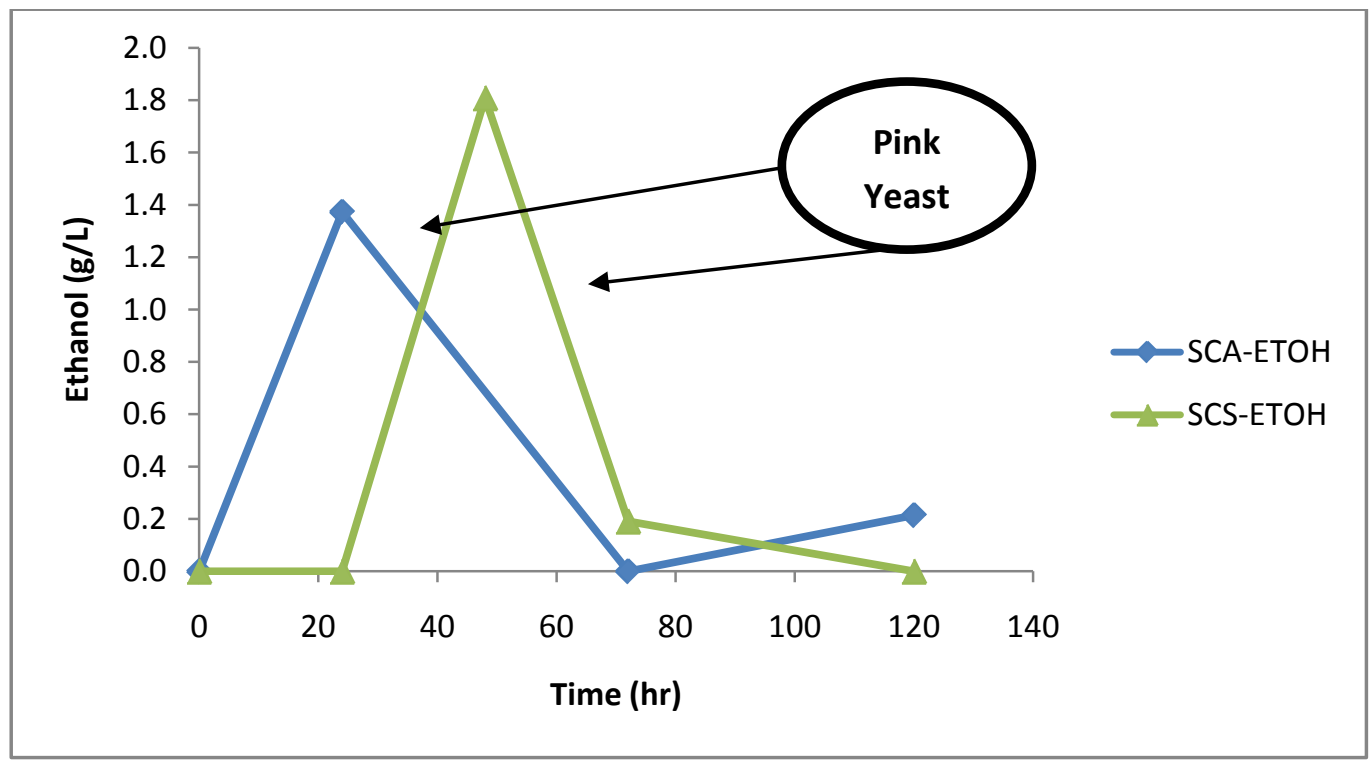

Figure 11. Ethanol yield from enzymatic pretreated hydrolysate (Aspen -SCA, Balsam SCB, and Switchgrass- SCS) fermented by S. cerevisiae (ER) over 120 hours $\left(30^{\circ} \mathrm{C}, \mathrm{pH}\right.$ $5.5)$.

Fermentation of Synthetic Dilute Acid Pretreated Hydrolysate by Pichia stipitis

P. stipitis was used to test whether or not it could produce ethanol from a synthetic media containing a mixture of sugars at the concentrations seen in the aspen, balsam, and switchgrass dilute acid pretreated hydrolysates. After HPLC analysis it was concluded that Pichia could in fact produce ethanol from the mixture of sugars found in all three synthetic hydrolysates types (Table 12). In all three hydrolysate types, the hexose sugars were completely utilized in the 72 hour period (Appendix B). Arabinose was not utilized 
in any of the treatments. Xylose was utilized in all three hydrolysate types, but only the balsam showed its complete disappearance within 72 hours. Although, synthetic media were used, the sugar concentrations mimicked those seen in the real dilute acid pretreated hemicellulose. Any differences in sugar consumption related directly to the concentration (Table 12). Dilute acid pretreated balsam only has $6.5 \mathrm{~g} / \mathrm{L}$ xylose compared to aspen and switchgrass which have 18.5 and $22 \mathrm{~g} / \mathrm{L}$, respectively. This study was performed as a screening measure for the adaptation study to determine if $P$. stipitis would grow and produce ethanol from the sugars present in the hydrolysate. These initial results matched that of the literature for synthetic hydrolysate media and therefore were not repeated (Nigam, 2001).

Table 12. Ethanol yield by Pichia stipitis on synthetic non-toxic hydrolysate after $72 \mathrm{hrs}$. of growth $\left(30^{\circ} \mathrm{C}, \mathrm{pH} 5.5\right)$.

\begin{tabular}{|c|c|c|c|c|}
\hline $\begin{array}{c}\text { Hydrolysate } \\
\text { Type }\end{array}$ & Total Sugars & $\begin{array}{c}\text { \% Sugars } \\
\text { Utilized }\end{array}$ & $\begin{array}{c}\text { Ethanol Conc. } \\
\text { (g/L) }\end{array}$ & $\begin{array}{c}\text { Ethanol Yield } \\
\text { (g/g_substrate) }\end{array}$ \\
\hline Aspen & 27 & 83.9 & 8.25 & 0.38 \\
\hline Balsam & 27.5 & 92.1 & 8.79 & 0.36 \\
\hline Switchgrass & 34 & 70.1 & 8.52 & 0.37 \\
\hline
\end{tabular}

\subsection{Toxicity}

Furfural Toxicity-Saccharomyces cerevisiae (ER) 
Several growth experiments were performed to determine if furfural had any inhibitory effects on the growth of S. cerevisiae (ER). It has been determined that different strains of $S$. cerevisiae have different tolerance levels to furfurals (Martin et al., 2003). The concentrations of furfural used in this experiment were determined by what is typically seen in a wood hydrolysate, (1.0-4.0 g/L) (Jensen et al., 2008). Concentrations of furfural at 1 and $2 \mathrm{~g} / \mathrm{L}$ resulted in an increase in lag phase. Eventually those cultures reached the similar concentrations of biomass as the control (Figure 16). This result was expected because furfural causes an increase in the duration of lag phase in batch growth (Liu et al., 2004). Delgenes et al. (1996) reported a $90 \%$ reduction in biomass production compared to the control on $2 \mathrm{~g} / \mathrm{L}$ furfural for S. cerevisiae. That drastic of an inhibition was not observed in this work, but it was not stated at which time the growths were compared in that study. However, both Delgenes et al. (1996) and this work contradict the finding of Taherzadeh et al. (1999), who found that increases in the lag phase of batch growth occur at concentrations above $2 \mathrm{~g} / \mathrm{L}$. The $4 \mathrm{~g} / \mathrm{l}$ concentration of furfural did have a negative impact on culture growth. No growth was observed during the normal time period ( $2-8$ hours). This culture was left in the incubator for $24 \mathrm{hrs,} \mathrm{after} \mathrm{which} \mathrm{time}$ similar biomass concentrations were seen as in the control and the other furfural concentrations. Although furfural has been shown to be inhibitory to biomass production by $S$. cerevisiae, this inhibition can be over come through adaption to increased concentrations of furfural (Banerjee et al., 1981). It is also able to reduce furfural to a less toxic furfuryl alcohol (Almeida et al., 2008). These characteristics are especially important for S. cerevisiae when used in dilute acid pretreated fermentations. 


\section{Pichia stipitis Toxicity Assays}

Three separate studies evaluating the effect of furfural, acetic acid, and combinations of the two on the biomass production of $P$. stipitis were conducted. The first study evaluated the effect of furfural and acetic acid in YPX media. The second evaluated furfural, acetic acid, and combinations of the two in synthetic dilute acid pretreated hydrolysate. The third was done in concentrated synthetic dilute acid pretreated aspen hydrolysate (1X, 2X, and $3 \mathrm{X}$ ) with comparable levels of furfural and acetic acid.

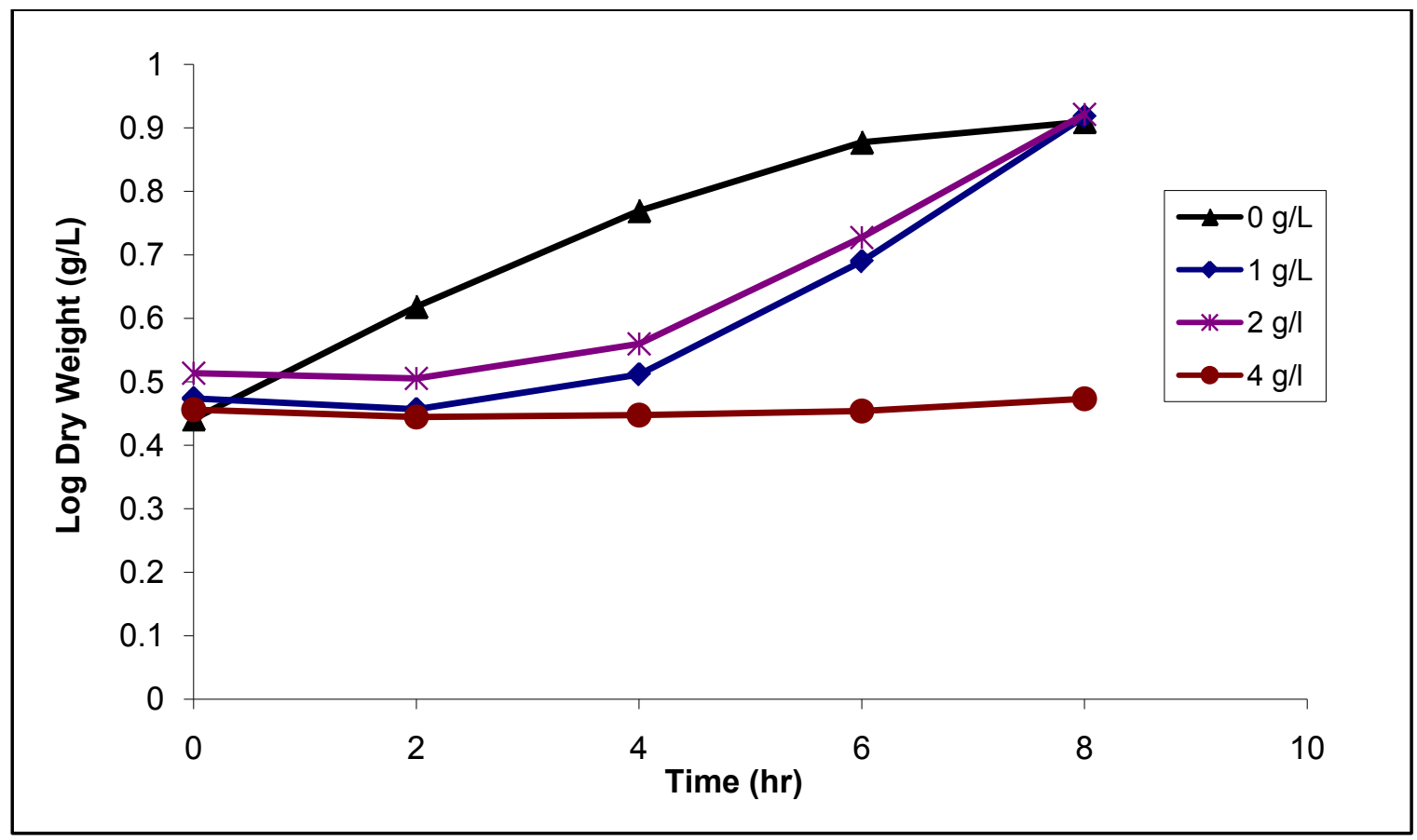

Figure 12. The effects of furfural concentrations on $S$. cerevisiae (ER) ( biomass production in YPG media for 24 hours $\left(30^{\circ} \mathrm{C}, \mathrm{pH} 5.5\right)$.

Pichia stipitis Furfural and Acetic Acid Toxicity Assays in YPX 
In YPX (20 g/L) media, furfural was not inhibitory at $1 \mathrm{~g} / \mathrm{L}$ but at $2 \mathrm{~g} / \mathrm{L}$ and $4 \mathrm{~g} / \mathrm{L}$ showed substantial growth inhibition, as seen by a decrease in the biomass production (Table 14). Under aerobic conditions furfural is inhibitory to $P$. stipitis above $2 \mathrm{~g} / \mathrm{L}$ (Palmqvist and Hahn-Hagerdal, 2000). Previous studies have shown that furfural concentration of 0.5 and $2 \mathrm{~g} / \mathrm{L}$ cause a $25 \%$ and $99 \%$ decrease in growth, respectively (Delgenes et al., 1996). Ethanol production, at the same concentrations, is reduced 29\% and 95\% (Delgenes et al., 1996). Similar results were achieved in this study (Table 13). At $1 \mathrm{~g} / \mathrm{L}$, furfural causes a $43.6 \%$ reduction in biomass production and $2 \mathrm{~g} / \mathrm{L}$ furfural resulted in a $98.2 \%$ reduction in biomass.

Acetic acid was inhibitory at concentrations above $2 \mathrm{~g} / \mathrm{L}$ (Table 14). Van zyl et al., (1991) reported a $17 \%$ reduction in the growth rate at $2.1 \mathrm{~g} / \mathrm{L}$. In this work a $18.75 \%$ reduction in the growth rate at $2.0 \mathrm{~g} / \mathrm{L}$ was observed. Previous work has shown that at a concentrations of $5 \mathrm{~g} / \mathrm{L}$ a $37 \%$ reduction in growth and at $10 \mathrm{~g} / \mathrm{L}$ a $36 \%$ reduction in growth compared to the control is observed (Delgenes et al., 1996). At these same concentrations there is a $70 \%$ and $75 \%$ reduction in ethanol production (Delgenes et al., 1996). These results could not be confirmed through this study. At $10 \mathrm{~g} / 1$ a $98 \%$ decrease in biomass was observed. Acetic acid inhibits cell growth by decreasing the internal $\mathrm{pH}$ of the cell (Palmqvist and Hahn-Hagerdal, 2000). Neutralization of the media to $\mathrm{pH}$ of 6.5 tends to negate the toxic effect of acetic acid. However, xylose is converted to ethanol optimally by $P$. stipitis by a pH between 4-5.5 (Van Zyl et al., 1991).

Any compound that results in a decrease in biomass production or a declined growth rate affects the production of ethanol. Ethanol is a primary metabolite that is made only 
during exponential growth phase in batch growth. Overall furfural and acetic acid have negative impacts on biomass production. Both compounds, however, have been used to improve ethanol yields at concentrations below the inhibitory levels (Klinke et al., 2004). Like S. cerevisiae (ER), the inhibitory effect of these compounds on growth and ethanol production by $P$. stipitis can be over come through adaptation (Nigam 2001). Growth rates for this investigation can be found in Appendix C.

Table 13. Biomass production $(\mathrm{g} / \mathrm{L})$ by Pichia stipitis with different concentrations of furfural in YPX medium after 24 hours $\left(30^{\circ} \mathrm{C}, \mathrm{pH} 5.5\right)$.

\begin{tabular}{|c|c|c|c|c|c|}
\hline Furfural (g/L) & $\begin{array}{c}\text { Initial } \\
\text { Biomass } \\
(\mathbf{g} / \mathbf{L})\end{array}$ & $\begin{array}{c}\text { Final } \\
\text { Biomass } \\
(\mathbf{g} / \mathbf{L})\end{array}$ & $\begin{array}{c}\text { Total } \\
\text { Biomass } \\
(\mathbf{g} / \mathbf{L})\end{array}$ & $\begin{array}{c}\text { \% } \\
\text { Biomass } \\
\text { Increase }\end{array}$ & $\begin{array}{c}\text { \% of } \\
\text { Control }\end{array}$ \\
\hline $\mathbf{0}$ & 2.1 & 5.2 & 3.1 & $148.2 \%$ & \\
\hline $\mathbf{1}$ & 2.1 & 4.2 & 2.1 & $98.9 \%$ & $66.4 \%$ \\
\hline $\mathbf{2}$ & 2.1 & 2.2 & 0.1 & $2.7 \%$ & $1.8 \%$ \\
\hline $\mathbf{4}$ & 2.1 & 2.2 & 0.1 & $3.6 \%$ & $2.4 \%$ \\
\hline
\end{tabular}

Table 14. Biomass production $(\mathrm{g} / \mathrm{L})$ by Pichia stipitis with different concentrations of acetic acid in YPX medium after 24 hours $\left(30^{\circ} \mathrm{C}, \mathrm{pH} 5.5\right)$.

\begin{tabular}{|c|c|c|c|c|c|}
\hline $\begin{array}{c}\text { Acetic Acid } \\
(\mathrm{g} / \mathrm{L})\end{array}$ & $\begin{array}{c}\text { Initial } \\
\text { Biomass }\end{array}$ & $\begin{array}{c}\text { Final } \\
\text { Biomass }\end{array}$ & $\begin{array}{c}\text { Total } \\
\text { Biomass }\end{array}$ & $\begin{array}{c}\text { \% Biomass } \\
\text { Increase }\end{array}$ & $\begin{array}{c}\% \text { of } \\
\text { Control }\end{array}$ \\
\hline
\end{tabular}




\begin{tabular}{|c|c|c|c|c|c|}
\hline & $\mathbf{( g / L )}$ & $\mathbf{( g / L )}$ & $\mathbf{( g / L )}$ & & \\
\hline $\mathbf{0}$ & 2.2 & 4.6 & 2.4 & $106.8 \%$ & \\
\hline $\mathbf{2}$ & 2.1 & 2.9 & 0.77 & $35.9 \%$ & $32.3 \%$ \\
\hline $\mathbf{4}$ & 2.2 & 2.1 & 0 & $0 \%$ & $0 \%$ \\
\hline $\mathbf{6}$ & 2.2 & 2.1 & 0 & $0 \%$ & $0 \%$ \\
\hline $\mathbf{8}$ & 2.1 & 2.1 & 0.08 & $3.9 \%$ & $3.4 \%$ \\
\hline $\mathbf{1 0}$ & 2.1 & 2.2 & 0.05 & $2.2 \%$ & $2.0 \%$ \\
\hline
\end{tabular}

Pichia stipitis Furfural and Acetic Acid Toxicity Assays in Synthetic Aspen Media

The inhibitory effects of furfural and acetic acid were tested on P. stipitis in synthetic aspen hydrolysate media (Table 15). This study was performed to show that, at the levels typically seen in dilute acid pretreated hydrolysate, there is inhibitory effect caused by furfural and acetic acid. This study was not performed to determine at which levels the compound was inhibitory or the degree of inhibition. This study was used as the justification for performing the adaptation study because it showed that the compounds found in the hydrolysate at these levels are inhibitory and need to be dealt with. No net growth was observed in these treatments over an 18-hr period compared to the control (Table 16). Results for the individual toxins in synthetic aspen hydrolysate media (furfural 2 and $4 \mathrm{~g} / \mathrm{L}$ and acetic acid 8 and $10 \mathrm{~g} / \mathrm{L}$ ) were similar to those generated from the same concentrations in media containing just xylose. The synergistic effect of the toxins could not be determined from these data because without replicates any growth 
can be attributed to a number of factors. Graphical representation of this data and growth rates can be found in Appendix C.

Table 15. Biomass production $(\mathrm{g} / \mathrm{L})$ by Pichia stipitis with different concentrations of furfural(ff), acetic acid(aa), and combinations of the two in synthetic aspen media.

\begin{tabular}{|l|l|l|l|l|l|}
\hline $\begin{array}{l}\text { Treatment } \\
(\mathbf{g} / \mathbf{L})\end{array}$ & $\begin{array}{l}\text { Initial } \\
\text { Biomass } \\
(\mathbf{g} / \mathbf{L})\end{array}$ & $\begin{array}{l}\text { Final } \\
\text { Biomass } \\
(\mathbf{g} / \mathbf{L})\end{array}$ & $\begin{array}{l}\text { Total } \\
\text { Biomass } \\
\mathbf{( g / L )}\end{array}$ & $\begin{array}{l}\text { \% Biomass } \\
\text { Increase }\end{array}$ & $\begin{array}{l}\text { \% } \\
\text { Control }\end{array}$ \\
\hline $\begin{array}{l}\text { Aspen- } \\
\text { control }(\mathbf{0})\end{array}$ & 2.15 & 5.25 & 3.10 & 144.0 & 1.39 \\
\hline ff2 & 2.11 & 2.15 & 0.04 & 2.0 & 0.99 \\
\hline ff4 & 2.11 & 2.14 & 0.03 & 1.5 & 4.18 \\
\hline aa8 & 2.14 & 2.27 & 0.13 & 6.1 & 1.63 \\
\hline aa10 & 2.15 & 2.20 & 0.05 & 2.3 & 3.63 \\
\hline ff2:aa8 & 2.22 & 2.27 & 0.05 & 2.3 & 4.8 \\
\hline ff4:aa10 & 2.23 & 2.34 & 0.11 & & \\
\hline
\end{tabular}

Concentrated Sugar and Furfural and Acetic Acid Toxicity-Pichia stipitis

Typical lignocellulosic pretreatment will yield anywhere from 10 - $60 \mathrm{~g} / \mathrm{L}$ fermentable sugars (Robinson et al., 2003). This concentration is low compared to a typical starch fermentation (100 - $300 \mathrm{~g} / \mathrm{L})$ (Robinson et al., 2003). Methods exist for concentrating the sugars in the hydrolysate and are focused on the removal of the water from the feedstream. Evaporation has yielded glucose concentrations of $170 \mathrm{~g} / \mathrm{L}$ (Lee et al., 1999). The main problem with concentrating of the sugars in hydrolysate is that toxins present could also be concentrated making fermentation that much more difficult. However, there 
are several methods used to detoxify the hydrolysate that fall in the categories of biological, chemical, and physical (Mussatto and Roberto, 2004). Evaporation, in fact, is also a method of detoxification. It removes acetic acid, vanillin, furfural, and other volatiles (Mussatto and Roberto, 2004). Treating the hydrolysate with activated charcoal and overliming are other effective methods that have been employed. The very cheap and effective means of detoxification is culture adaptation.

The inhibitory compounds, furfural and acetic acid were tested at levels that mimic what would be seen in a $1 \mathrm{X}, 2 \mathrm{X}$, and $3 \mathrm{X}$ aspen hydrolysates. The initial experiment resulted in minimal biomass production in all treatments expect for acetic acid, $4 \mathrm{~g} / \mathrm{L}$ and furfural, $1.5 \mathrm{~g} / \mathrm{L}$; growth was seen at $3 \mathrm{~g} / \mathrm{L}$ furfural after 96 hours (See Appendix C). The synergistic effect of the inhibitory compounds was apparent in that no growth was seen at 72 hours in any combined treatment (Table 16). These samples were not tested for ethanol production. Acetic acid has been shown to not be toxic at levels below $4 \mathrm{~g} / \mathrm{L}$ (Van Zyl et al., 1991). Also, most concentrating methods result in its removal. As a result the samples were not tested for ethanol production. The furfural samples were tested for ethanol production. The $1.5 \mathrm{~g} / \mathrm{L}$ furfural concentration had an ethanol yield of $0.27 \mathrm{~g} / \mathrm{g}$ (48 hrs.) compared to the control's $0.40 \mathrm{~g} / \mathrm{g}(72 \mathrm{hrs})$ yield. Furfural concentrations of $3.0 \mathrm{~g} / \mathrm{L}$ and $4.5 \mathrm{~g} / \mathrm{L}$ yielded no ethanol (see Appendix C). 
Table 16. Biomass production by Pichia stipitis CBS 6054 in the presence of: acetic acid (aa; 4, 8, $12 \mathrm{~g} / \mathrm{L}$ ), 5B. furfural (ff; $1.5,3,4.5 \mathrm{~g} / \mathrm{L}$ ); and combinations of the two (4:1.5, $8: 3,12: 4.5 \mathrm{~g} / \mathrm{L}$ ) in synthetic aspen hydrolysate in synthetic aspen media after 24 hours $\left(30^{\circ} \mathrm{C}, \mathrm{pH} 5.5\right)$.

\begin{tabular}{|c|c|c|c|c|c|}
\hline Treatment & $\begin{array}{c}\text { Initial } \\
\text { Biomass } \\
(\mathrm{g} / \mathrm{L})\end{array}$ & $\begin{array}{c}\text { Final } \\
\text { Biomass } \\
(\mathrm{g} / \mathrm{L})\end{array}$ & $\begin{array}{c}\text { Total } \\
\text { Biomass } \\
(\mathrm{g} / \mathrm{L})\end{array}$ & $\begin{array}{c}\text { \% Biomass } \\
\text { Increase }\end{array}$ & $\begin{array}{c}\% \text { of } \\
\text { Control }\end{array}$ \\
\hline Control & 2.2 & 3.9 & 1.8 & 81.0 & \\
\hline ff 1.5 & 2.1 & 4.1 & 2.0 & 91.9 & 111.7 \\
\hline ff 3 & 2.3 & 2.2 & -0.1 & -4.9 & $\begin{array}{l}-6.3 \\
\end{array}$ \\
\hline ff 4.5 & 2.5 & 2.2 & -0.3 & -13.8 & -19.7 \\
\hline aa 4 & 2.4 & 2.3 & -0.1 & -2.8 & -3.7 \\
\hline aa 8 & 2.2 & 2.3 & 0.0 & 1.9 & 2.3 \\
\hline aa 12 & 2.0 & 2.2 & 0.1 & 7.1 & 8.2 \\
\hline ffaa4: 1.5 & 2.4 & 2.4 & 0.0 & -0.5 & -0.7 \\
\hline ffaa8:3 & 2.2 & 2.3 & 0.1 & 3.8 & 4.7 \\
\hline ffaa12:4.5 & 2.3 & 2.2 & -0.1 & -4.0 & -5.2 \\
\hline
\end{tabular}

\section{Sugar Level Toxicity on P. stipitis}

Another factor to consider when concentrating the hydrolysate is the inhibitory effect of the sugars. High sugar concentrations can cause osmotic stress. Xylose has been shown to be inhibitory to growth at levels between $76-99$ g/L (du Preez et al. , 1986). Maximum ethanol production occurs at $50 \mathrm{~g} / \mathrm{L}$ (Agbogbo and Coward-Kelly, 2008). The goal of this study was to determine the effect, if any, concentrated sugars had on fermentations by $P$. 
stipitis. In each treatment, $100 \%$ of the sugars were used within 48 hours. Aspen $2 \mathrm{X}$ had the highest ethanol yield $(0.51 \mathrm{~g} / \mathrm{g})$. Ethanol productivity was the lowest in aspen $3 \mathrm{X}$, which could be due to osmotic stress (Table 17). The ethanol yield on aspen $3 \mathrm{X}$ was $73 \%$ of the theoretical yield $(0.51 \mathrm{~g} / \mathrm{g})$, which is still considered a sufficient yield (du Preez et al., 1986). P. stipitis is more sensitive to low substrate concentrations then high substrate concentrations in terms of ethanol productivity (du Preez et al., 1986). The biomass yields were highest on aspen $1 \mathrm{X}$. They were slightly less on aspen $3 \mathrm{X}$ and lowest on aspen $2 \mathrm{X}$. Without replicates these data cannot be verified.

Table 17. Maximum ethanol yields from concentrated sugar mixtures modeled after aspen hydrolysate by P. stipitis CBS 6054 over 120 hours in $\mathrm{YP}\left(30^{\circ} \mathrm{C}, \mathrm{pH} 5.5\right)$.

\begin{tabular}{|l|l|l|l|l|l|}
\hline Treatment & $\begin{array}{l}\text { Total } \\
\text { Sugars } \\
(\mathbf{g} / \mathbf{L})\end{array}$ & $\begin{array}{l}\text { \% Sugar } \\
\text { Utilized }\end{array}$ & $\begin{array}{l}\text { Ethanol } \\
\text { Conc. } \\
\text { (g/L) }\end{array}$ & $\begin{array}{l}\text { Ethanol Yield } \\
\text { (g_EtOH/g_sugar) }\end{array}$ & $\begin{array}{l}\text { Dry } \\
\text { Weight } \\
\text { (g/L) }\end{array}$ \\
\hline $\mathbf{1 X}$ & 17.30 & $100 \%$ & $7.30^{\mathrm{a}}$ & 0.42 & 22.4 \\
\hline $\mathbf{2 X}$ & 36.95 & $100 \%$ & $18.97^{\mathrm{a}}$ & 0.51 & 16.6 \\
\hline $\mathbf{3 X}$ & 65.03 & $100 \%$ & $23.96^{\mathrm{b}}$ & 0.37 & 18.6 \\
\hline
\end{tabular}

${ }^{a} 48$ hour value

${ }^{\mathrm{b}} 64$ hour value

\subsection{Adaptation}

Adaptation to Dilute Acid Pretreated Hydrolysate

P. stipitis was adapted to dilute acid pretreated aspen hydrolysate. The hydrolysate differs between batches but the overall characteristics remain the same (Table 18). Using dilute acid-pretreated aspen hydrolysate made by the Chemical Engineering Dept. and synthetically made hydrolysate, $P$. stipitis has been adapted to media containing up to $80 \%$ hydrolysate. The $65 \%-80 \%$ adapted strains have not yet reached optimal production 
ethanol yields $(0.06-0.19 \mathrm{~g} / \mathrm{g})$ and are not reported in this work. At $60 \%(\mathrm{v} / \mathrm{v})$ of hydrolysate, ethanol yields are between $0.28-0.33 \mathrm{~g} / \mathrm{g}$ (Table 19). Compared to the unadapted strain, there was a $2.7 \pm 0.31$-fold increase in $\mathrm{g} / \mathrm{g}$ ethanol yield. This is comparable with $2.4 \pm 0.10$-fold increase in ethanol yields from an adapted strain of $P$. stipitis on $60 \%$ dilute acid pretreated wheat straw (Nigam, 2001c). It has been reported that a 1.6-fold increase in ethanol yields has been achieved through adaptation to dilute acid pretreated hardwood (60\%) (Nigam, 2001a). Nigam (2001a) reported data for an adapted strain of $P$. stipitis CBS 6054 for up to $60 \%(\mathrm{v} / \mathrm{v})$ dilute acid pretreated red oak hydrolysate. Ethanol yields of $0.4 \mathrm{~g} / \mathrm{g}$ ssugar were reported for that adapted strain. Several other adapted cultures have reported similar values (Table 20). Michigan Tech's adapted strain of Pichia is performing as well as other adapted and wild type strains grown in similar studies in terms of ethanol yields (Agobogbo and Wenger, 2007). In terms of time to maxiumu ethanol concentrations, it is performing better. P. stipitis CBS 6054 typically produces $0.37-0.44 \mathrm{~g} / \mathrm{g}$ within $48-72$ hours; the adapted strain in this work is producing ethanol at those levels (Figure 13).

The adapted stain at Michigan Tech was compared to its parent stain through a series of fermentations in order to verify a successful adaptation. The ethanol yields are from the yeast's first exposure to the hydrolysate after adaptation. If the cells are recycled (actively growing cultures repeatedly transferred to media of the same composition), higher ethanol yields, shorter fermentation times, and greater substrate utilization arelikely to be observed (Amartey and Jefferies, 1996). Every batch of hydrolysate is different (Table 18). The synthetic media were made from an average pretreatments. Comparisons between the adapted and unadapted parent strain can be found in Appendix D section 1 . 
Table 18. Composition of two batches of dilute acid pretreated aspen hydrolysate.

\begin{tabular}{|c|c|c|}
\hline Compound & $\begin{array}{c}\text { Aspen } \\
\text { Hydrolysate } \\
\text { Batch 1 (g/L) }\end{array}$ & $\begin{array}{c}\text { Aspen } \\
\text { Hydrolysate } \\
\text { Batch 2 (g/L) }\end{array}$ \\
\hline Glucose & 1.72 & 1.65 \\
\hline Xylose & 6.92 & 7.00 \\
\hline Galactose & 0.56 & 0.56 \\
\hline Mannose + & 1.62 & 1.27 \\
\hline Arabinose & 0.96 & 1.14 \\
\hline Furfural & $\mathbf{1 0 . 8 2}$ & $\mathbf{1 1 . 6 1}$ \\
\hline Total sugars & & \\
\hline
\end{tabular}

Table 19. Ethanol yields from an adapted strain of Pichia stipitis CBS 6054 on real dilute acid pretreated aspen hydrolysate after 72 hours $\left(30^{\circ} \mathrm{C}, \mathrm{pH} 5.5\right){ }^{\mathrm{a}}$

\begin{tabular}{|c|c|c|c|c|c|}
\hline $\begin{array}{c}\text { Percent } \\
\text { Hydrolysate }\end{array}$ & $\begin{array}{c}\text { Total } \\
\text { Sugars } \\
\text { (g/L) }\end{array}$ & $\begin{array}{c}\text { \% } \\
\text { Sugars } \\
\text { Utilized }\end{array}$ & $\begin{array}{c}\text { Ethanol } \\
\text { Conc. } \\
\text { (g/L) }\end{array}$ & $\begin{array}{c}\text { Ethanol Yield } \\
\text { (g_EtOH/g_Sugar) }\end{array}$ & $\begin{array}{c}\text { Biomass } \\
\text { (g/L) } \mathbf{b}\end{array}$ \\
\hline $\mathbf{3 0 \%}$ & $28.62 \pm 0.16$ & 100 & $\begin{array}{c}12.47 \pm \\
0.9\end{array}$ & $0.44 \pm .032$ & 8.43 \\
\hline $\mathbf{4 0 \%}$ & $24.63 \pm 0.22$ & 100 & $\begin{array}{c}11.07 \pm \\
0.6\end{array}$ & $0.45 \pm .024$ & 6.98 \\
\hline $\mathbf{5 0 \%}$ & $13.24 \pm 0.11$ & 100 & $\begin{array}{c}4.10 \pm \\
0.03\end{array}$ & $0.31 \pm .0018$ & 10.1 \\
\hline $\mathbf{6 0 \%}$ & $11.72 \pm 0.13$ & 100 & $3.56 \pm 0.4$ & $0.30 \pm .033$ & 6.19 \\
\hline
\end{tabular}

${ }^{\mathrm{a}}$ Mean $(\mathrm{n}=2) \pm 2 \mathrm{SD}$

${ }^{\mathrm{b}}$ The biomass was determined on one sample only 


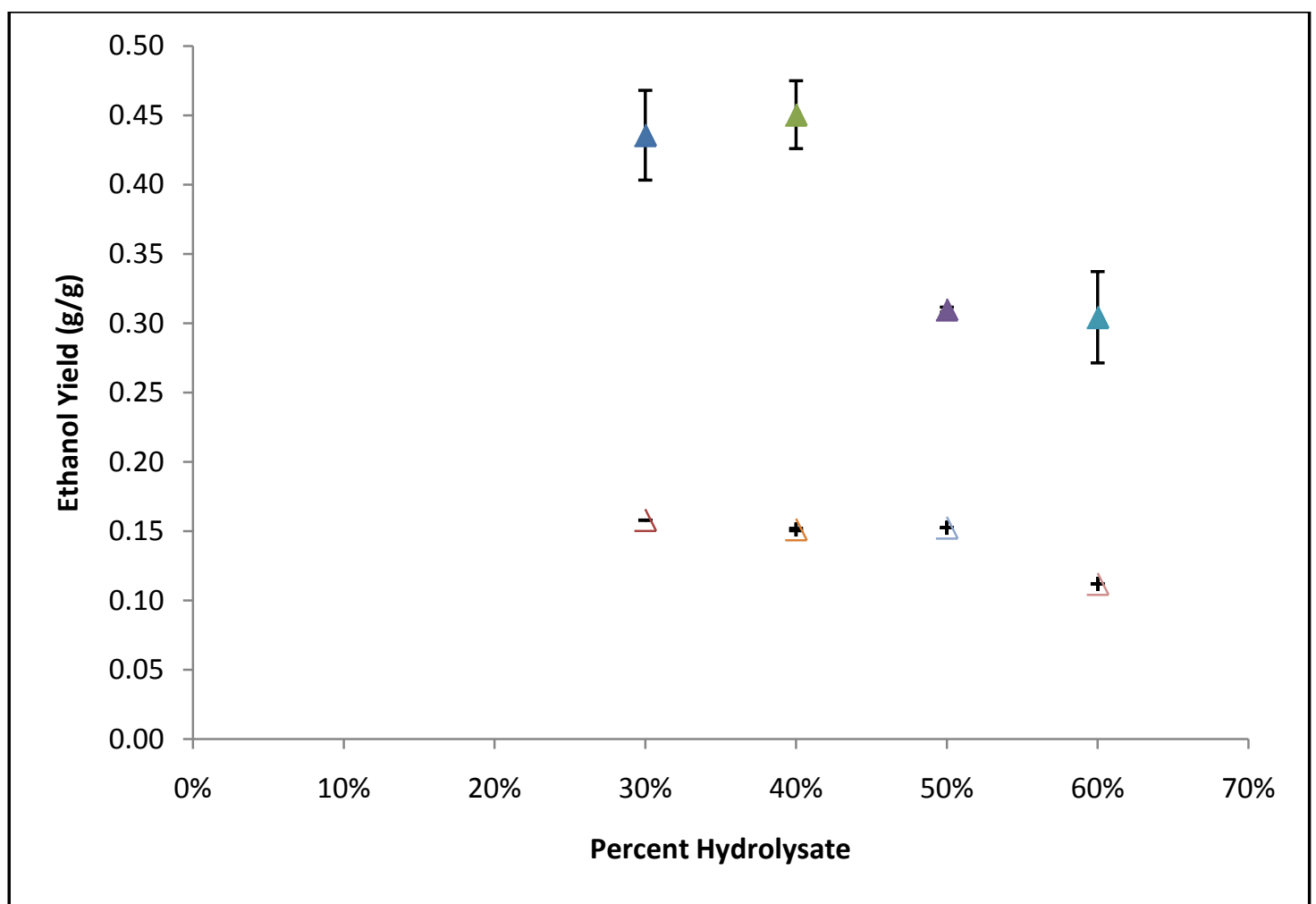

Figure 13. Comparison of 72 hour ethanol yields produced by an adapted Pichia stipitis CBS 6054(solid markers) and the parent strain (hollow markers) on varying percentages of dilute acid pretreated aspen hydrolysate supplemented with a sugar mix. Data presented as mean $(n=2) \pm 2$ SD. 
Table 20. MTU adapted strain of Pichia stipitis CBS 6054 compared to other adapted strains of Pichia strains in the literature.

\begin{tabular}{|c|c|c|c|c|c|c|}
\hline $\begin{array}{c}\text { Hydrolysate } \\
\text { Type }\end{array}$ & $\begin{array}{c}\% \\
\text { Hydrolysate }\end{array}$ & $\begin{array}{c}\text { \% Sugar } \\
\text { Utilized }\end{array}$ & $\begin{array}{c}\text { Ethanol } \\
\text { Yield } \\
\text { (g/g) }\end{array}$ & $\begin{array}{l}\% \mathrm{~T}^{\mathrm{c}} \\
\text { Yield }\end{array}$ & $\begin{array}{c}\text { Fer- } \\
\text { mentation } \\
\text { Time (hr) }\end{array}$ & Ref. \\
\hline DAP ${ }^{\mathrm{a}}$ Aspen & 60 & 99.9 & $\begin{array}{l}0.30- \\
0.33\end{array}$ & $61-65$ & 72 & $\begin{array}{c}\text { This } \\
\text { Study, } \\
\text { (2009) }\end{array}$ \\
\hline $\begin{array}{l}\text { DAP Red } \\
\text { Oak }\end{array}$ & 30 & 66.94 & 0.31 & 62 & 140 & $\begin{array}{l}\text { Nigam, } \\
\text { (2001a) }\end{array}$ \\
\hline $\begin{array}{l}\text { AP }{ }^{b} \text { Aspen } \\
\text { woodchips }\end{array}$ & Not reported & 95 & $\begin{array}{c}0.41- \\
0.47\end{array}$ & $82-94$ & 96 & $\begin{array}{c}\text { Parekh } \\
\text { et al., } \\
\text { (1988) }\end{array}$ \\
\hline DAP Poplar & Not reported & $\begin{array}{c}\text { Not } \\
\text { reported }\end{array}$ & $\begin{array}{l}0.31- \\
0.38\end{array}$ & $62-76$ & 50 & $\begin{array}{c}\text { Fenske } \\
\text { et al., } \\
\text { (1998) }\end{array}$ \\
\hline $\begin{array}{l}\text { DAP hard } \\
\text { and } \\
\text { softwood } \\
\text { mixes }\end{array}$ & $80 \%{ }^{\mathrm{d}}$ & $\begin{array}{c}\text { Not } \\
\text { reported }\end{array}$ & 0.44 & 88 & 72 & $\begin{array}{c}\text { Sreenath } \\
\text { and } \\
\text { Jeffries } \\
\text { (2000) }\end{array}$ \\
\hline
\end{tabular}

${ }^{\mathrm{a} D A P}$ - Dilute sulfuric acid pretreatment

${ }^{\mathrm{b}}$ AP - Sulfuric Acid Pretreatment

${ }^{\mathrm{c}} \mathrm{T}$ - Theorectical yield

dPartially detoxified 


\subsection{Fermentation Optimization}

Media composition

The effects of different fermentation media on ethanol production by $P$. stipitis was determined. Three media were evaluated: YNB, YPX, and CSL (Table 21) (Agbogbo and Coward-Kelly, 2008). Growth and biomass production for YNB and YPX have been assessed. The growth rate was slower for YPX than YNB, 1.32 and $0.72 \mathrm{hr}^{-1}$, respectively (Appendix E). In preliminary studies, YNB produced a mean ethanol yield of $0.52 \mathrm{~g} / \mathrm{g}$, whereas YPX produced $0.23 \mathrm{~g} / \mathrm{g}$. Another fermentation study was conducted with all three media types (Table 18). CSL and YNB were supplemented with 50:50 glucose: xylose. YPX consisted just of xylose $(50 \mathrm{~g} / \mathrm{L})$. CSL media gave the highest ethanol yieldsbut utilized the least amount of sugar. YPX utilized the greatest percentage of sugar (and had relatively high ethanol yields.

Table 21. Summary of fermentation results of three different media types: (Yeast Nitrogen Base (YNB), Yeast Peptone Broth (YPX), and Corn Steep Liquor Media (CSL) using Pichia stipitis on glucose and/or xylose $\left(30^{\circ} \mathrm{C}, \mathrm{pH} 5.5\right)^{\mathrm{a}}$.

\begin{tabular}{|c|c|c|c|c|c|}
\hline Medium & $\begin{array}{c}\text { Total } \\
\text { Sugars } \\
(\mathbf{g} / \mathbf{L})\end{array}$ & $\begin{array}{c}\text { \% Sugar } \\
\text { Utilized }\end{array}$ & $\begin{array}{c}\text { Ethanol } \\
\text { Conc. } \\
(\mathbf{g} / \mathbf{L})\end{array}$ & $\begin{array}{c}\text { Ethanol Yield } \\
(\mathbf{g} \text { EtOH/g_sugar) }\end{array}$ & $\begin{array}{c}\text { Dry } \\
\text { Weight } \\
(\mathbf{g} / \mathbf{L})\end{array}$ \\
\hline YPX & $49.0 \pm 0.1$ & 49.9 & $10.3 \pm 1.46$ & $0.42 \pm 0.01$ & 13.6 \\
\hline YNB & $77.6 \pm 0.7$ & 35.5 & $8.25 \pm 0.49$ & $0.30 \pm 0.07$ & 13.4 \\
\hline CSL & $75.0 \pm 1.3$ & 24.9 & $9.44 \pm 1.44$ & $0.51 \pm 0.01$ & 15.4 \\
\hline
\end{tabular}

${ }^{\mathrm{a}}$ Mean $(\mathrm{n}=2) \pm 2 \mathrm{SD}$ 


\section{Conclusions}

- S. cerevisiae (ER) could not utilize the pentose sugars present in the dilute acid pretreated hydrolysate and was not considered for fermentations where pentose sugars were present. Pichia stipitis was able to grow on all five sugars present in the hydrolysate. It also could produce ethanol from four out of the five.

- Some compounds (furfural and acetic acid) that are produced as a result of dilute acid pretreatment are inhibitory to both types of yeast.

- P. stipitis was successfully adapted to dilute acid pretreated hydrolysate for improved ethanol yields. The final adaptation resulted in 2.6 fold increase in ethanol production compared to the unadapted parent strain.

- Adaptation is an effective and inexpensive means of improving ethanol yields from lignocellulosic feedstocks.

- Three media were tested to determine the optimum for ethanol production by $P$. stipitis CBS 6054. The three tested media all had comparable yields. CSL had higher ethanol yields than the YPX and YNB. 


\section{Recommendations}

The adapted strain of P. stipitis needs to be adapted to higher concentrations of dilute acid pretreated hydrolysate. Cell recycle also needs to be looked at as a means of improving ethanol yields. Scale-up needs to be done with the adapted strain of $P$. stipitis in order to determine if the procedures that worked in the bench scale studies can be applied to large scale fermentations. It also needs to be determined that this is in fact adaptation and not just acclamation. In termed of media, given these results more factors, such as cost and availability, need to be examined in order to optimize the fermentation on the basis of media.

More work needs to be done with concentrated hydrolysate and mixed hydrolysate fermentations should be examined. Each biomass type has it own characteristic and properties that can lead to increased ethanol yields. Fermentation involving combinations of the enzymatic and dilute acid hydrolysate and co-culture fermentations so be a performed.

The fermentation of lignocellulosic feedstocks have the potential to become as commercially and economically feasible as corn based ethanol. It hinges on producing comparable ethanol yields. This can be done by selecting the right organism and then adapting it to the feedstock. The condition must be optimized for that organism. A small scale example is presented in this these but it can and should be applied to scale-up methods in similar studies. 


\section{References}

1. Agbogbo FK, Coward-Kelly G, Torry-Smith M, Wenger KS (2006) Fermentation of glucose/xylose mixtures using Pichia stipitis. Process Biochem 41:2333-2336.

2. Agbogbo FK, Coward-Kelly G, Torry-Smith M, Wenger KS, Jefferies TW (2007) The effect of initial cell concentration on xylose fermentation by Pichia stipitis. Appl. Biochem Biotechnol 136-140:653-662.

3. Agbogbo FK, and Wenger KS (2007) Production of ethanol from corn stover hemicellulose hydrolysate using Pichia stipitis. J Ind Microbiol Biotechnol 34:723727.

4. Agbogbo FK, and Coward-Kelly G (2008) Cellulosic ethanol production using the naturally occurring xylose-fermenting yeast, Pichia stipitis. Biotechnol Lett 30:15151524.

5. Almeida JRM, Modig T, Roder A, Linde G, Gorwa-Grauslund MF (2008) Pichia stipitis xylose reductase helps detoxifying lignocellulose hydrolysate by reducing 5hydroxymethly-firfiral (HMF). Biotechnol Biofuels 1(12):NP

6. Amartey SA, Jefferies TW (1994) Comparison of corn steep liquor with other nutrient in the fermentation of d-xylose by Pichia stipitis CBs 6054. Biotechnol Lett $16: 211-214$

7. Amartey S, and TW Jefferies (1996) An improvement in Pichia stipitis fermentation of acid hydrolyses hemicellulose achieved by overlimiting (calcium hydroxide treatment) and strain adaptation. World J Microbiol Biotechnol 12:281-283 
8. Arroyo-Lopez FN, Orlic A, Querol A, Barrio E (2009) Effects of temperature, pH, and sugar concentration on the growth parameters of Saccharomyces cerevisiae, $S$. kudriavzevii and their interspecific hybrid Int J Food Microbiol doi:10.1016/j.ijfoodmicro.2009.01.035

9. Ballesteros M, Oliva JM, Negro MJ, Manzanares P, Ballesteros I (2004) Ethanol from lignocellulosic materials by a simultaneous saccharification and fermentation process (SFS) with Kluyveromyces marxianus CECT 10875. Process Biochem 39:1843-1848

10. Belloch C, Villa-Carvajal M, Alvarez-Rodríguez ML, Coque JJ (2007) Rhodotorula subericola sp. nov., an anamorphic basidiomycetous yeast species isolated from bark of Quercus suber (cork oak) Int J Syst Evol Microbiol 571668-71.

11. Brandberg T, Sanandaji N, Gustafaaon L, Franzen CJ (2005) Continuous fermentation of undetoxified dilute acid lignocellulose hydrolysate by Saccharomyces cerevisiae ATCC 96581 using cell recirculation. Biotechnol Progress 21: 1093-1101

12. Brandberg, T., C.J. Franzen, L. Gustafaaon (2004) The fermentation performance of nine strains of Saccharomyces cerevisiae in batch and fed-batch cultures in diluteacid wood hydrolysate. Biosci Bioeng 98: 112-125

13. Brigham JS, Adney WS, Himmel ME (1996) Hemicelluloses: diversity and applications. In: Wyman CE (ed) Handbook on bioethanol: production and utilization. Taylor and Francis, Washington DC, pp 119-142.

14. Delengenes JP, Moletta R, Baarro JM (1996) Effects of lignocellulosic degradation products on ethanol fermentation of glucose and xylose by Saccharomyces cerevisiae, 
Zymononas mobilis, Pichia stipitis, and Candida shehatae. Enzyme Microb Technol $19: 220-225$

15. Devantier R, Pedersen S, Olssin L (2004) Characterization of very high gravity ethanol fermentation of corn mash. Effect of glucoamylase dosage, presaccharification and yeast strain. Appl Microbiol Biotechnol. 68:622-629

16. du Preez JC, Bosch M, Prior BA (1985) Xylose fermentation by Candida shehatae and Pichia stipitis: effect of $\mathrm{pH}$, temperature and substrate concentration. Enzyme Microb Technol 8:360-364

17. du Preez JC, Bosch M, Prior BA (1986) The fermentation of hexose and pentose sugars by Candida shehatae and Pichia stipitis. Appl Microbiol Biotechnol 23:228233

18. Ezeji T, Qureshi N, Blaschek HP (2004) Butanol fermentation research: upstream and downstream manipulations. The Chemical Record. 305-314.

19. Ezeji T, Qureshi N, Blaschek HP (2007) Butanol production from agricultural residues: impact of degradation on Clostridium beijerinckii growth and butanol fermentation. Biotechnol Bioeng 1460-1469

20. Fenske JJ, Hashimoto A, Penner MH (1993) Relative fermentability of lignocellulosic dilute-acid prehydrolysate- application of Pichia based toxicity assay. App Biochem Biotechnol 73:145-157

21. Govindaswamy S and Vane LM (2006) Kinetics of growth and ethanol production on different carbon substrates using genetically engineered xylose-fermenting yeast. Biores Technol 98:677-685 
22. Hahn-Hagerdal B, Karhumaa K, Larsson C, Gorwa-Grauslund M, Gorgens J, van Zyl W (2005) Role of cultivation media in the development of yeast strains for large scale industrial use. Microbial Cell Factories 4:31

23. Karakashev D, Thomsen AB, Angelidaki I (2007) Anaerobic biotechnological approaches for production of liquid energy carriers from biomass. Biotechnol Lett 29:1005-1012

24. Karimi K, Emtiazi G, Taherzadeh MJ (2006) Ethanol production from dilute-acid pretreated rice straw by simultaneous saccharification and fermentations with Mucor indicus, Rhizopus oryzae, and Saccharomyces cerevisiae. Enzyme Microbial Tech $40: 139-144$

25. Klinke HB, Thomsen AB, Ahring BK (2004) Inhibition of ethanol-producing yeast and bacteria by degradation products produced during pre-treatment of biomass. Appl Microbiol Biotechnol 66:10-26

26. Kuyper M, Hartog MMP, Toirkens MJ, Almering MJH, Winkler AA, van Dijken JP, Pronk JT (2005) Metabolic engineering of xylose-isomerase-expressing Saccharomyces cerevisiae strain for rapid anaerobic xylose fermentation. Yeast Rese 5:399-408

27. Jeffries TW, Jin YS (2000) Ethanol and thermotolerance in the bioconversion of xylose by yeast. Adv Appl Microbiol 47:221-68

28. Jefferies TW, Grigoriev IV, Grimwood J, Laplaza JM, Aerts A, Salamov A, Schmutz J, Lindquist E, Dehal P, Shapiro H, Jin Y, Passoth V (2007) Genome sequence of the lignocellulose-bioconverting and xylose fermenting yeast Pichia stipitis. Nature Biotechnol 25: 319-326 
29. Jensen J, Morinelly J, Aglan A, Mix A, Shonnard DR (2008) Kinetic characterization of biomass dilute sulfuric acid hydrolysis: Mixtures of hardwoods, softwood, and switchgrass. AIChE J 6:1637-1645.

30. Jensen JR, Morinelly JE, Gossen KR, Brodeur-Campbell MJ, Shonnard DR (2009) Effects of Dilute Acid Pretreatment Conditions on Enzymatic Hydrolysis Monomer and Oligomer Sugar Yields for Aspen, Balsam, and Switchgrass. Submitted to Biores Technol.

31. Jeppsson H, Yu S, Hahn-Hagerdal B (1996) Xylose and Glucose fermentation by Saccharomyces cerevisiae in chemostat culture. Appl Environ Microbiol 62:17051709

32. Kim Y, Ingram LO, Shanmugam KT (2007) Construction of an Escherichia coli K-12 mutant for homoethanolgenic fermentation of glucose or xylose without foreign genes. Appl. Environ Microbiol 73:1766-1771

33. Lawford HG, Rousseau JD (1994) Relative rates of sugar utilization b y an ethanologenic recombinant Escherichia coli using mixtures of glucose, mannose, and xylose. Appl Biochem Biotechnol 45-46:367-381

34. Lee WG, Lee JS, Shin CS, Park SC, Chang HN, Chang YK (1999) Ethanol production using concentrated oak wood hydrolysate and methods to detoxify. Appl Biochem Biotechnol 77-79:547-559

35. Lin Y, Tanaka S (2005) Ethanol fermentation from biomass resources: current state and prospects. Appl Microbiol Biotechnol 69:627-642

36. Lui ZL, Slininger PJ, Dien BS, Berhow MA, Kurtman CP, Gorsich SW (2004) Adaptive response of yeasts to furfural and 5-hydroxymethylfurfural and new 70 
chemical evidence for HMF conversion to 2,5-bis-hydroxymethylfuran. $\mathrm{J}$ Ind Microbiol 31:345-352

37. Moniruzzaman M, Ingram LO (1998) Ethanol production from dilute acid hydrolysate of rice hulls using genetically engineered Escherichia coli. Biotechnol Lett 20:943-947

38. Nichols NN, Dien BS, Bothast RJ (2001) Use of catabolite repression mutants for fermentation of sugar mixtures to ethanol. Appl Microbiol Biotechnol 56:120-125

39. Nigam JN (2001a) Development of xylose-fermenting yeast Pichia stipitis for ethanol production through adaptation on hardwood hemicellulose acid prehydrolysate. $\mathrm{J}$ Appl Microbiol 90:208-215.

40. Nigam JN (2001b) Ethanol production from hardwood spen sulfite liqour using an adapted strain of Pichia stipitis. J Ind Microbiol Biotechnol 26:145-150

41. Nigam JN (2001c) Ethanol production from wheat straw hemicellulose hydrolysate by Pichia stipitis. J Biotechnol 87:17-27

42. Ohgren K, Bengtsson O, Gorwa-Grauslund MF, Galbe M, Hahn-Hagerdal B, Zacchi G (2006) Simultaneous saccharification and co-fermentation of glucose and xylose in steam-pretreated corn stover at high fiber content with Saccharomyces cerevisiae TMB3400. J Biotechnol 126:488-498

43. Okuda N, Ninomiya K, Takao M, Katakura Y, Shioya S ( 2007) Microaeration Enhances productivity of bioethanol from hydrolysate of waste house wood using ethanologenic Escherichia coli KO11. J Biosci Bioeng 103:350-357

44. Olsson L, and Han-Hagerdal B (1996) Fermentation of lignocellulosic hydrolysates for ethanol production. Enzyme Microbial Technol 18:312-331 
45. Pamnqvist E, Hanh-Hagerdal B (2000) Fermentation of lignocellulosic hydrolysate. II: inhibitors and mechanisms of inhibition. Biores Technol 74:25-33

46. Papagianni M, Boonpooh Y, Mattey M, Kristiansen B (2007) Substrate inhibition kinetics of Saccharomyces cerevisiae in fed-batch cultures operated at constane glucose and maltose concentration levels. J Ind Microbiol Biotechnol 34:301-309

47. Parekh SR, Yu S, and Wayman M (1986) Adaptation of Candida shehatae and Pichia stipits to wood hydrolysates for increased ethanol production. Appl Microbiol Biotechnol 25:300-304

48. Parekh SR, Parekh RS, Wayman M (1988) Fermentation of xylose and cellobiose by Pichia stipitis and Brettanomycetes clausenii. Appl Biochem Biotechnol 18:325-338.

49. Robinson J, Keating JD, Mansfield SD, Saddler JN (2003) The fermentability of concentrated softwood-derived hemicellulose fractions with and without supplemental cellulose hydrolysates. Enz Microbial Technol 33:757-765.

50. Roca C, Haack MB, Olsson L (2004) Engineering of carbon catabolite repression in recombinant xylose fermenting Saccharomyces cerevisiae. Appl Microbiol Biotechnol 63:578-583

51. Ruiz S, Romero I, Moya M, Sanchez S, Bravo V, Castro E (2006) Sugar fermentation by Fusarium oxysporum to produce ethanol. World J Microbiol Biotechnol 23:259267

52. Skoog K and Han-Hagerdal B (1990) Effect of oxygenation of xylose fermentation by Pichia stipitis. Appl Environ Microbiol 56:3389-3394

53. Sreenath HK and Jeffries TW (2000) Production of ethanol from wood hydrolysate by yeasts. Biore Technol 72:253-260 
54. Taherzadeh MJ and Karimi K (2007) Acid based hydolysis processes for ethanol from lignocellulosic materials: A review. Biores Technol 2:472-499

55. Taherzadeh MJ, Niklasson C, Liden (1998) Conversion of Dilute-acid hydrolyzates of spruce and birch to ethanol by fed-batch fermentation. BioresTechnol 69:59-66

56. Underwood SA, Buszko ML, Shanmugam KT, Ingram LO ( 2002) Flux through citrate synthase limits the growth of ethanologenic Escherichia coli KO11 during xylose fermentation. Appl Environ Microbiol 68:1071-1081

57. van Maris AJA, Abbott DA, Hellissimi E, Van den Brink J, Kuyper M, Luttik MAH, Wouter Wisselink H, Scheffers WA, Luttik AH (2006) Alcoholic fermentation of carbon sources in biomass hydrolysates by Saccharomyces cerevisiae: current status. Antonie van Leeuwenhoek 90:391-418

58. Van Zyl C, Prior BA, du Preez JC. 1988. Production of ethanol from sugar cane bagasse hemicellulose hydrolysate by Pichia stipitis. Appl Biochem Biotechnol 17:357-369.

59. Yomano LP, York SW, Ingram LO (1998) Isolation and characterization of ethanoltolerant mutants of Escherichia coli KO11 for fuel ethanol production. J Ind Microbiol Biotechnol 20:132-138

60. Zaldivar J, Nielsen J, Olsson L (2000) Fuel ethanol production from lignocellulose: a challenge for metabolic engineering and process integration. Appl Microbiol Biotechnol 56:17-34 


\section{Appendix A. Supplementary Data for S. cerevisiae}

\section{A.1 Ethanol production from glucose by $S$. cerevisiae (ER)}

S. cerevisiae (ER) was tested in the bench scale flask system to obtain baseline ethanol production data for the system. YPG $(20 \mathrm{~g} / \mathrm{L})$ was used. A mathematical equation was developed to predict ethanol yields using the bench scale system.

Table A.1. Production of ethanol from glucose by S. cerevisiaein 24 hours $\left(30^{\circ} \mathrm{C}, \mathrm{pH} 5.5\right)$.

\begin{tabular}{|c|c|c|c|}
\hline $\begin{array}{c}\text { Glucose } \\
(\mathbf{g} / \mathbf{L})\end{array}$ & $\begin{array}{c}\text { EtOH } \\
(\mathrm{g} / \mathbf{L})\end{array}$ & $\begin{array}{c}\text { Ethanol } \\
\mathbf{g} / \mathbf{g} \\
\text { Yield }\end{array}$ & $\begin{array}{c}\text { \% } \\
\text { Theoretical }\end{array}$ \\
\hline $\mathbf{2 0}$ & 3.27 & 0.17 & $33.17 \%$ \\
\hline $\mathbf{2 0}$ & 3.87 & 0.20 & $39.47 \%$ \\
\hline $\mathbf{2 0}$ & 5.69 & 0.29 & $57.87 \%$ \\
\hline
\end{tabular}

Preliminary ethanol production data for Ethanol Red (S. cerevisiae) led to the creation of an equation for predicting ethanol yield within this experimental design (equation A.1.1).

\section{Equation A 1}

Initial Sugar Conc. $(\mathrm{g} / \mathrm{L})$ - Final Sugar Conc. $(\mathrm{g} / \mathrm{L}) \quad=$ EtOH Conc. $(\mathrm{g} / \mathrm{L})$

\section{9}

Table A.2. Example of the ethanol yield model using results of HPLC data for a $100 \%$ glucose $(5 \mathrm{~g} / \mathrm{L})$ fermentation using $S$. cerevisiae (ER) after 24 hours in YP media $\left(30^{\circ} \mathrm{C}\right.$. ph 5.5).

\begin{tabular}{|c|c|c|c|c|c|c|}
\hline Treatment & $\begin{array}{c}\text { Initial } \\
\text { Glucose } \\
(\mathbf{g} / \mathbf{L})\end{array}$ & $\begin{array}{c}\text { Final } \\
\text { Glucose } \\
(\mathbf{g} / \mathbf{L})\end{array}$ & $\begin{array}{c}\text { Difference } \\
\mathbf{( g / L )}\end{array}$ & $\begin{array}{c}\text { Expected } \\
\text { EtOH } \\
(\mathbf{g} / \mathbf{l})\end{array}$ & $\begin{array}{c}\text { Actual } \\
\text { EtOH } \\
(\mathbf{g} / \mathbf{l})\end{array}$ & $\begin{array}{c}\text { \% of } \\
\text { expected }\end{array}$ \\
\hline $100 \%$ & 4.17 & 0.46 & 3.70 & 0.75 & 0.73 & 96 \\
Glucose & & & & & & \\
\hline
\end{tabular}




\section{A.2 Fermentation results for $S$. cerevisiae (ER) in xylose and glucose mixtures}

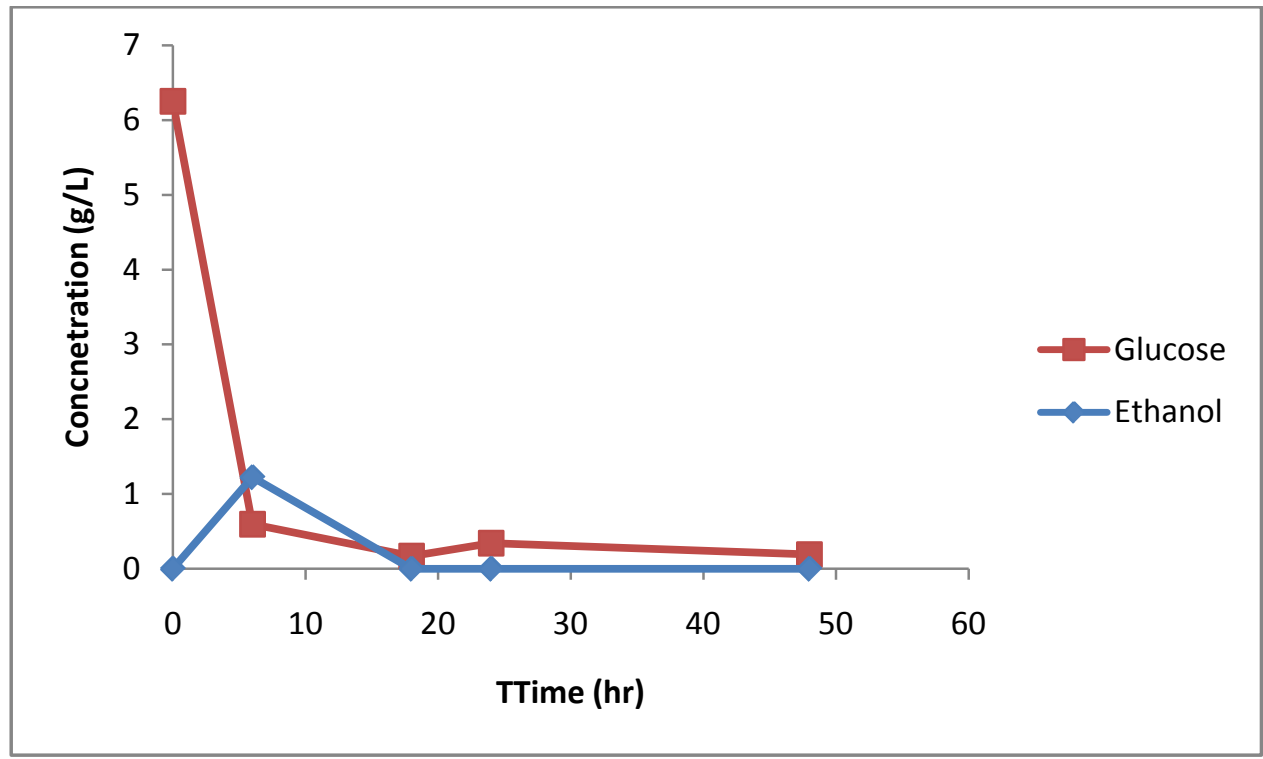

Figure A.1. Ethanol production and substrate utilization by S. cerevisiae on $100 \%$ glucose $(6.25 \mathrm{~g} / \mathrm{L})$ after 24 hours in $\mathrm{YP}$ media $\left(30^{\circ} \mathrm{C}, \mathrm{pH} 5.5\right)$.

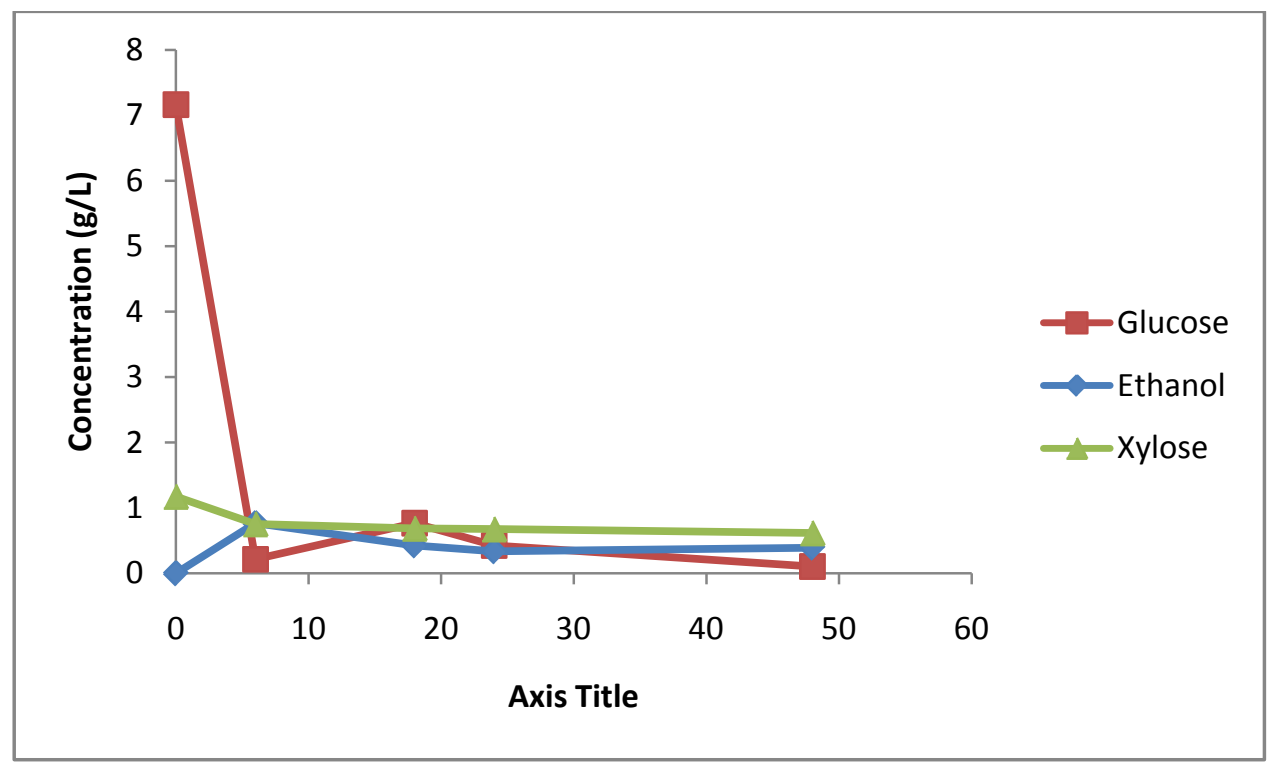

Figure A.2. Ethanol production and substrate utilization by S. cerevisiae on $75 \%$ glucose:25\% xylose mixtures $(8.2 \mathrm{~g} / \mathrm{L})$ after 24 hours in YP media $\left(30^{\circ} \mathrm{C}, \mathrm{pH} 5.5\right)$. 


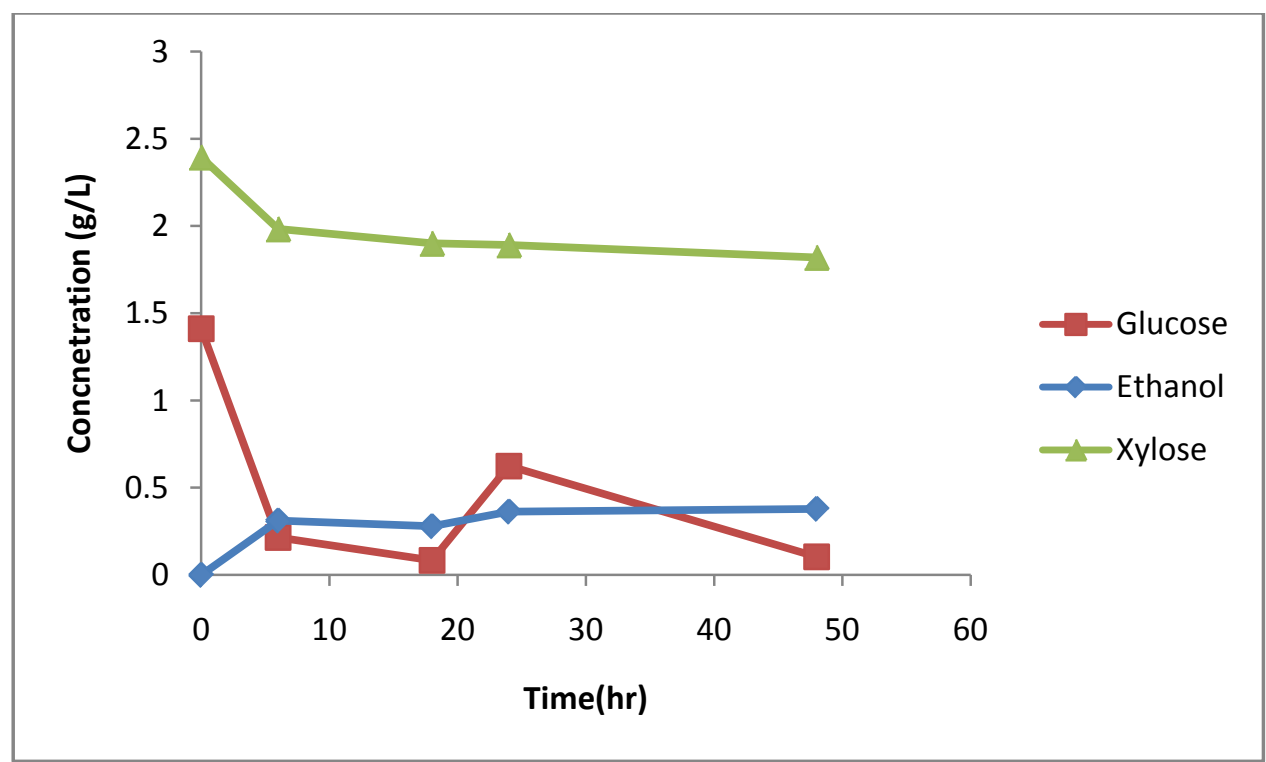

Figure A.3. Ethanol production and substrate utilization by $S$. cerevisiae on $60 \%: 40 \%$ glucose : xylose $(3.8 \mathrm{~g} / \mathrm{L})$ after 24 hours in YP media $\left(30^{\circ} \mathrm{C}, \mathrm{pH} 5.5\right)$.

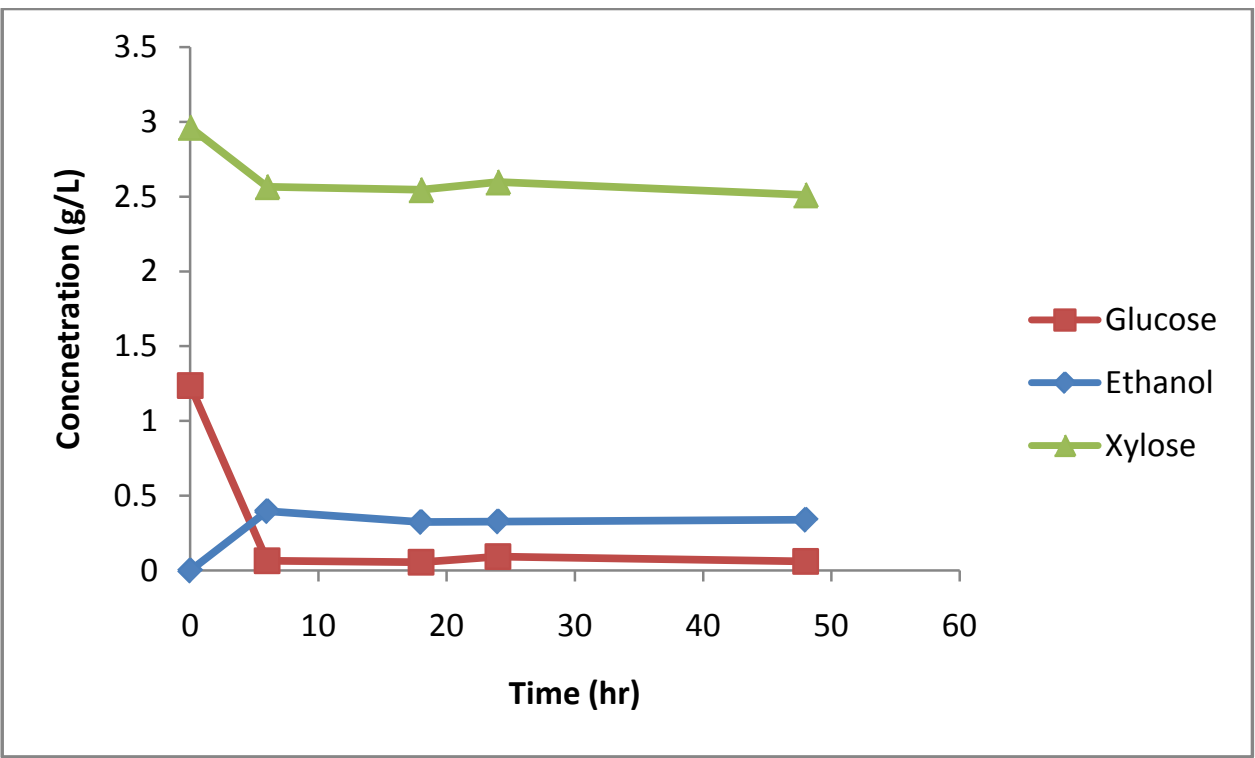

Figure A.4. Ethanol production and substrate utilization by $S$. cerevisiae on $25 \%: 75 \%$ glucose : xylose $(4.1 \mathrm{~g} / \mathrm{L})$ after 24 hours in YP media $\left(30^{\circ} \mathrm{C}, \mathrm{pH} 5.5\right)$. 


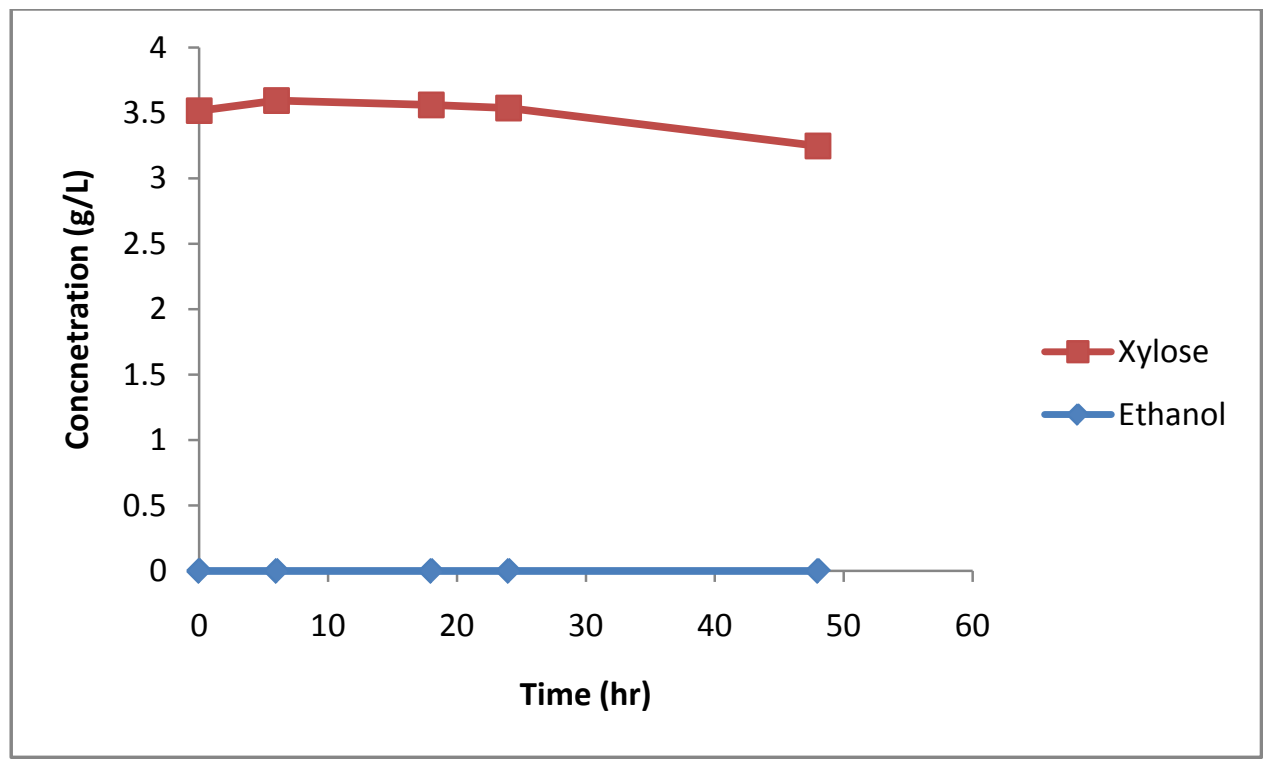

Figure A.5. Ethanol production and susbstrate utilization by $S$. cerevisiae on $25 \%: 75 \%$ glucose : xylose $(3.5 \mathrm{~g} / \mathrm{L})$ after 24 hours in YP media $\left(30^{\circ} \mathrm{C}, \mathrm{pH} 5.5\right)$. 
Appendix B. Supplementary Data for Fermentations by P.stipitis and Enzymatic Hydrolysate Fermentations by $\boldsymbol{S}$. cerevisiae (ER)

B.1 Growth of $P$. stipitis on YP-sugar free vs. YPX

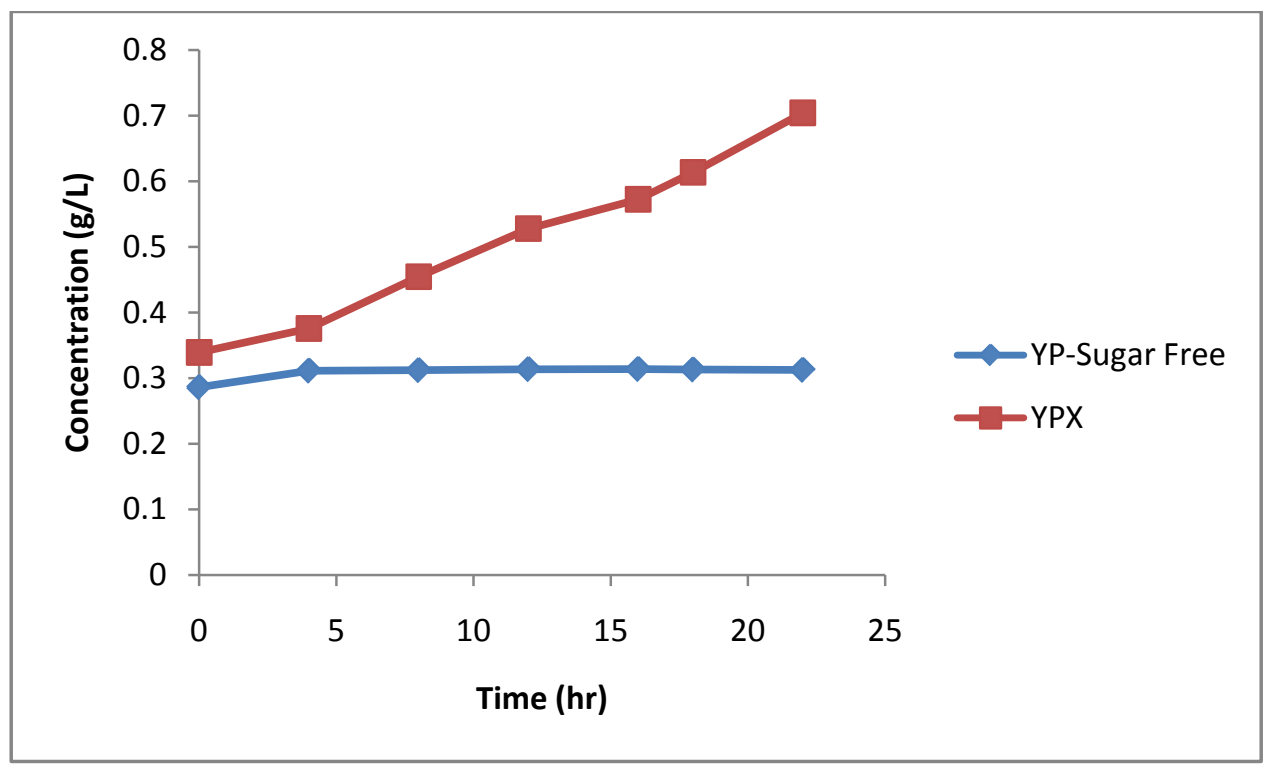

Figure B.1. Growth of P. stipitis on YP media without a carbon source compared to YPX $(20 \mathrm{~g} / \mathrm{L})$ media after 24 hours $\left(30^{\circ} \mathrm{C}, \mathrm{pH} 5.5\right)$. 


\section{B.2 mixed substrate fermentations by $P$. stipitis}

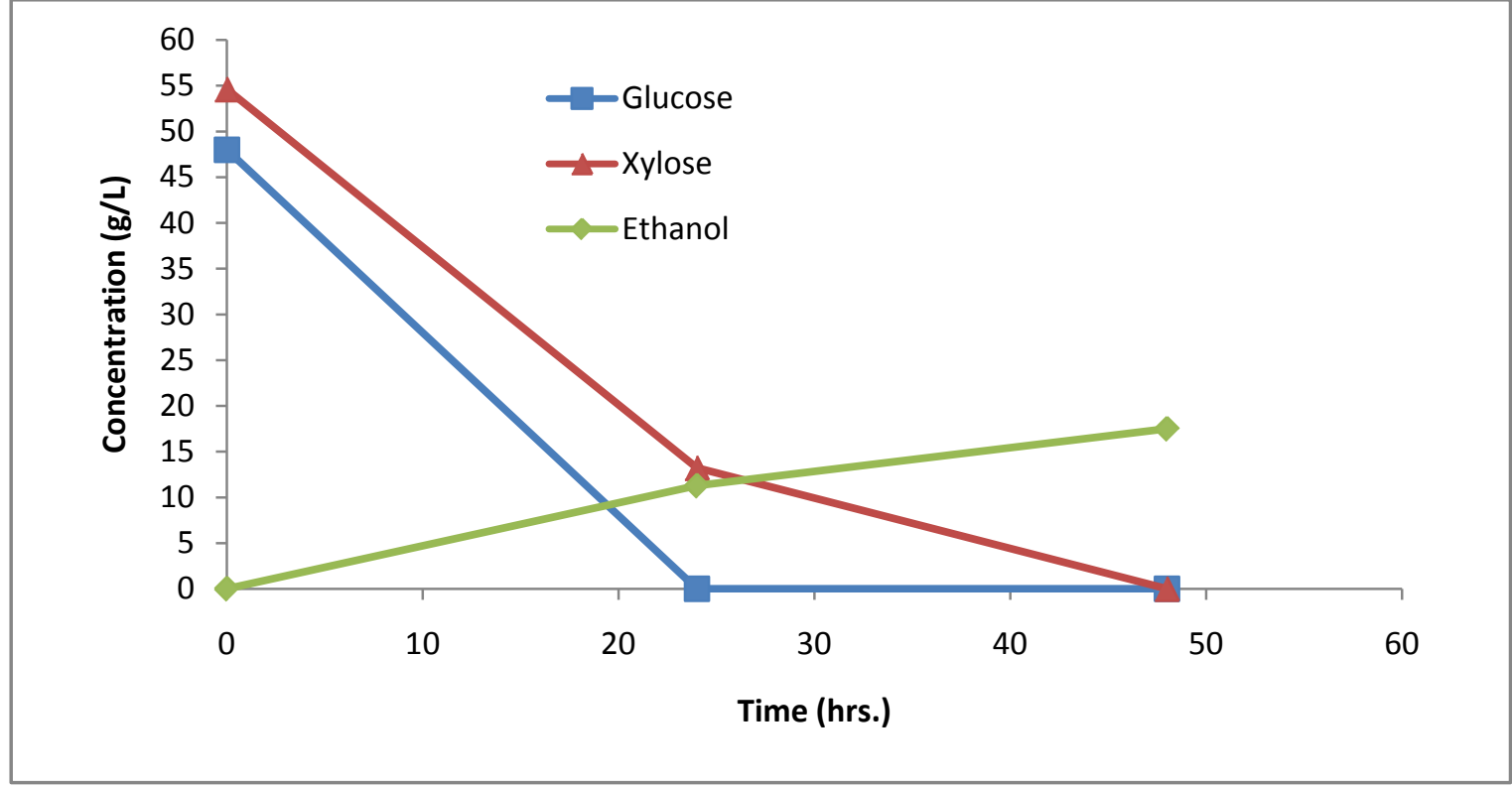

Figure B.2. Fermentation of a 50:50 mixture xylose $(50 \mathrm{~g} / \mathrm{L})$ and glucose $(50 \mathrm{~g} / \mathrm{L})$ in YP media by Pichia stipitis CBS 6054 after 72 hours $\left(30^{\circ} \mathrm{C}, \mathrm{pH} 5.5\right)$.

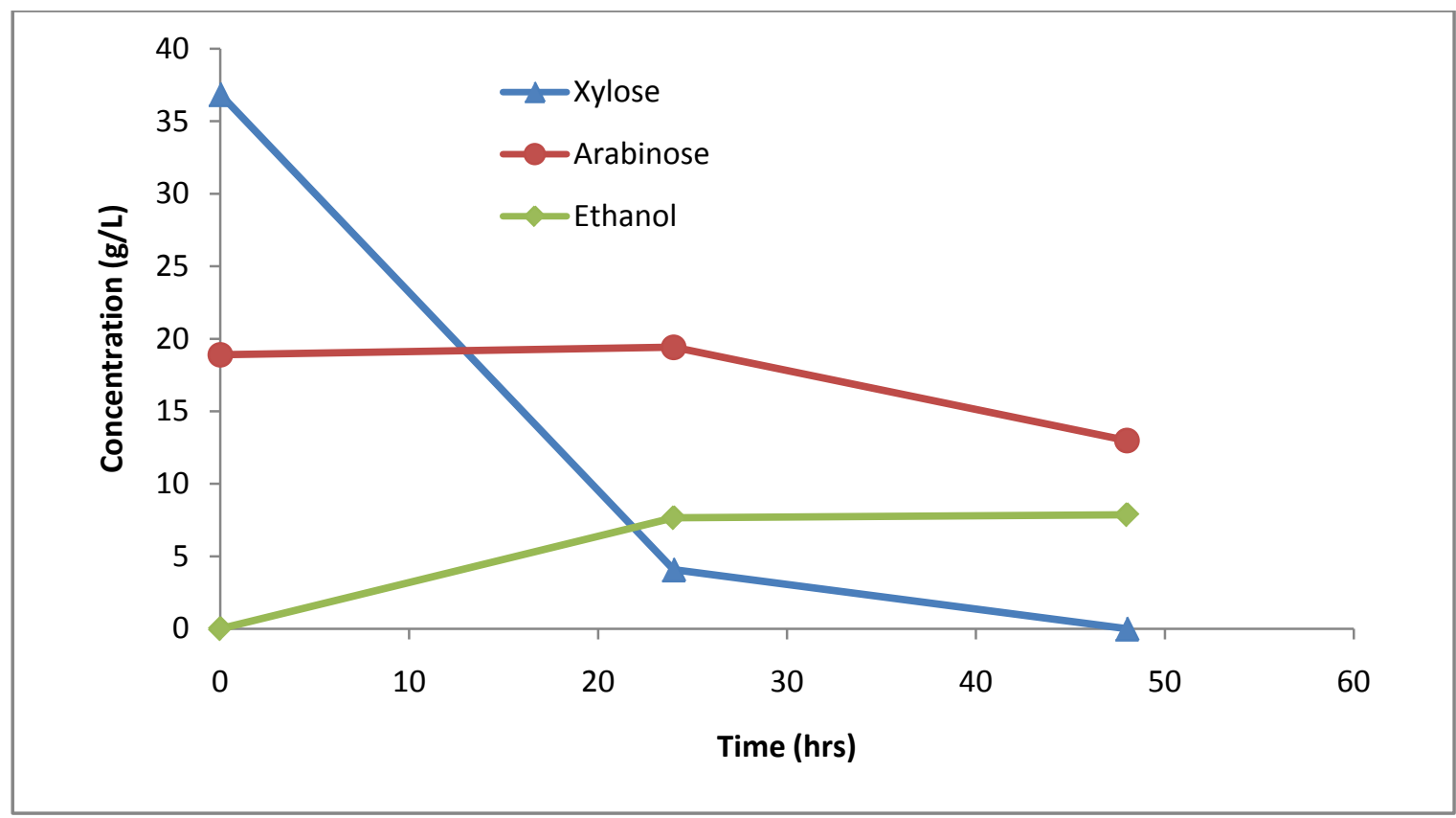

Figure B.3. Fermentation of a mixture of 1:2 mixture of arabinose and xylose in YP Media by Pichia stipitis CBS 6054 after 72 hours $\left(30^{\circ} \mathrm{C}\right.$, pH 5.5). 


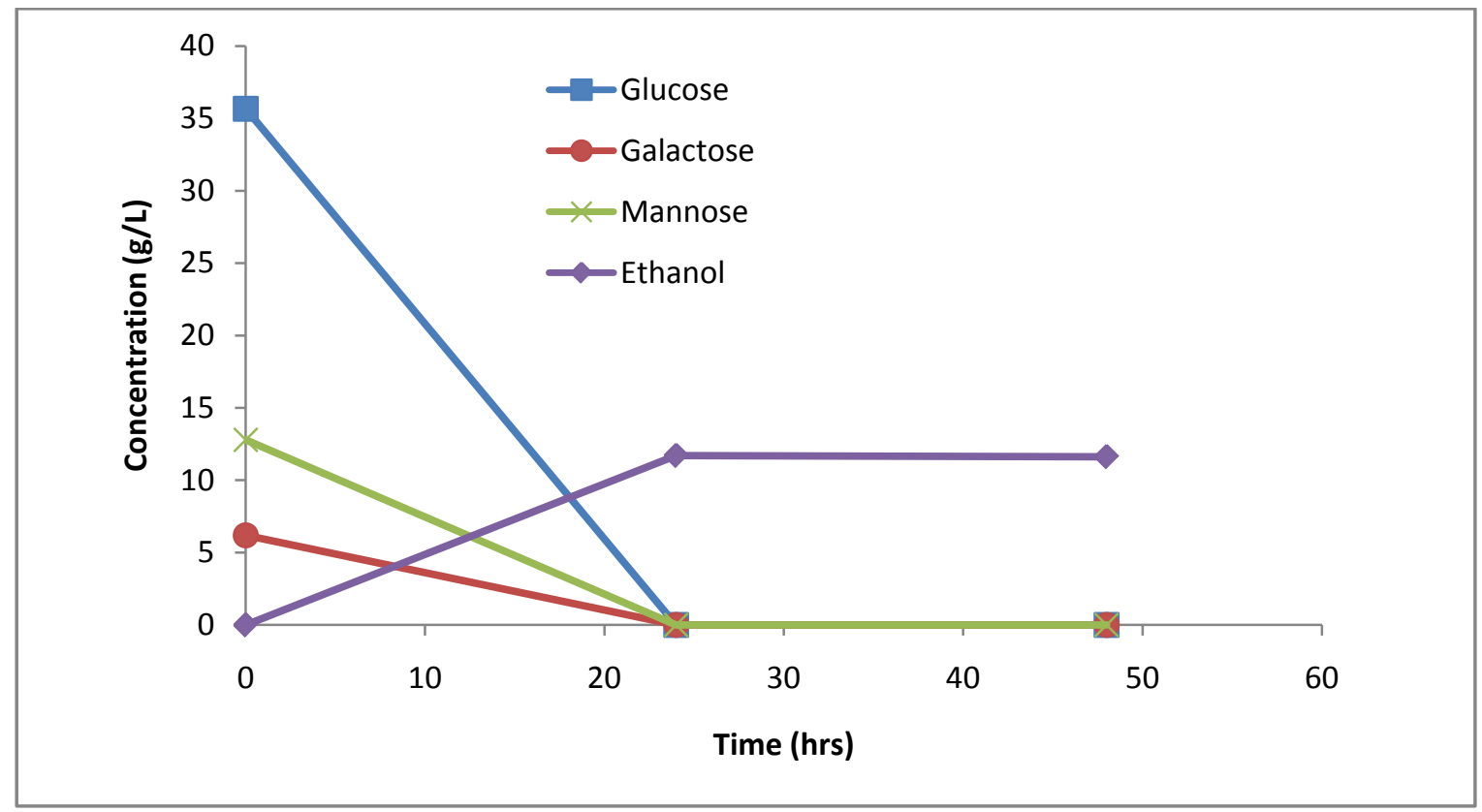

Figure B.4. Fermentation of a mixture of 1:1:2 mixture of galactose, mannose, and glucose in YP Media by Pichia stipitis CBS 6054 after 72 hours $\left(30^{\circ} \mathrm{C}\right.$, pH 5.5).

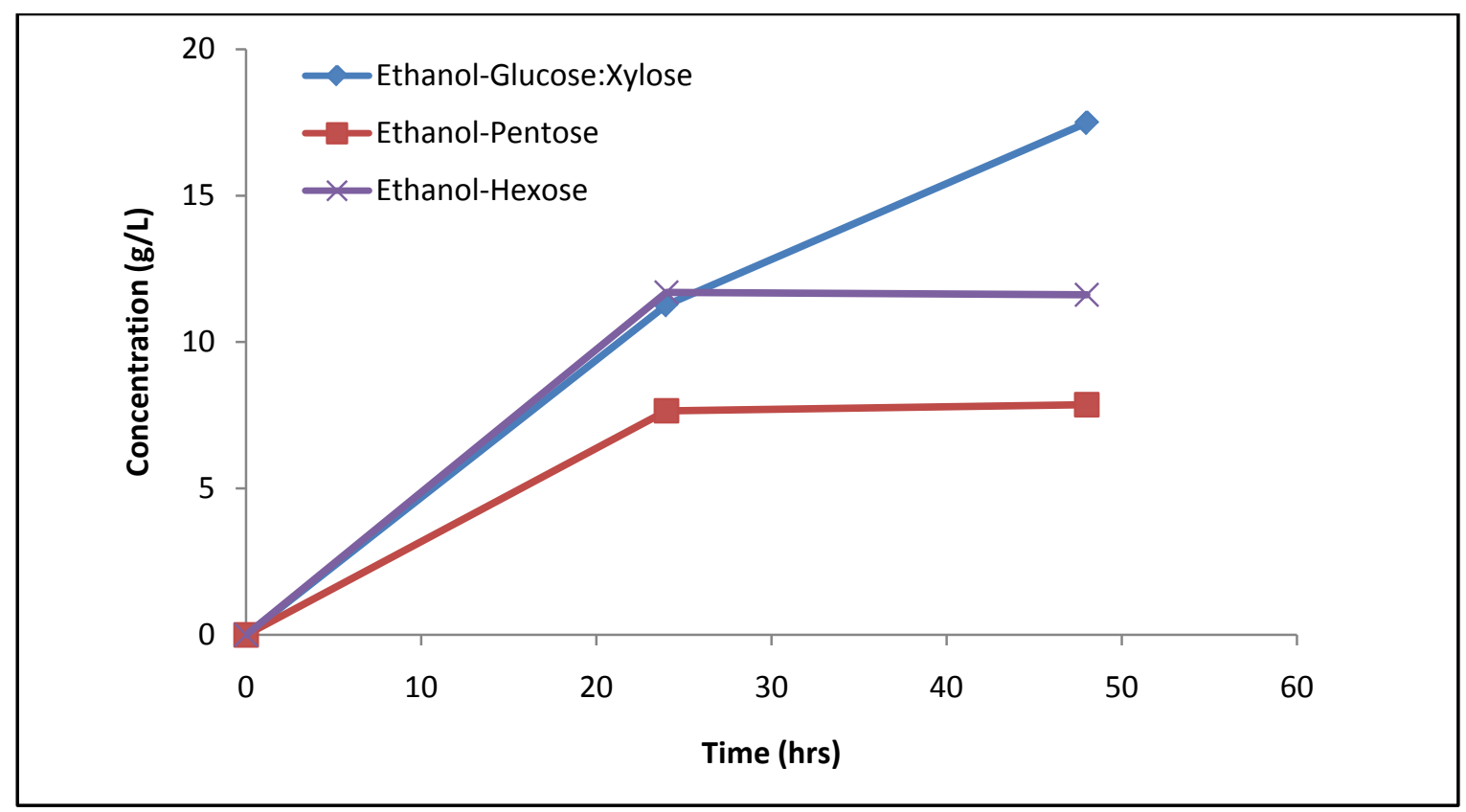

Figure B.5. Comparison of ethanol concentrations in a glucose: xylose, pentose, and hexose fermentation by Pichia stipitis CBS 6054 after 72 hours in YP media $\left(30^{\circ} \mathrm{C}, \mathrm{pH}\right.$ 5.5). 
B.2 Ethanol production by $\boldsymbol{P}$. stipitis in synthetic hydrolysate media

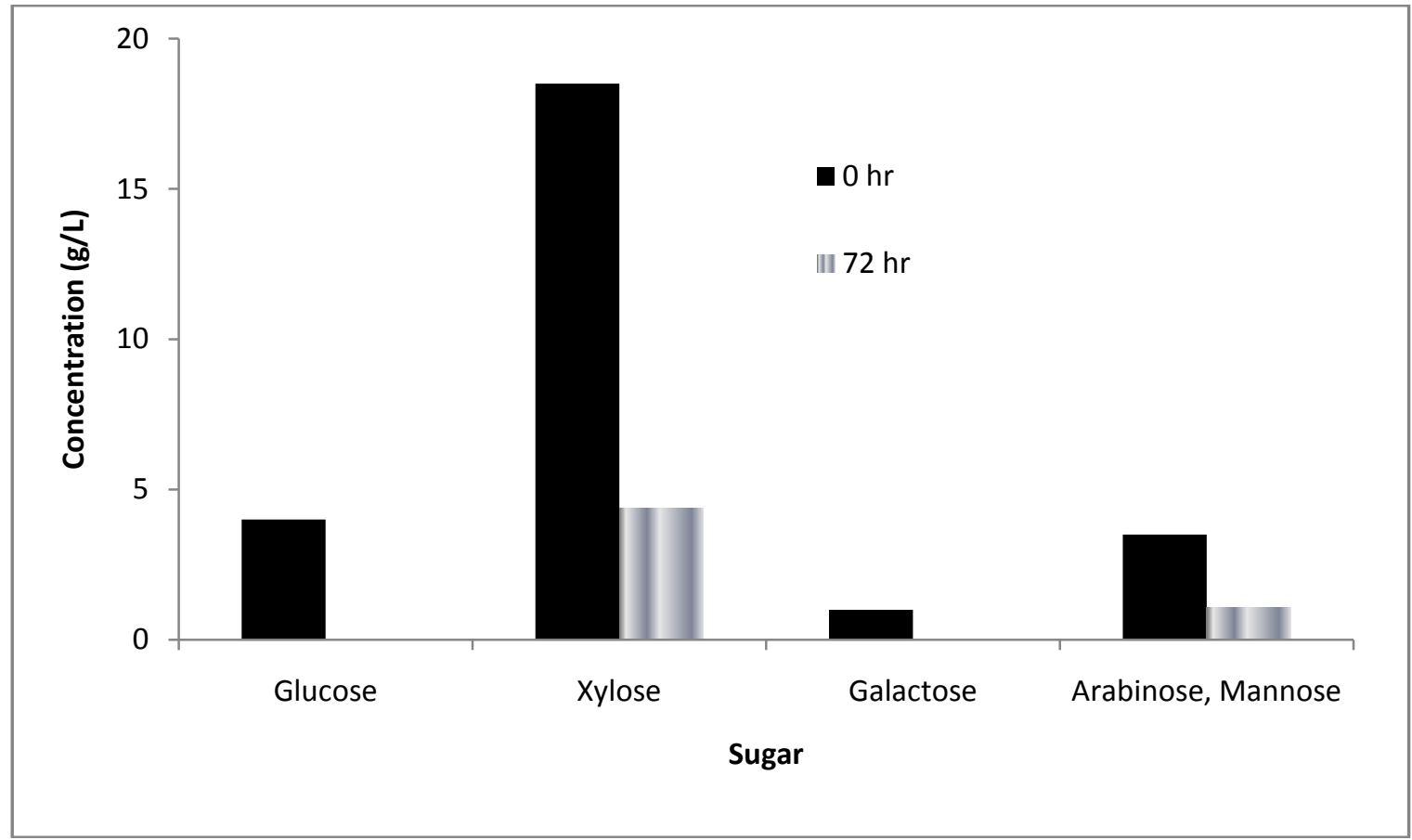

Figure B.6. Sugar concentrations in synthetic dilute acid pretreated aspen hydrolysate at 0 and 72 hours during a fermentation b y P. stipits $\left(30^{\circ} \mathrm{C}, \mathrm{pH} 5.5\right)$.

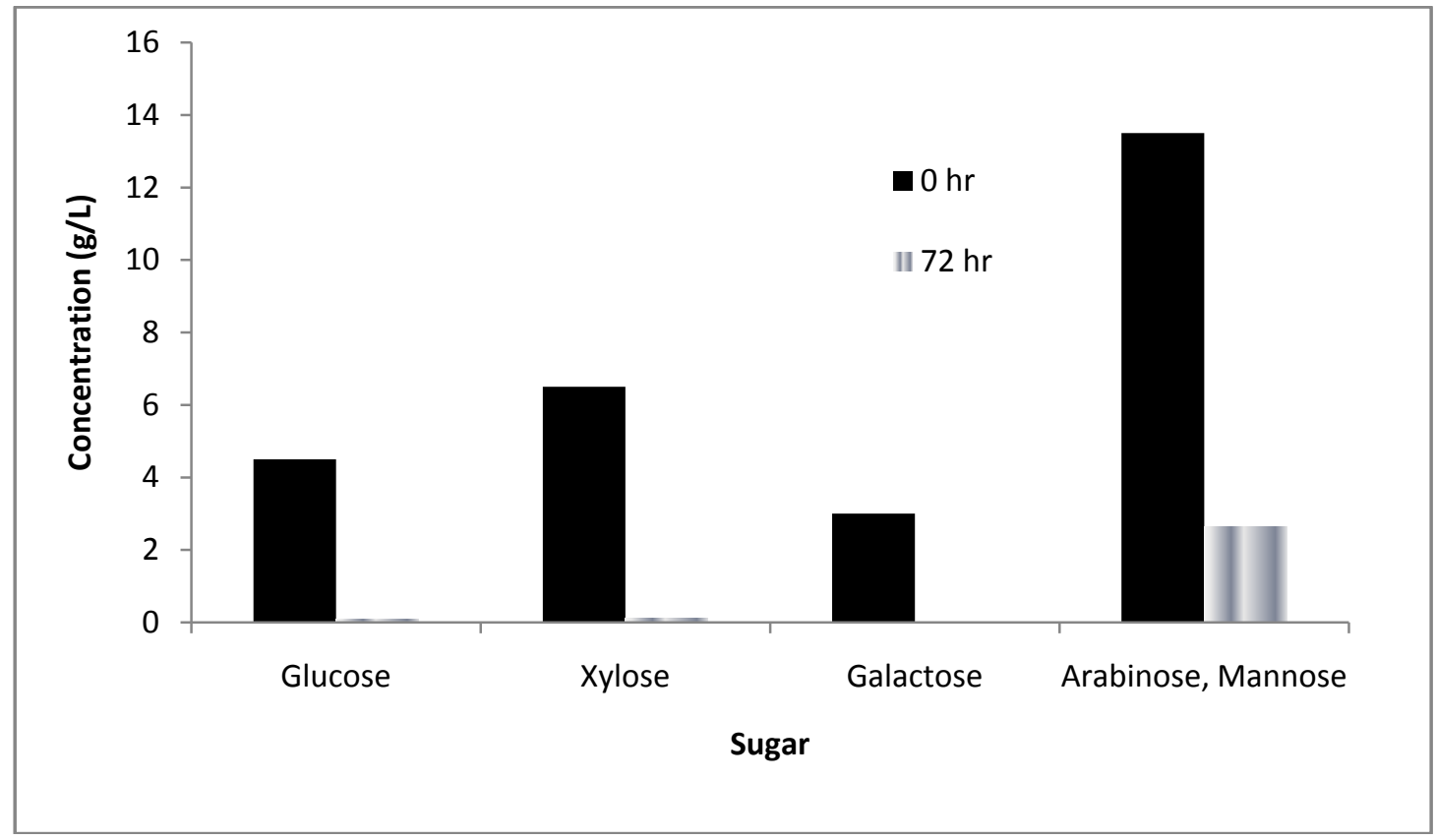

Figure B.7. Sugar concentrations in synthetic dilute acid pretreated balsam hydrolysate at 0 and 72 hours during a fermentation b y $P$. stipits $\left(30^{\circ} \mathrm{C}, \mathrm{pH} 5.5\right)$. 


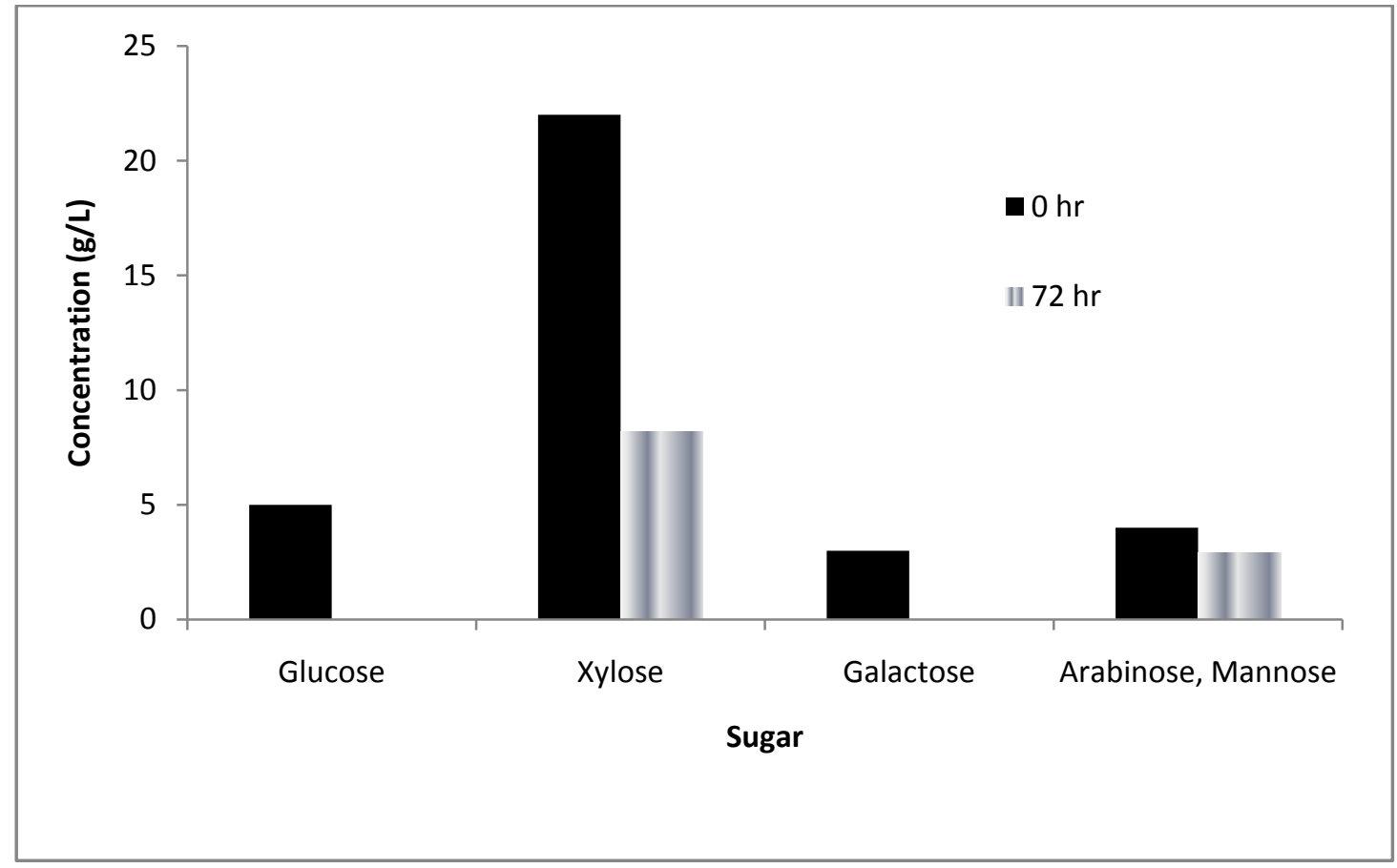

Figure B.8. Sugar concentrations in synthetic dilute acid pretreated switchgrass hydrolysate at 0 and 72 hours during a fermentation b y $P$. stipits $\left(30^{\circ} \mathrm{C}, \mathrm{pH} 5.5\right)$. 
B.3 Fermentation of aspen, balsam, and switchgrass enzymatic hydrolysate by $S$. cerevisiae (ER)

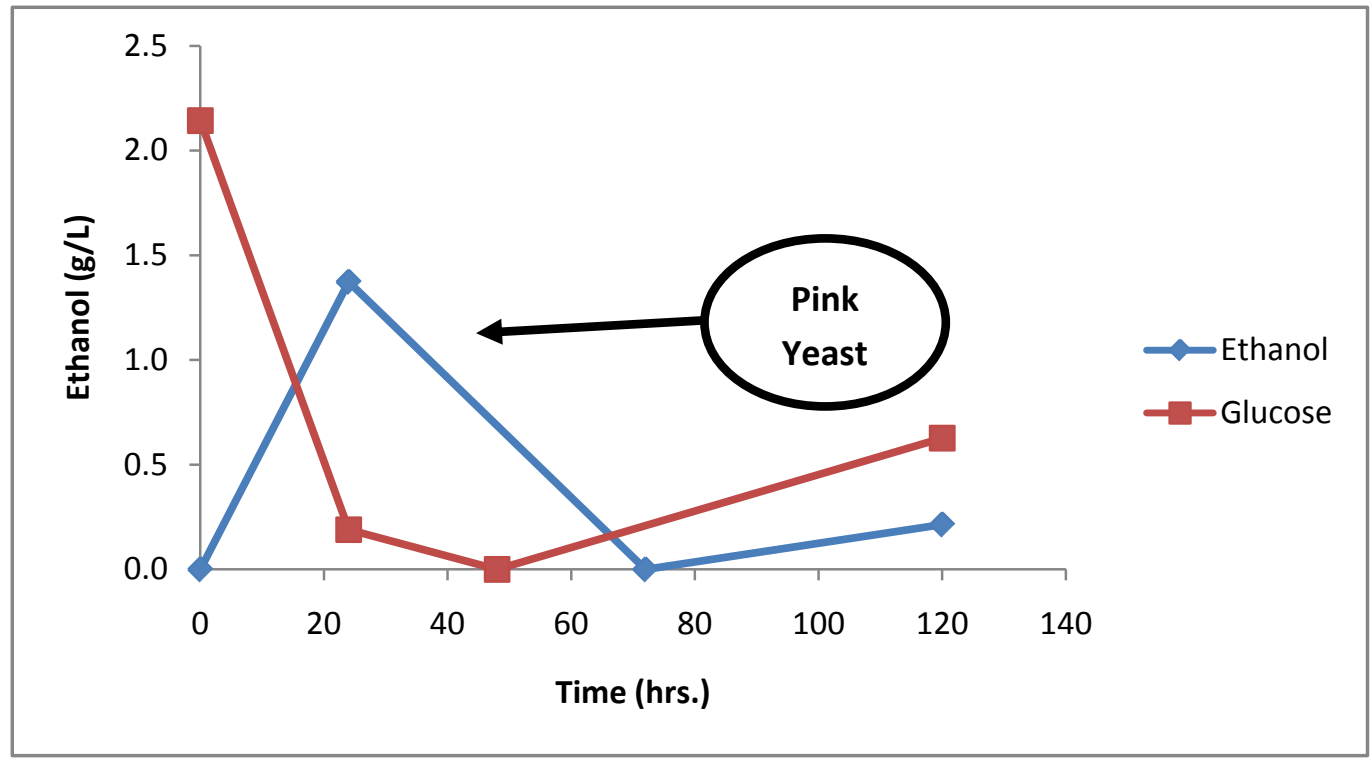

Figure B.9. Fermentation results of ethanol production from enzymatic pretreated aspen by $S$. cerevisiae after 24 hours in Enzymatic hydrolysate supplemented withYP media $\left(30^{\circ} \mathrm{C}, \mathrm{pH} 5.5\right)$.

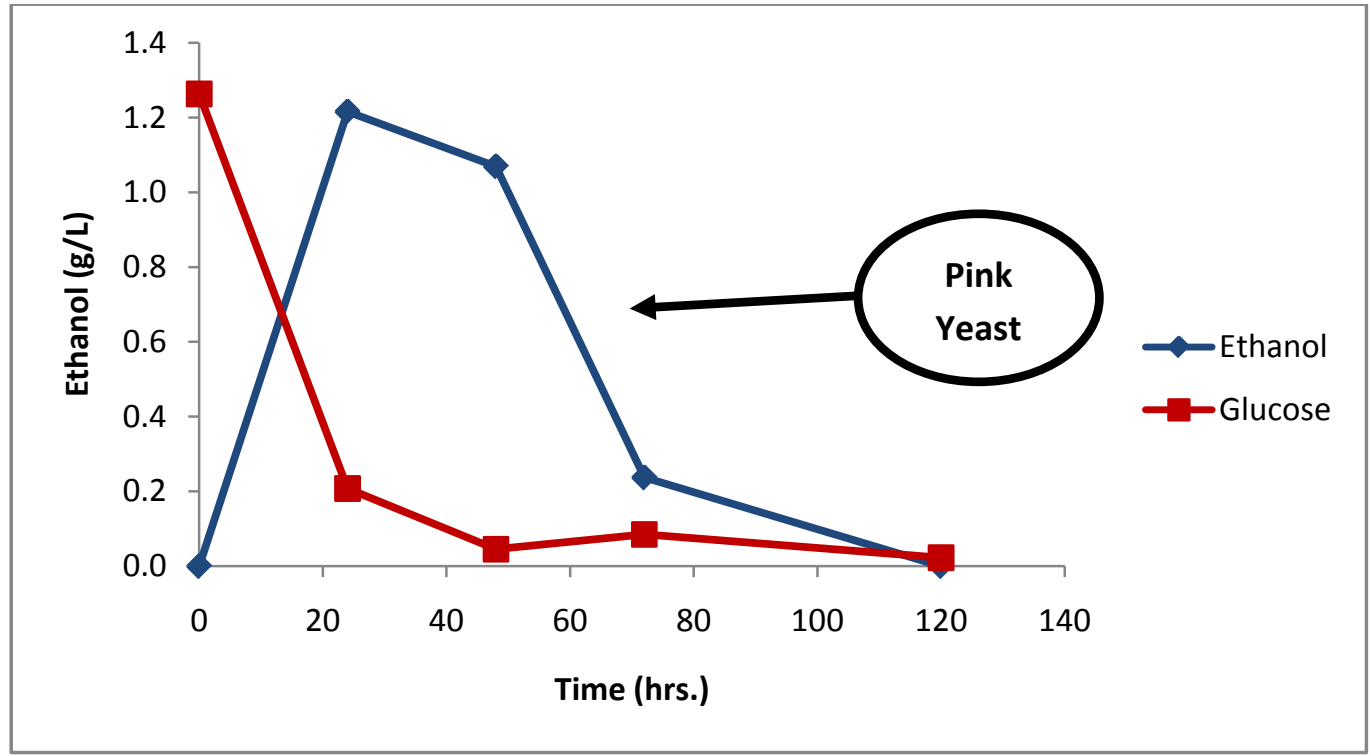

Figure B.10. Fermentation results of ethanol production from enzymatic pretreated balsam by S.cerevisia after 24 hours in Enzymatic hydrolysate supplemented withYP media $\left(30^{\circ} \mathrm{C}, \mathrm{pH} 5.5\right)$. 


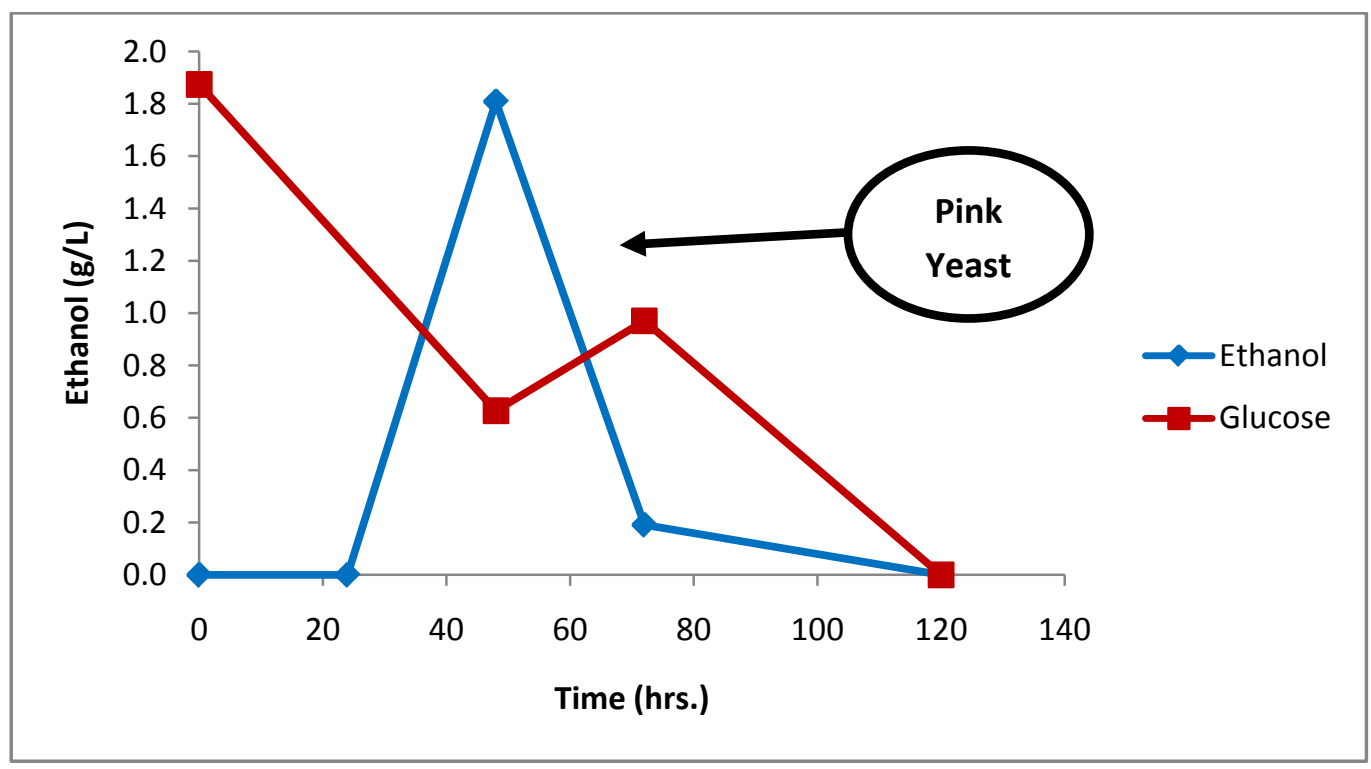

Figure B.11. Fermentation results of ethanol production from enzymatic pretreated switchgrass by S.cerevisiae after 24 hours in Enzymatic hydrolysate supplemented withYP media $\left(30^{\circ} \mathrm{C}, \mathrm{pH} 5.5\right)$. 


\section{Appendix C. Toxicity Assay Supplementary Information}

C.1 Effect of furfural and acetic acid in YPX media on biomass production by $P$. stipitis

Table C.1.The growth rate (k) of Pichia stipitis with different concentrations of furfural in YPX after 24 hours $\left(30^{\circ} \mathrm{C}, \mathrm{pH} 5.5\right)$.

\begin{tabular}{|c|c|}
\hline Furfural (g/L) & $\mathbf{k}\left(\mathbf{h r}^{-\mathbf{1}}\right)$ \\
\hline 0 & 0.23 \\
\hline 1 & 0.21 \\
\hline 2 & $\leq 0.05$ \\
\hline 4 & $\leq 0.05$ \\
\hline
\end{tabular}

Table C.2. The growth rate (k) and generation time (t) of Pichia stipitis with different concentrations of acetic acid in YPX after 24 hours $\left(30^{\circ} \mathrm{C}, \mathrm{pH} 5.5\right)$.

\begin{tabular}{|c|c|}
\hline Furfural (g/L) & $\mathbf{k}\left(\mathbf{h r}^{-\mathbf{1}}\right)$ \\
\hline 0 & 0.16 \\
\hline 2 & 0.13 \\
\hline 4 & $\leq 0.05$ \\
\hline 6 & $\leq 0.05$ \\
\hline 8 & 0.09 \\
\hline 10 & $\leq 0.05$ \\
\hline
\end{tabular}


C.2. Effect of furfural, acetic acid and combinations of the two compounds in synthetic aspen media on biomass production by $P$. stipitis

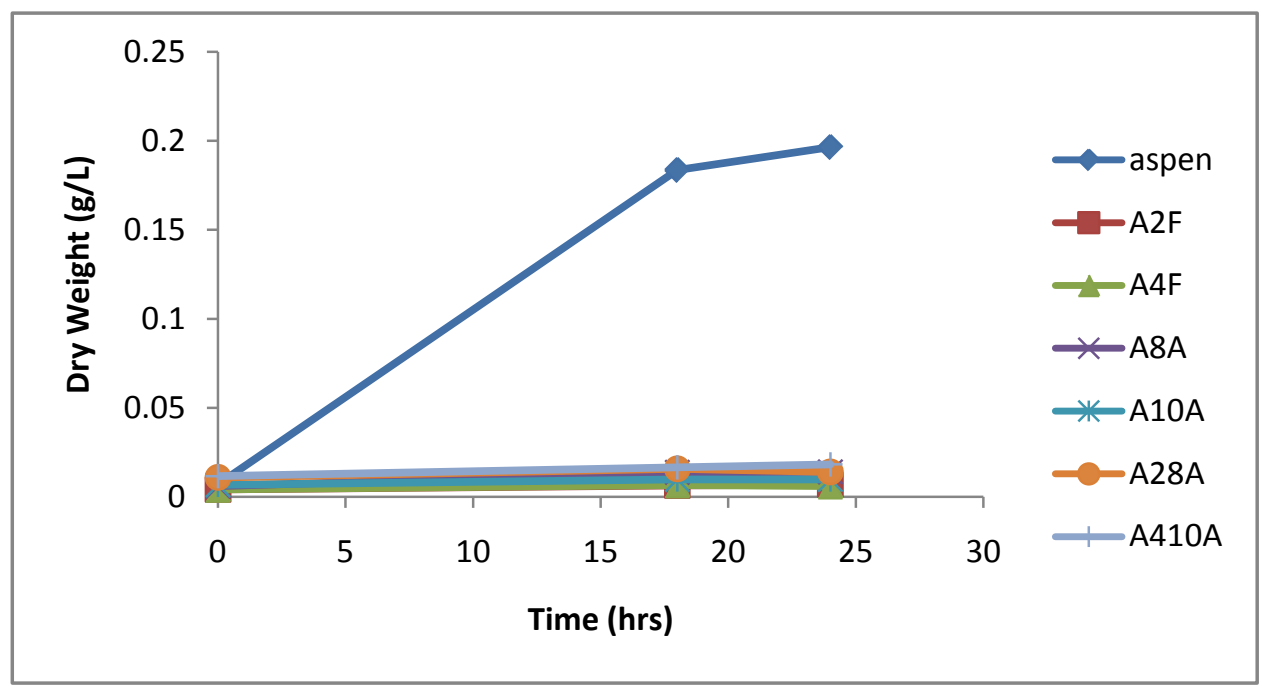

Figure C.1 Biomass production of Pichia stipitis in synthetic aspen hydrolysate supplemented with acetic acid $[8 \mathrm{~g} / \mathrm{L}(\mathrm{A} 8 \mathrm{~A})$ and $10 \mathrm{~g} / \mathrm{L}(\mathrm{A} 10 \mathrm{~A}))$, furfural $(2 \mathrm{~g} / \mathrm{L}$ (A2F) and $4 \mathrm{~g} / \mathrm{L}(\mathrm{A} 4 \mathrm{~F})]$, and combinations of the two toxins $[2 \mathrm{~g} / \mathrm{L}$ furfural with $8 \mathrm{~g} / \mathrm{L}$ acetic acid (A28A) and $4 \mathrm{~g} / \mathrm{L}$ furfural with $10 \mathrm{~g} / \mathrm{L}$ acetic acid (A410A) ] in synthetic aspen media $\left(30^{\circ} \mathrm{C}, \mathrm{pH} 5.5\right)$.

Table C.3 Growth rate (k) of Pichia stipitis in synthetic aspen hydrolysate supplemented with acetic acid $[8 \mathrm{~g} / \mathrm{L}(\mathrm{A} 8 \mathrm{~A})$ and $10 \mathrm{~g} / \mathrm{L}(\mathrm{A} 10 \mathrm{~A})$ ), furfural $(2 \mathrm{~g} / \mathrm{L}$ (A2F) and $4 \mathrm{~g} / \mathrm{L}$ (A4F) ], and combinations of the two toxins $[2 \mathrm{~g} / \mathrm{L}$ furfural with $8 \mathrm{~g} / \mathrm{L}$ acetic acid (A28A) and 4 $\mathrm{g} / \mathrm{L}$ furfural with $10 \mathrm{~g} / \mathrm{L}$ acetic acid (A410A) ] in synthetic aspen media $\left(30^{\circ} \mathrm{C}, \mathrm{pH} 5.5\right)$.

\begin{tabular}{|c|c|}
\hline Growth rate & $\mathbf{k}\left(\mathbf{h r}^{-\mathbf{1}}\right)$ \\
\hline Aspen & 0.20 \\
\hline $\mathbf{A 2 F}$ & $\leq 0.05$ \\
\hline A4F & $\leq 0.05$ \\
\hline A8A & $\leq 0.05$ \\
\hline A10A & $\leq 0.05$ \\
\hline A28A & $\leq 0.05$ \\
\hline A410A & $\leq 0.05$ \\
\hline
\end{tabular}




\section{C.3. Effect of concentrated furfural levels on biomass and ethanol production}

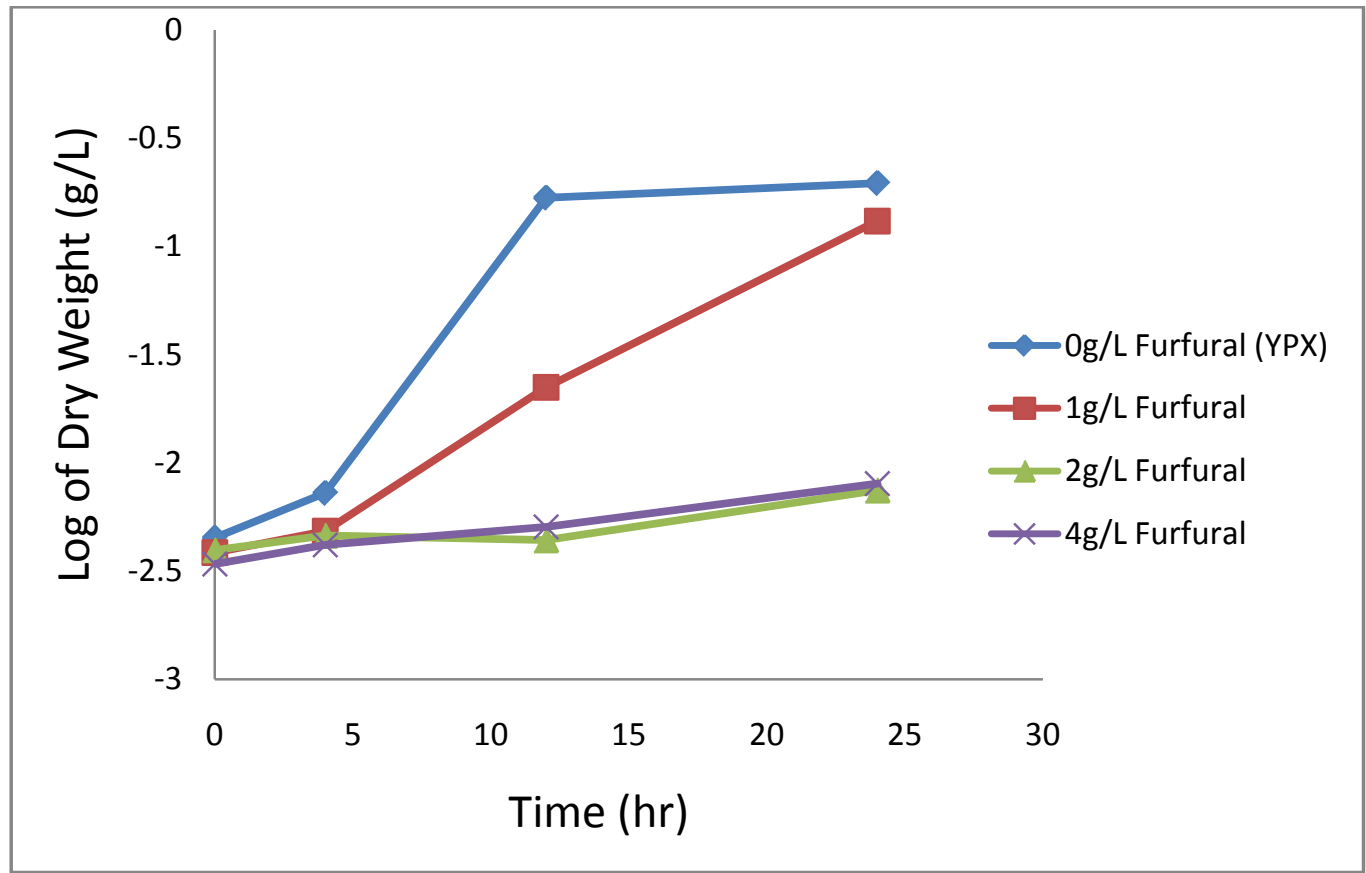

Figure C.2. Biomass production by $P$. stipitis in the presence of furfural after 24 hours in YPX $\left(30^{\circ} \mathrm{C}, \mathrm{pH} 5.5\right)$.

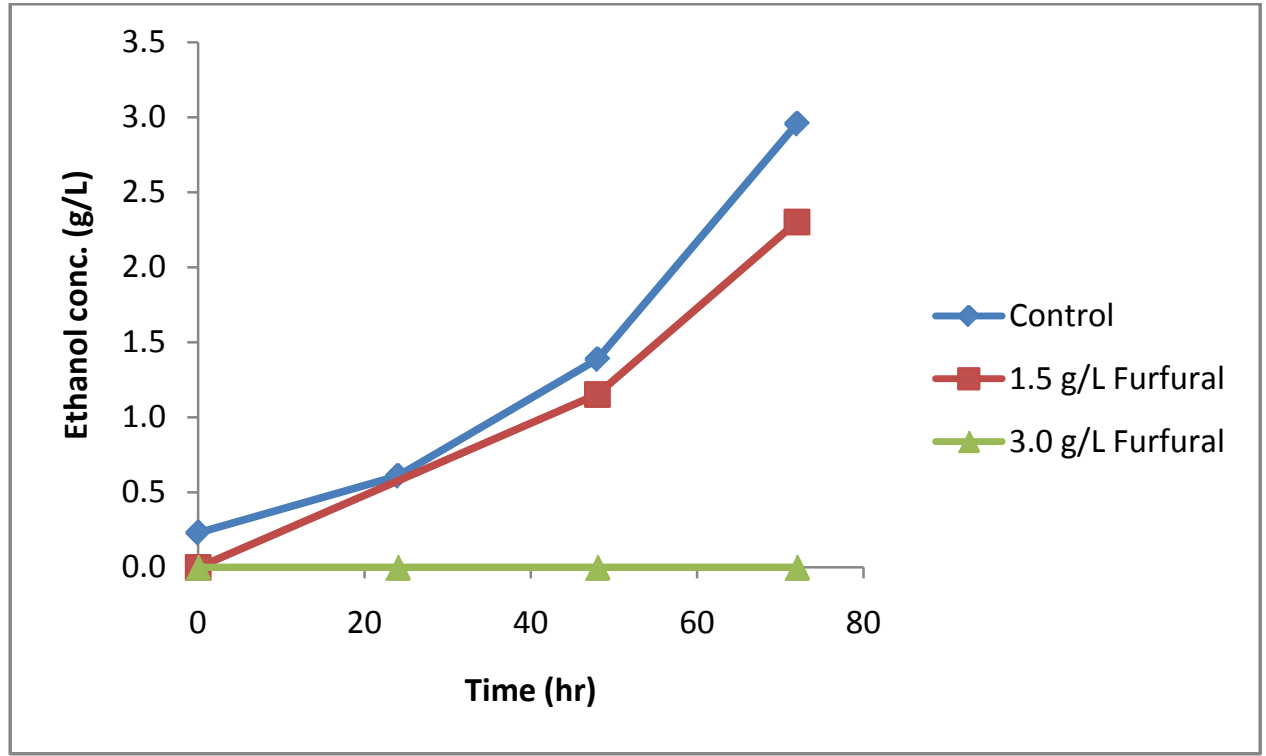

Figure C.3. Ethanol production by $P$. stipitis in the presence of furfural in after 72 hours synthetic aspen media $\left(30^{\circ} \mathrm{C}, \mathrm{pH} 5.5\right)$. 


\section{Appendix D. Supplementary Adaptation Data}

\section{D.1 Adaptation studies comparison data}

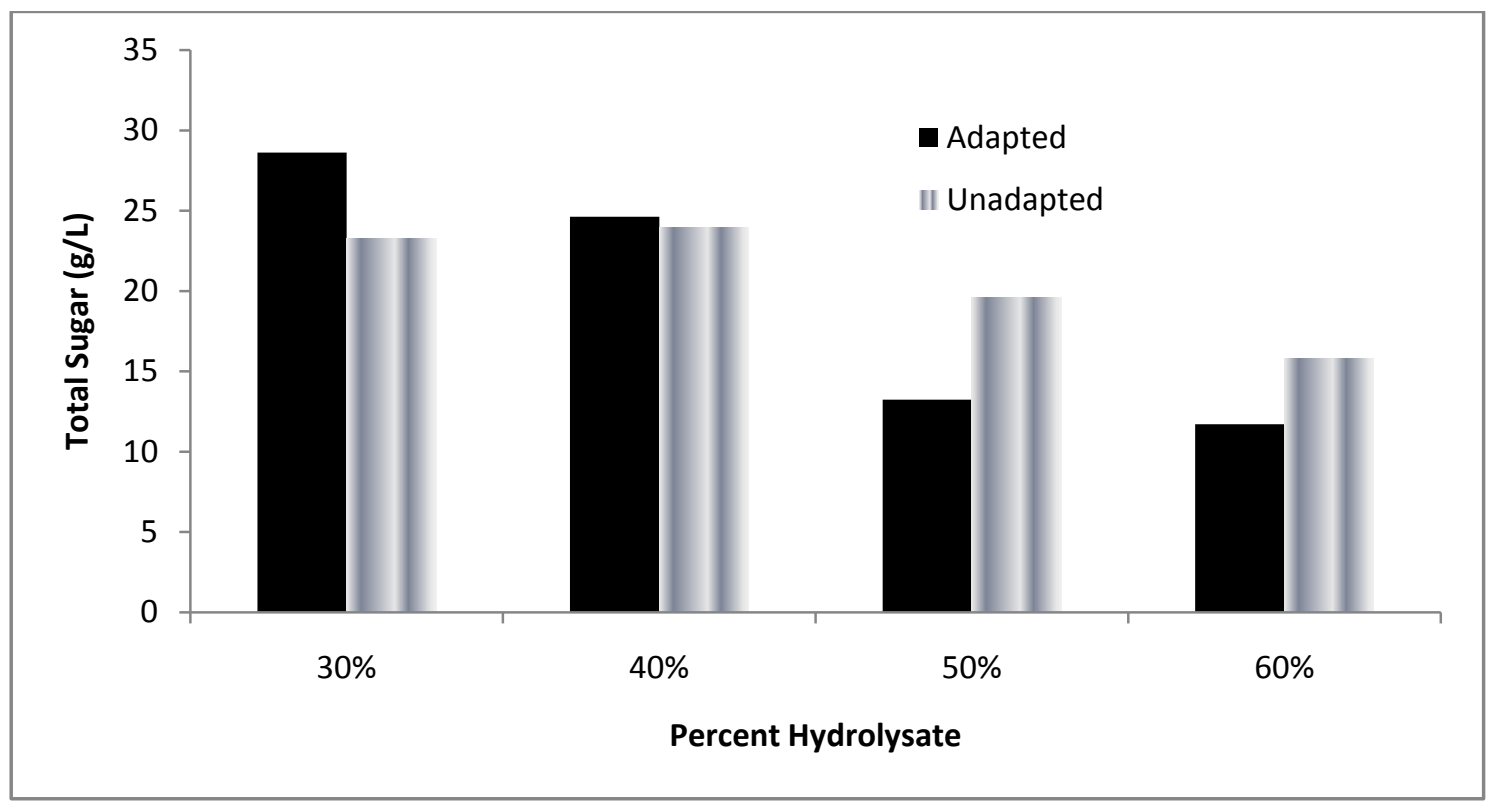

Figure D.1. Comparison of total starting sugars used by an adapted Pichia stipitis CBS 6054 and the parent strain on varying percentages of dilute acid pretreated aspen hydrolysate supplemented with a sugar mix $(\mathrm{n}=2)\left(30^{\circ} \mathrm{C}, \mathrm{pH} 5.5\right)$.

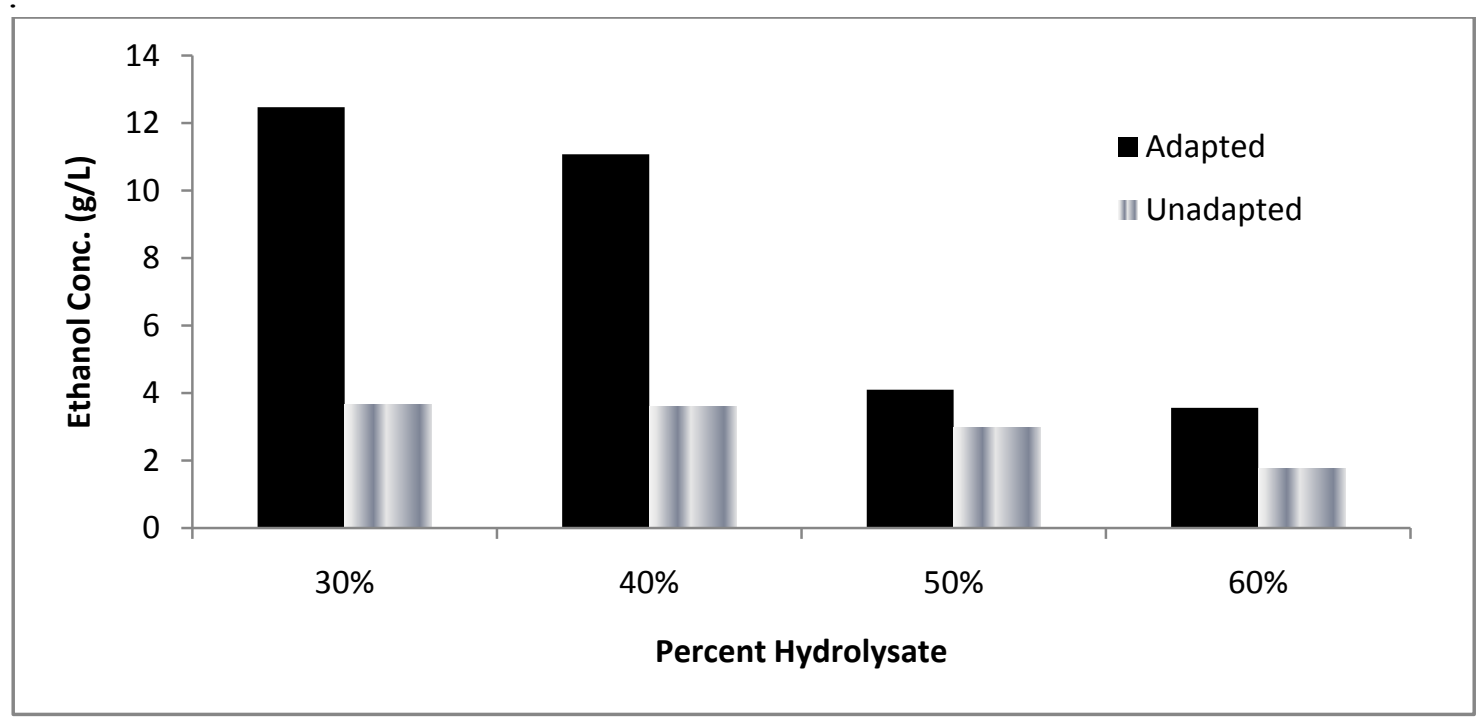

Figure D.2. Comparison of 72 hour ethanol concentrations produced by an adapted Pichia stipitis CBS 6054 and the parent strain on varying percentages of dilute acid pretreated aspen hydrolysate supplemented with a sugar mix $(\mathrm{n}=2)\left(30^{\circ} \mathrm{C}, \mathrm{pH} 5.5\right)$. 


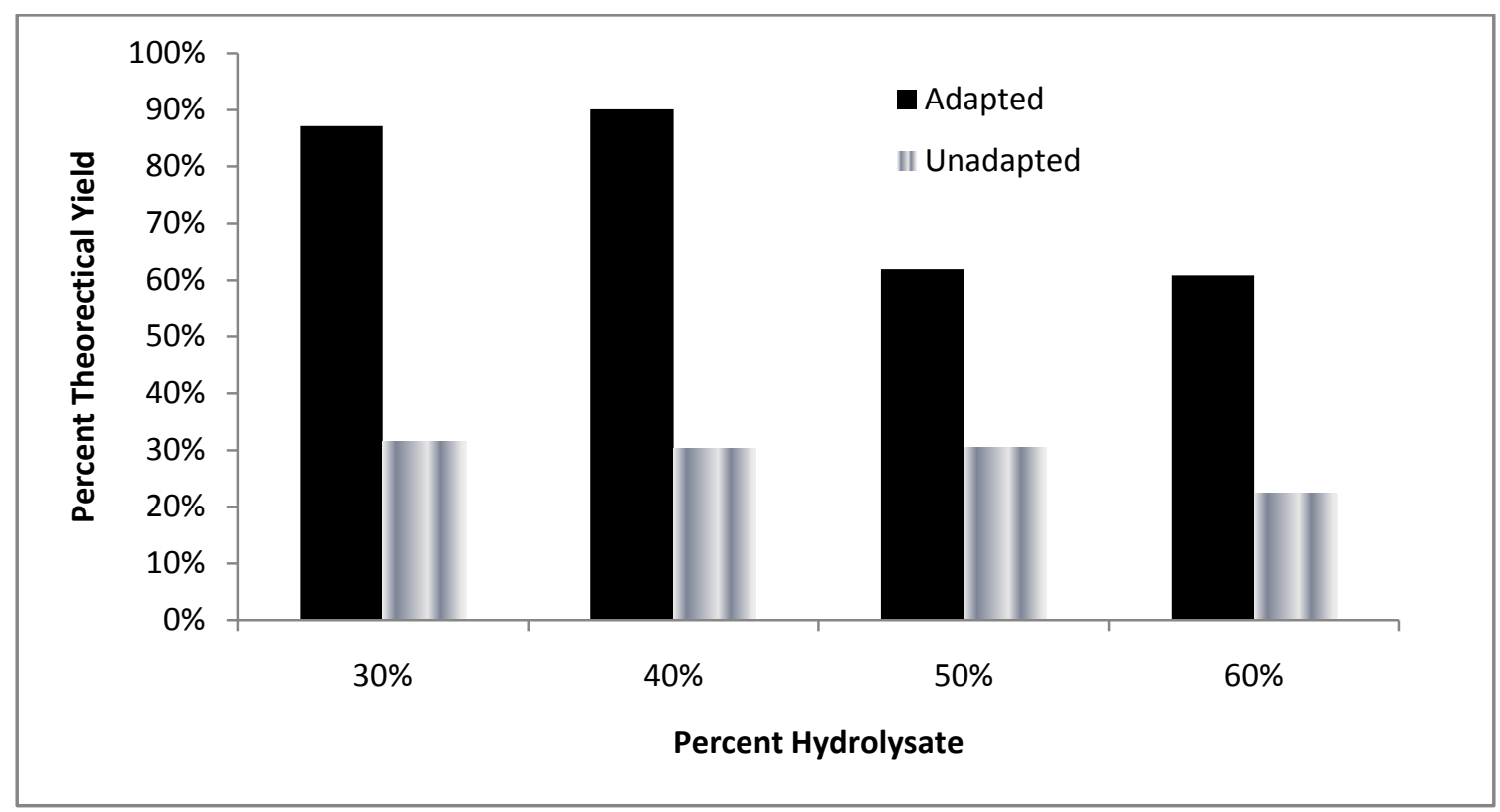

Figure D.3. Comparison of 72 hour percent theoretical yield produced by an adapted Pichia stipitis CBS 6054 and the parent strain on varying percentages of dilute acid pretreated aspen hydrolysate supplemented with a sugar mix $(n=2)\left(30^{\circ} \mathrm{C}, \mathrm{pH} 5.5\right)$.

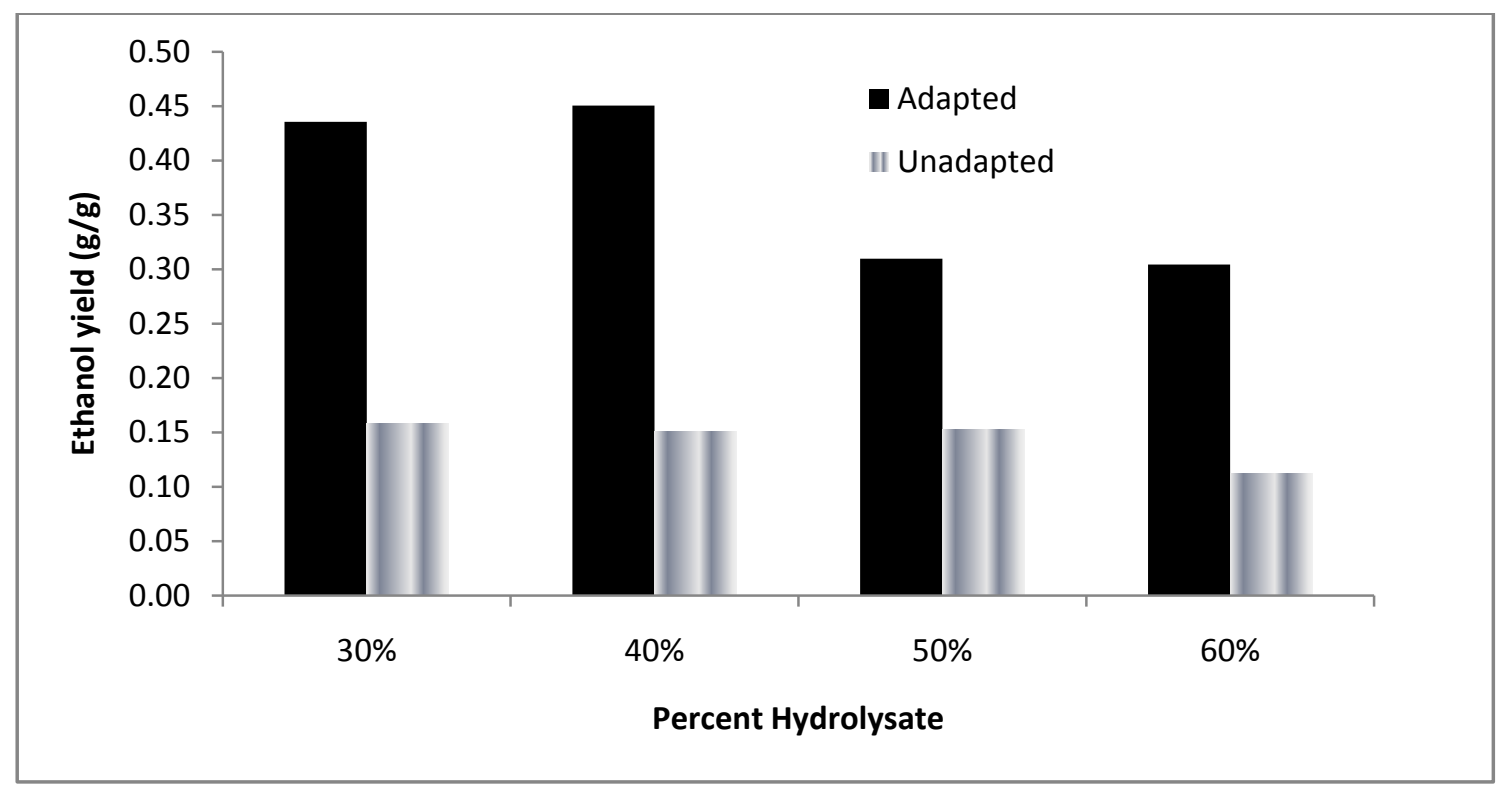

Figure D.4. Comparison of 72 hour ethanol yields produced by an adapted Pichia stipitis CBS 6054 and the parent strain on varying percentages of dilute acid pretreated aspen hydrolysate supplemented with a sugar mix $(n=2)\left(30^{\circ} \mathrm{C}, \mathrm{pH} 5.5\right)$. 
Table D.1. Summary of adapted Pichia stipitis CBS 6054 adapted to dilute acid pretreated hydrolysate $\left(30^{\circ} \mathrm{C}, \mathrm{pH} 5.5\right) .^{\mathrm{a}}$

\begin{tabular}{|c|c|c|c|c|}
\hline $\begin{array}{l}\text { Unadapted } \\
\text { Strain }\end{array}$ & & & & \\
\hline $\begin{array}{c}\text { Percent } \\
\text { Hydrolysate }\end{array}$ & $\begin{array}{l}\text { \% Sugars } \\
\text { Utilized }\end{array}$ & $\begin{array}{c}\text { Ethanol } \\
(\mathrm{g} / \mathrm{L})\end{array}$ & 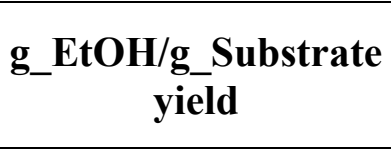 & $\begin{array}{c}\% \\
\text { Theoretical } \\
\text { yield } \\
\end{array}$ \\
\hline 30 & 99.6 & $3.7 \pm 0.4$ & $0.16 \pm 0.30$ & 31.4 \\
\hline 40 & 99.6 & $3.6 \pm 0.5$ & $0.15 \pm 0.11$ & 29.4 \\
\hline 50 & 99.7 & $3.0 \pm 0.1$ & $0.15 \pm 0.03$ & 29.2 \\
\hline 60 & 99.8 & $1.8 \pm 0.1$ & $0.11 \pm 0.0$ & 21.6 \\
\hline \multicolumn{5}{|l|}{ Adapted Strain } \\
\hline 30 & 100.0 & $12.5 \pm 0.9$ & $0.44 \pm 0.03$ & 99.7 \\
\hline 40 & 99.8 & $11.1 \pm 0.6$ & $0.45 \pm 0.02$ & 90.1 \\
\hline 50 & 99.9 & $4.1 \pm 0.03$ & $0.31 \pm 0.00$ & 61.9 \\
\hline 60 & 99.9 & $3.6 \pm 0.4$ & $0.30 \pm 0.03$ & 60.9 \\
\hline
\end{tabular}

${ }^{\mathrm{a}}$ Mean $(\mathrm{n}=2) \pm 2 \mathrm{SD}$ 


\section{Appendix E. Growth of $P$. stipitis in YPX and YNB}

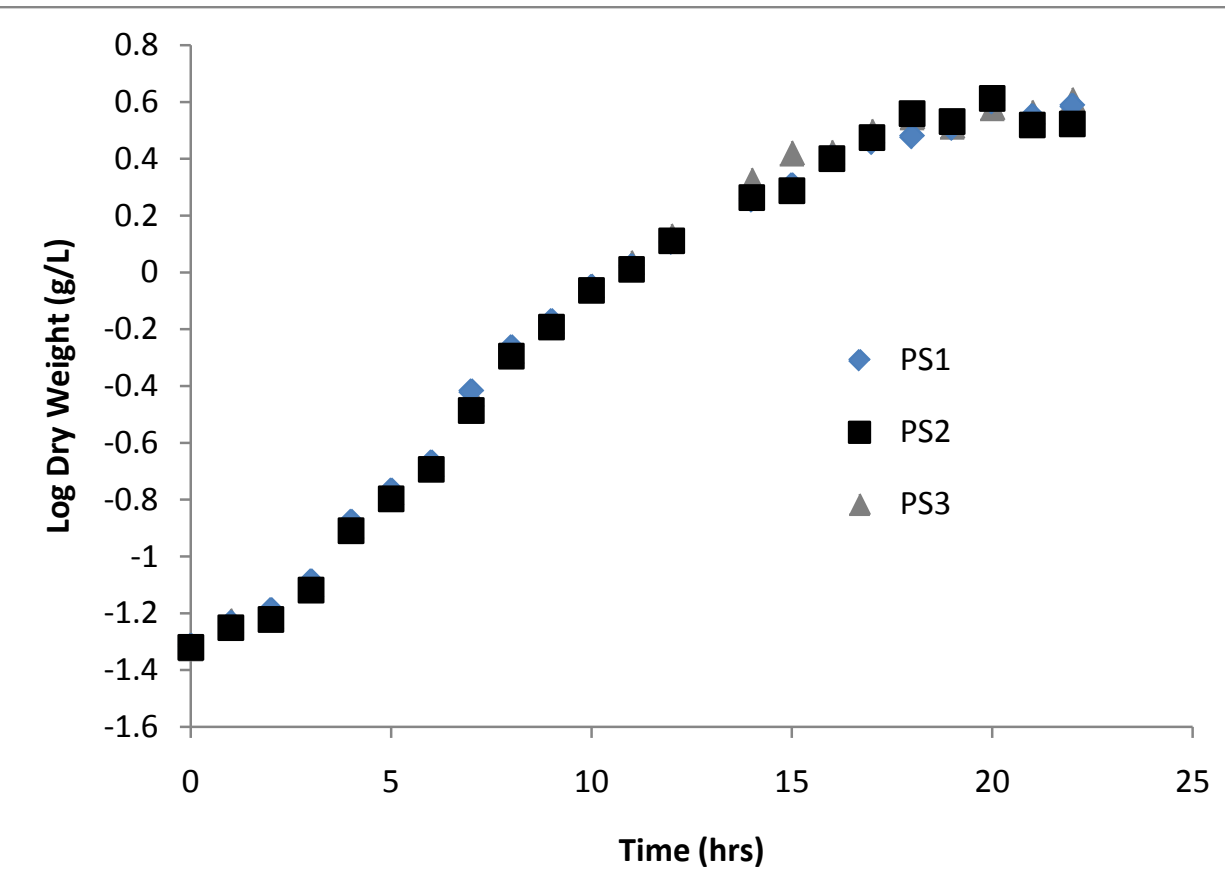

Figure E. 1. Growth of $P$,stipits in YPX media (50g/L) during 24 hours $\left(30^{\circ} \mathrm{C}, \mathrm{pH} 5.5\right)$.

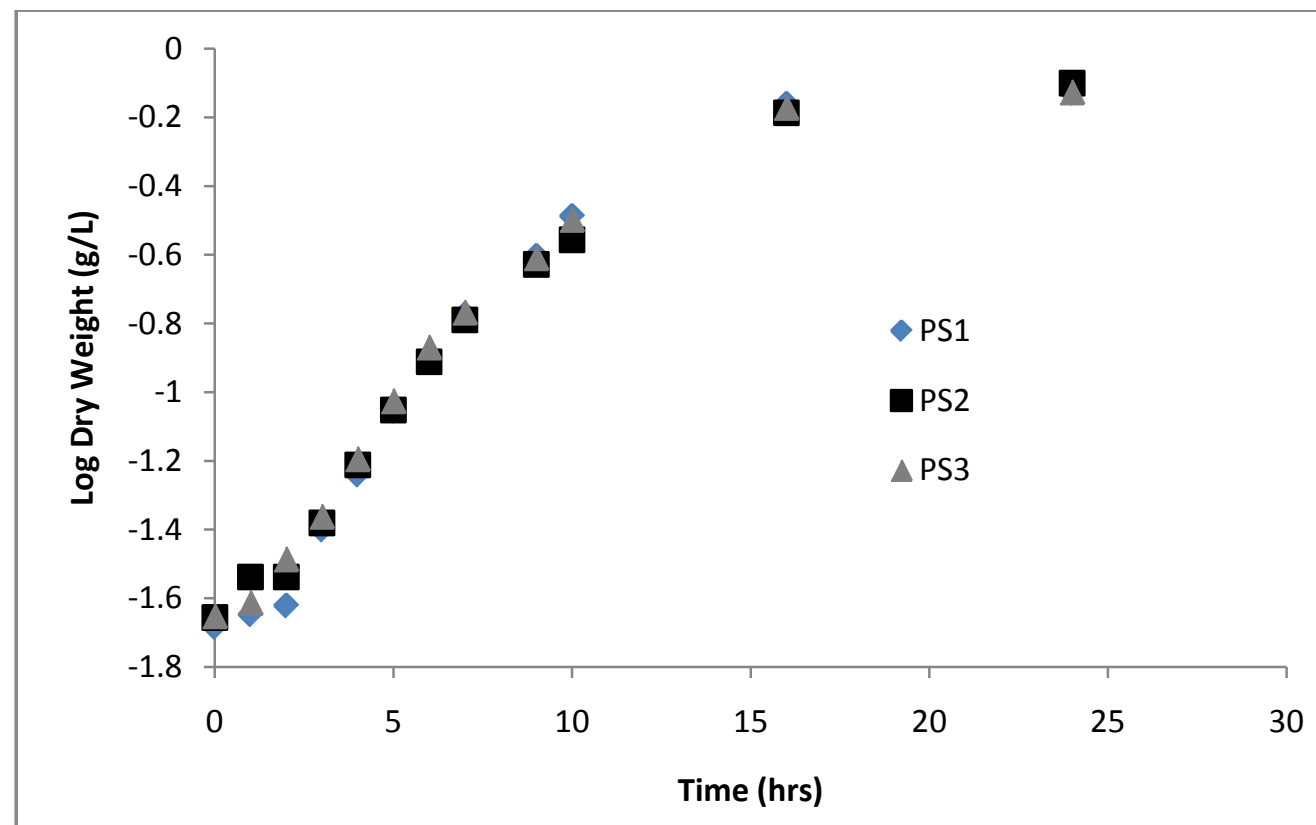

Figure E. 2. Growth of $P$. stipitis in YNB media (50g/L) over 24 hours $\left(30^{\circ} \mathrm{C}, \mathrm{pH} 5.5\right)$. 